\title{
Changes in Preservice Elementary Teachers' Personal Science Teaching Efficacy and Science Teaching Outcome Expectancies: The Influence of Context
}

Richard P. Hechter

How does access to this work benefit you? Let us know!

Follow this and additional works at: https://commons.und.edu/theses

Part of the Psychology Commons

\section{Recommended Citation}

Hechter, Richard P., "Changes in Preservice Elementary Teachers' Personal Science Teaching Efficacy and Science Teaching Outcome Expectancies: The Influence of Context" (2008). Theses and Dissertations. 707.

https://commons.und.edu/theses/707

This Dissertation is brought to you for free and open access by the Theses, Dissertations, and Senior Projects at UND Scholarly Commons. It has been accepted for inclusion in Theses and Dissertations by an authorized administrator of UND Scholarly Commons. For more information, please contact und.commons@library.und.edu. 
CHANGES IN PRESERVICE ELEMENTARY TEACHERS' PERSONAL SCIENCE

TEACHING EFFICACY AND SCIENCE TEACHING OUTCOME EXPECTANCIES:

THE INFLUENCE OF CONTEXT

by

Richard P. Hechter

Bachelor of Education, University of Winnipeg, 1998

Bachelor of Science, University of Winnipeg, 1998

Master of Education, University of Manitoba, 2004

\author{
A Dissertation \\ Submitted to the Graduate Faculty \\ of the \\ University of North Dakota \\ in partial fulfillment of the requirements
}

for the degree of

Doctor of Philosophy

Grand Forks, North Dakota

May

2008 
UMI Number: 3324268

\section{INFORMATION TO USERS}

The quality of this reproduction is dependent upon the quality of the copy submitted. Broken or indistinct print, colored or poor quality illustrations and photographs, print bleed-through, substandard margins, and improper alignment can adversely affect reproduction.

In the unlikely event that the author did not send a complete manuscript and there are missing pages, these will be noted. Also, if unauthorized copyright material had to be removed, a note will indicate the deletion.

(B)

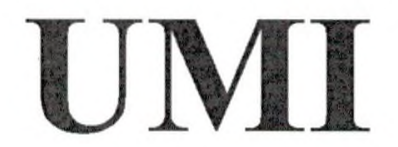

UMI Microform 3324268

Copyright 2008 by ProQuest LLC.

All rights reserved. This microform edition is protected against unauthorized copying under Title 17, United States Code.

ProQuest LLC

789 E. Eisenhower Parkway PO Box 1346

Ann Arbor, Ml 48106-1346 
Copyright 2008 Richard P. Hechter 
This dissertation submitted by Richard P. Hechter in partial fulfillment of the requirements for the Degree of Doctor of Philosophy from the University of North Dakota, has been read by the Faculty Advisory Committee under whom the work has been done and is hereby approved.

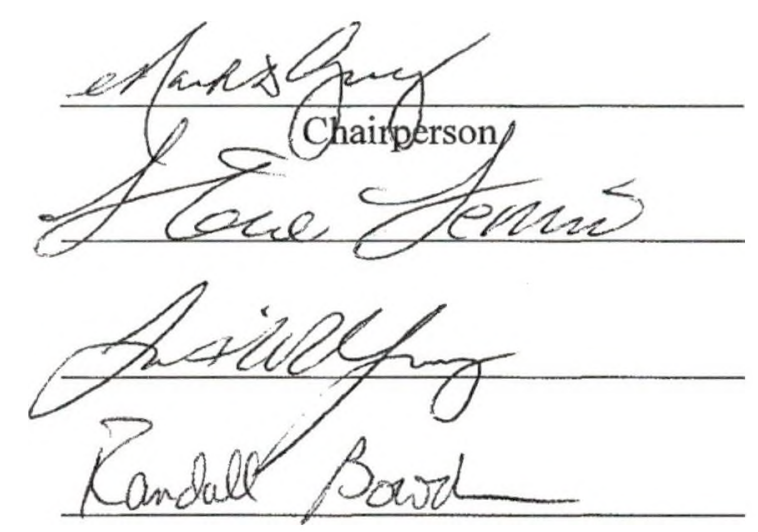

This dissertation meets the standards for appearance, conforms to the style and format requirements of the Graduate School of the University of North Dakota, and is hereby approved.

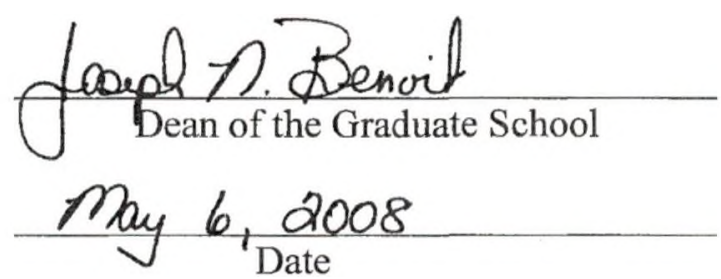




\section{PERMISSION}

Title Changes in Preservice Elementary Teachers' Personal Science Teaching Efficacy and Science Teaching Outcome Expectancies: The Influence of Context

Department Teaching and Learning

Degree Doctor of Philosophy

In presenting this dissertation in partial fulfillment of the requirements for a graduate degree from the University of North Dakota, I agree that the library of this University shall make it freely available for inspection. I further agree that permission for extensive copying for scholarly purposes may be granted by the professor who supervised my dissertation work or, in his absence, by the chairperson of the department or the dean of the Graduate School. It is understood that any copying or publication or other use of this dissertation or part thereof for financial gain shall not be allowed with my written permission. It is also understood that due recognition shall be given to me and to the University of North Dakota in any scholarly use which may be made of any material in my dissertation.

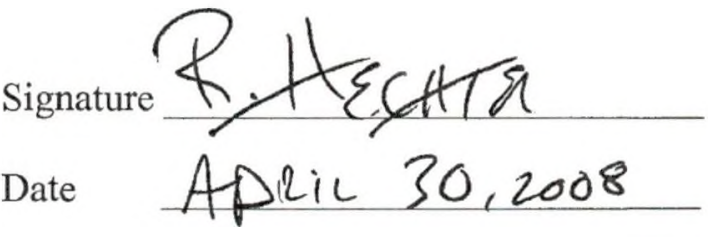




\section{TABLE OF CONTENTS}

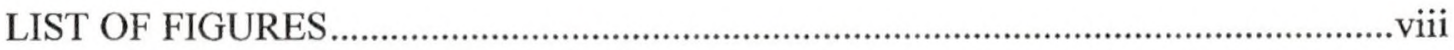

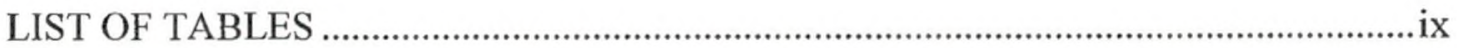

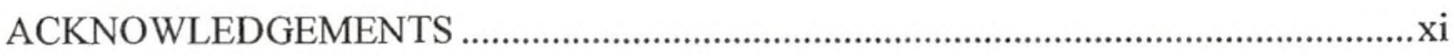

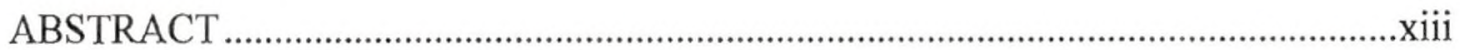

\section{CHAPTER}

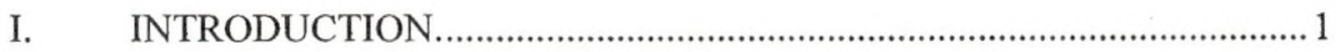

Background of the Problem........................................................ 1

Statement of the Problem ......................................................... 7

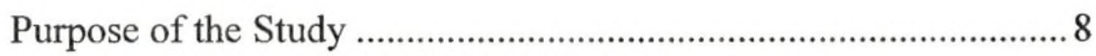

Theoretical Framework .......................................................... 10

Research Questions ............................................................... 13

Definition of Terms .............................................................. 14

Importance of the Study ........................................................... 17

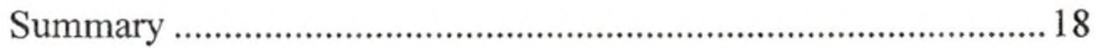

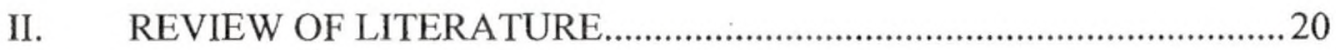

Perception of Science in the Elementary School ........................220

Self-Efficacy as a Psychosocial Construct ...................................22

Measurement of Self-Efficacy Using the STEBI ........................27

Defining Self-Efficacy in the Context of This Study ...................28 
Self-Efficacy in Teaching and Teacher Preparation .................... 31

Preservice Science Teacher Education...........................................36

Bettering Science Content Area Knowledge............................... 38

Measurement of Preservice Teachers' Levels of

Science Teaching Self-Efficacy ................................................... 40

Science Methods Courses........................................................ 43

Measuring Science Teaching Self-Efficacy

Through Alternative Interventions ..............................................47

Factors Affecting Science Teaching Self-Efficacy ..................... 48

Response-Shift Bias and Retrospective-Testing .......................53

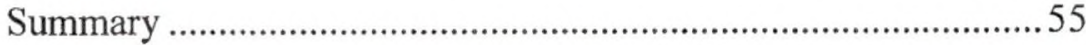

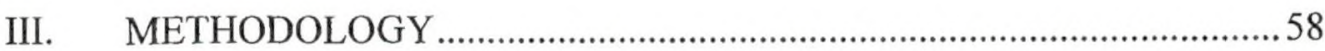

Research Design ............................................................... 58

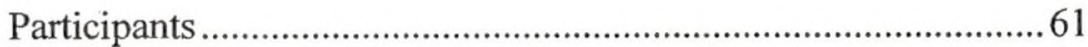

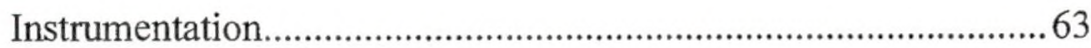

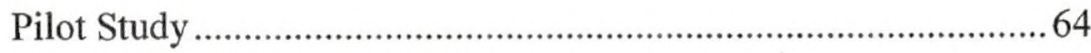

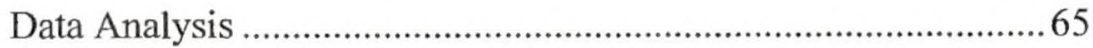

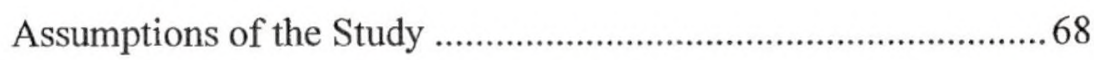

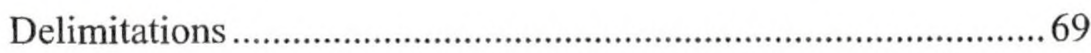

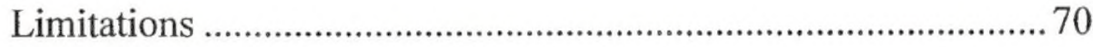

Summary …................................................................... 70

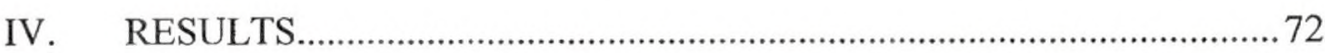

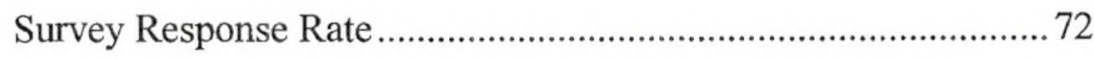

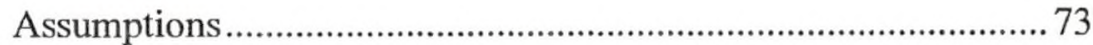


Descriptives Relevant to the Study .......................................... 75

Instrument Reliability......................................................... 88

Research Question Results ....................................................91

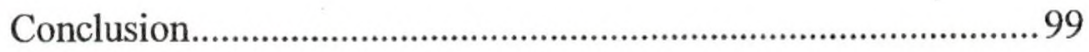

V. SUMMARY, DISCUSSION, CONCLUSIONS, AND

RECOMMENDATIONS FOR FUTURE RESEARCH....................... 102

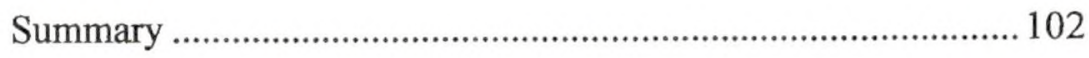

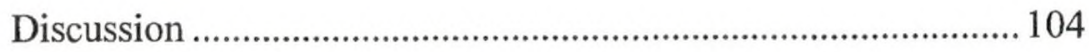

Conclusions and Recommendations........................................ 118

Recommendations for Future Research .................................. 125

Conclusion..................................................................... 128

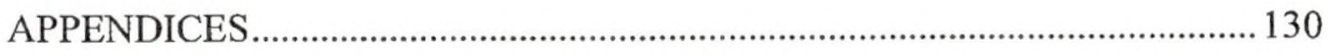

Appendix A: Demographic Grouping Questions ............................... 131

Appendix B: The STEBI-B Instrument Used for Data Collection.......... 132

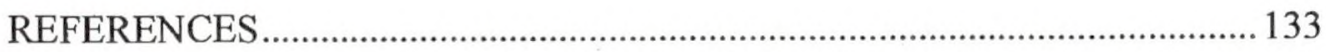




\section{LIST OF FIGURES}

Figure

Page

1. Conceptual breakdown of science teacher self-efficacy ....................................... 4

2. Interaction graph of changes in PSTE subscale scores ........................................95

3. Interaction graph of changes in STOE subscale scores.................................. 96 


\section{LIST OF TABLES}

Table

Page

1. Descriptive Statistics for Residuals of Changes in Scores in PSTE and STOE Subscales 73

2. Descriptive Data for Changes in Scores in PSTE Subscale ................................. 74

3. Descriptive Data for Changes in Scores in STOE Subscale .............................. 75

4. Descriptive Statistics of the Subscales for each Test Administration....................76

5. Descriptive Statistics for Changes in Subscale Scores Between Retrospective-Test and Post-Test.................................................................. 78

6. Descriptive Statistics of Independent Variables............................................... 79

7. Group Statistics of Team 6 and TEAM 7 During Fall 2007 Semester ................83

8. Group Statistics of Spring 2007 and Fall 2007 Semesters...................................86

9. Group Statistics of Spring 2007 and Fall 2007 Semesters for Researchers Taught Sections

$\mathrm{S}$

10. Instrument Reliability Statistics Based on Administration Time for All Items

11. Instrument Reliability Statistics Based on Administration Time for PSTE Subscale.

12. Instrument Reliability Statistics Based on Administration Time for STOE Subscale

13. Paired Sample Statistics for Pre-Test and Retrospective-Test Scores .92

14. Paired Sample Test Results for Pre-Test and Retrospective-Test Scores

15. Tests of Between-Subjects Effects for Changes of Scores on PSTE Subscale.....95 
16. Tests of Between-Subjects Effects for Changes of Scores on STOE Subscale ....96 


\section{ACKNOWLEDGEMENTS}

I find it almost as difficult to write this page as it was to write the dissertation. It is a challenge to adequately thank all the special people who supported me in various ways on this journey to achieve my educational goals. I am sincerely grateful for those people in ways I may not be able to articulate properly.

I am especially grateful for my advisor, mentor, and friend Dr. Mark Guy. His support, encouragement, insight, patience, and genuine care guided me through the multifaceted nature of my doctoral program. I simply would not have been able to complete my work. I thank Dr. Randall Bowden, who despite moving to a new University remained on my committee to help focus me and gather the strength to see my way through some very difficult times. His constant support and belief in me as a person, as well as his guidance into the professoriate provided me with the stepping stones and confidence I needed to surge ahead. I thank Dr. Steven LeMire for his continued encouragement and guidance not only during the dissertation process, but long before it as well. His parables and philosophic insight into the mosaic of research and academia taught me great lessons about life and education. I would also like to thank Dr. Tim Young for his continued positive advice and insight into my work and ideas, despite this not being an experiment.

Special thanks are due to the University of Winnipeg, and colleagues at The Collegiate for their continued support and encouragement throughout the entire doctoral 
program, particularly Mr. Rob Bend who supported my progress each step of the way. Also special thanks to Dr. Ralph Mason at the University of Manitoba for believing in me, even when I left education to be a dentist.

I would like to thank my core group of friends, in Winnipeg, Grand Forks and globally; specifically David, Lena, Lynette, Marc, Richard, and the Elm Street cool kids. Without your care, support, love, and companionship I would not have been able to progress forward through the last few years. It was you, at different times and in different places, who believed in me when it seemed to me that giving up was the better option. For this, I will be forever grateful.

I need to extend my utmost love and appreciation to my family. Completing my doctoral program is the fulfillment of a dream and the hope of a brighter future. You have been there each step of the way, and encouraged me along in my vision for a world of new opportunities. Each one of you have helped shape me into the person I am today, the scholar I will be in the coming years, and most importantly the father I am for Ella. For this, and the unconditional love and support you have shown me, I offer you my deepest and most heartfelt thank you.

Finally, I need to thank my daughter Ella. You have been very patient with me in the final days of preparation as you watched me do my "homework" instead of searching for treasure so I could "pass the big test" to get "a sticker, and a PhD". I will never be able to tell you how much I love you, and what your smile and gentle hug means to my heart and my soul, so I will just say this: I love you lovebug, thank you for being my best girl. 


\begin{abstract}
The purpose of this study was to investigate how retrospective-test / post-test perceptions of science teaching self-efficacy differ according to personal science expectancy and science teaching outcome expectancy among preservice elementary teachers when exposed to a science teaching methods course. Preservice elementary teacher candidates $(\mathrm{N}=69)$ enrolled in Spring and Fall 2007 sessions of an elementary science methods class were asked to assess their science teaching self-efficacy using the Science Teaching Expectancy Belief Instrument (STEBI-B). The survey was administered three times using pre-test, post-test and retrospective-test methodology. The 23-item instrument contains a Likert-scale with a 1 to 5 range of "strongly disagree" to "strongly agree". A higher score indicated a stronger sense science teaching self-efficacy. The dependent variable was change in self-efficacy. Science teaching self-efficacy comprises two subcomponents: (1) personal science teaching efficacy (PSTE); and (2) science teaching outcome expectancy (STOE). Both components were represented as subscales on the STEBI-B. The independent variables were: (1) number of postsecondary science content courses taken; (2) perceptions of prior science experiences; and (3) a science methods course. Research questions sought to investigate main effects and interaction effects of independent variables on each of the PSTE and STOE subscales. A 2X2 ANOVA was used to statistically analyze the data with a Type I error rate of 0.05 as the judgment criteria for statistical significance. The findings revealed that whether
\end{abstract}


preservice elementary teachers met or exceeded the number of postsecondary science courses required to graduate, and their positive or negative perceptions of prior school science experiences had a statistically significant main effect on the change in PSTE but not STOE. There was no evidence to suggest significant interaction effects of number of postsecondary science courses taken and perception of school science experiences on the change in both PSTE and STOE. Practical significance of the results is also discussed. The results will guide reforming teacher preparation to strengthen science teaching selfefficacy of preservice elementary teacher candidates throughout their programs of study leading out into the teaching profession. The implications of this study have bearing on current and future organization, structure, and dynamics of elementary science teacher preparation. 
To Ella, forever Daddy's best girl,

and

Zaida Irv and Zaida Lou, because you were taken too soon. 


\section{CHAPTER I}

\section{INTRODUCTION}

\section{Background of the Problem}

Teacher education programs are under intense scrutiny as graduates appear to be inadequately prepared to teach science. The National Research Council (NRC) (1990, 1996) asserts that preparation of preservice elementary science teachers is inadequate both in content and pragmatic delivery of instruction. Olson (2006) indicates that elementary science teaching practices do not promote meaningful science learning. The notion of inadequate preparations of elementary science teachers is not only affecting teacher preparation programs. The quality and frequency of science teaching and learning occurring at the elementary level as a whole, as in post graduation for teacher candidates, continues to be questioned and analyzed (Claxton, 1992; Driver \& Oldham, 1986; Fulp, 2002; Tilgner, 1990). Ginns and Watters (1990) purport that teacher candidates beliefs about their ability and inadequacy to teach science may manifest itself in the implementation of poorly designed, ineffective student science learning experiences that utilize meaningless and excessive use of effort and time. In an attempt to curb the sentiment that science teacher preparation is separated and disjointed in terms of science knowledge and pedagogical knowledge (Cochran, King, \& DeRuiter, 1993), teacher education programs are seeking ways to reform and therefore better prepare teacher candidates before they arrive in science methods courses. Tobias (1997) advocates for 
improvements in pedagogy and curriculum in undergraduate science content courses to meet this goal.

Many teacher candidates, especially those in the elementary stream, advance through their teacher education programs with negative attitudes towards science as a result of their high school science experiences (Mulholland, Dorman, \& Odgers, 2004; Young \& Kellogg, 1993). Effective methods courses that blend pedagogical knowledge with science knowledge can increase a teacher candidate's level of confidence in his or her ability to teach science (Appleton, 1995; Cantrell, Young and Moore, 2003; Palmer, 2006). For example, the capstone science course to a Bachelor of Science with specialty in elementary education at University of North Dakota is called T\&L 470 Science in the Elementary School. This is the science methods course for preservice elementary teacher candidates. The aforementioned increase in confidence that teacher candidates experience may be explained by an increase of self-efficacy.

The psychosocial construct of self-efficacy can be used to capture the relationship of an individual's beliefs to pedagogy (Bandura, 1977). Bandura (1997) suggested that individuals are motivated to act if the action is thought to elicit a favourable result, which he called outcome expectation. Further, Bandura referred to self-efficacy as an individual's confidence that he / she can successfully perform an action with a favorable result (Bleicher, 2004). Bandura (1986) distinguished between self-efficacy and outcome expectations in that they, "are differentiated because individuals can believe that a particular course of action will produce certain outcomes, but they do not act on that outcome belief because they question whether they can actually execute the necessary activities" (p. 392). 
The focus of improving the self-efficacy of teacher candidates has resulted in considerable amounts of research (Palmer, 2006). Reforming teacher candidates' programs of study to include an increase in postsecondary science content courses has been shown to have little if any effect in raising the levels of preservice teachers science teaching self-efficacy (Moore \& Watson, 1999; Palmer, 2006; Schoon \& Boone, 1998). Methods courses, as in those that focus on integrating science knowledge with pedagogical knowledge designed especially for elementary teacher candidates have had great success in elevating teacher candidate's science teaching self-efficacy (Appleton, 1995; Cantrell et al., 2003; Palmer, 2006).

Self-efficacy can be measured both qualitatively and quantitatively. Palmer (2001) references several studies that qualitatively investigate and report changes in teacher candidate beliefs within teacher education programs. Enochs and Riggs (1990) developed a quantitative measure for belief changes in preservice teacher candidates called the Science Teaching Efficacy Belief Instrument form B (STEBI-B).

The STEBI-B instrument is comprised of two subscales that measure Bandura's psychosocial construct. Figure 1 presents a concept map of the two subscale of science teaching self-efficacy. The first subscale, called the Personal Science Teaching Efficacy (PSTE), measures personal efficacy (Bleicher \& Lindgren, 2005). High scores on the PSTE indicate a strong personal perception in one's ability to teach science effectively (Johnston, 2003).The second scale, called the Science Teaching Outcome Expectancy (STOE), measures outcome expectancy (Bleicher \& Lindgren, 2005). A high score on the STOE indicates high expectations that future students will effectively learn science as a result of one's science teaching (Johnston, 2003). 


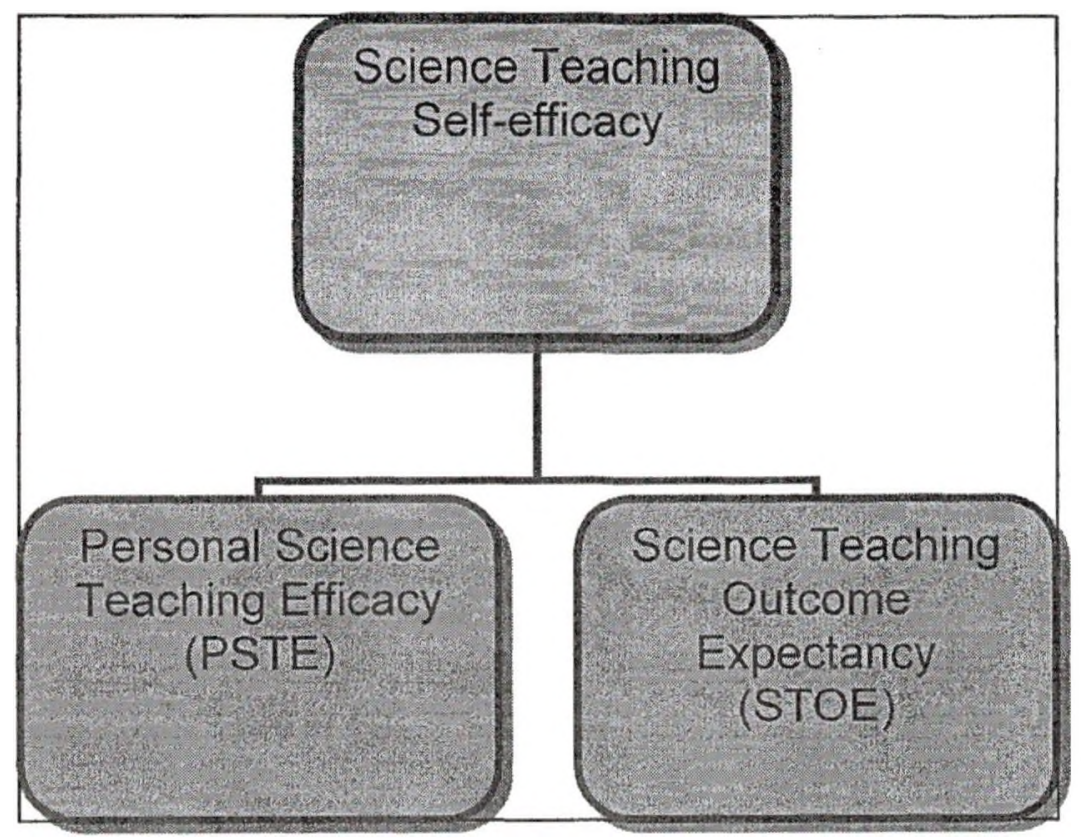

Figure 1. Conceptual breakdown of science teacher self-efficacy.

Scharmann and Hampton (1995) report that science teacher education students are concerned about their ability to teach science in a real classroom when they exit the program. Ramey-Gassert and Shroyer (1992) suggest that without healthy personal science teaching efficacy, teachers are less likely to actually teach science when out in a real classroom. It is therefore important to identify the self efficacy and outcome expectancy levels of teacher candidates to help them build confidence, and thus translate that into their teaching once graduated from the teacher education programs and into their own classrooms.

Much of the quantitative research done in this regard relies on a pre-test / post-test method for survey administration. There appears to be a subtle yet inherent challenge in this method. Preservice teacher candidates that arrive in a methods course on the first day carry baggage of science experiences of the past. While some of these experiences are 
positive, some are clearly negative. Appleton (2003) notes that elementary teacher education candidates typically have: had negative experiences with science; low content knowledge in science; and do not regard themselves as science teachers but rather language arts teachers. Irrespective of the actual student teacher candidates' classification of prior science experiences as either positive or negative experiences, or their subsequent meaning; these experiences comprise the context from which teacher candidates assess their self-efficacy and outcome expectancy. However, when compared to the perceptions of the science teaching self efficacy in writing the isomorphic post-test survey, the context from which students can assess themselves has changed substantially. When the treatment is as lengthy as an entire methods course or as short as a curricular unit, the context from which individuals can assess their self-efficacy has changed. This study will attempt to remedy this contextual disparity using a retrospective-test as further discussed in Chapter III.

A retrospective-test is a method used to minimize response-shift bias (Cantrell, 2003). Response-shift bias occurs when one's context for assessment has changed. In this study, there is contextual change for the preservice elementary teacher candidate from entry into the methods course until its conclusion. Upon arrival to the methods course, preservice elementary teacher candidates may or may not have been exposed to science knowledge integrated with pedagogical knowledge. Prior science school experiences have provided the context from which preservice elementary teacher candidates base their assessment of their science teaching self-efficacy can occur. Once the methods course has been completed, a preservice elementary teacher candidates' understanding of the relationship between science knowledge and pedagogical knowledge to effectively 
teach that content has been changed. Therein lay the response-shift bias. A retrospectivetest asks the preservice elementary teacher candidates to reflect back knowing what they now know, to what he or she should have responded on the pre-test upon arrival to the methods course.

Many preservice elementary teacher candidates, en route to their preservice activity of student teaching, have only now been introduced to the meshing of pedagogical knowledge with science knowledge within the science methods course. Here, science teacher candidates vicariously as well as personally experience the pragmatic and intricate aspects of effective science teaching. This is a problem. Stotsky (2006) suggested that it is not solely the responsibility of the department of education faculty to demonstrate effective science teaching in an effort to prepare better science teachers. Rather, it is a shared responsibility with the entire science content area faculty (Stotsky, 2006). Mestre (2001) advocates for faculty of science content areas like physics to employ, "instructional strategies that facilitate the construction of knowledge" (p. 45). This is a radical idea that is critical to improving preservice elementary teachers' science teaching efficacy throughout their programs of study as they progress towards the methods course. In order to pursue this avenue of teacher preparation reform, and ask for help in doing so from faculty from other departments, continued research that studies the levels science teaching self-efficacy in preservice elementary student teacher candidates preceding entry to the methods course must be done.

This research examined how perceptions of self-efficacy differ according to personal science teaching expectancy and science teaching outcome expectancy among preservice elementary teacher candidates when exposed to a science methods class. 


\section{Statement of the Problem}

There is a growing call for teacher education departments to strengthen their programs. Under the scrutiny of public and private assertions of preparing inadequate elementary science teachers, there is a significant push to improve the science teaching self-efficacy of the teacher candidates within the programs. Carter and Sottile (2002) suggested that improving a teacher candidate's self-efficacy will have longitudinal effects as delineated by being better classroom science teachers in the years to come. This hypothesized end will act as the catalyst to change the aforementioned negative perception.

There are studies that provide detailed recommendations on how to improve science teaching self-efficacy through treatments and interventions (Jay, 2000, Plourde, 1999). This is not one of those studies. Rather, this study examined the affect a science teaching methods course has on self-efficacy among preservice teachers by placing their responses in context. This context reflects a series of postsecondary school science experiences that has affected an individuals sense of capabilities in science and therefore in the ability to teach science. These experiences originate from the learning experiences in postsecondary science content classrooms. If these experiences have had negative effects on a preservice elementary teacher candidates' science teaching self-efficacy, then recommendations must be made to remedy this situation as it lowers a preservice elementary teacher candidate's science teaching self-efficacy even before entering the science methods course. Should preservice elementary teacher candidates arrive at the methods course with a high perception of self-efficacy as a result of the training they 
have had prior to the methods course, then the outlook for the future of elementary science teaching is bright as the methods course would only add to that genuinely high self-efficacy. Placing responses to the STEBI-B in context was therefore the key element to this study.

From that context, recommendations to help improve the perceived image of teacher education programs in strengthening the product of qualified and confident elementary science teachers by better preparing science teacher candidates throughout their programs of study will be made. Therefore, this study investigated the changes in personal science teaching efficacy and science teaching outcome expectancies among preservice elementary teachers after exposure to a science methods class.

\section{Purpose of the Study}

The purpose of this study was to investigate how retrospective-test / post-test perceptions of science teaching self-efficacy differ according to personal science expectancy and science teaching outcome expectancy among preservice elementary teacher candidates when exposed to a science teaching methods course. The changes in self-efficacy will place in context the changes in teacher candidate's levels of personal science teaching efficacy and science teaching outcome expectancy as that will help evaluate what teacher education programs need focus on to better prepare preservice elementary teacher candidates to teach science. The dependent variable in this study was the change in science teaching self-efficacy. Bandura (1997) defines self-efficacy as, "beliefs in one's capabilities to organize and execute the courses of action required to produce given attainments" (p. 3). Self-efficacy may also be defined as beliefs of an individual's capability to accomplish a certain level of performance (Huinker \& Madison, 
1997); and has been studied from many perspectives (Bleicher \& Lindegren, 2005, Tschannen-Moran, Hoy \& Hoy, 1998). Self-efficacy of preservice elementary teacher candidates related to science teaching, or science teaching self-efficacy, can be measured using the STEBI-B. The STEBI-B identifies and measures two subscales that comprise science teaching self-efficacy, which are: (a) personal science teaching efficacy (PSTE); and (b) science teaching outcome expectancy (STOE).

Personal science teaching efficacy reflects a preservice elementary teachers' confidence in effectively teaching science (El-Deghaidy, 2006). Science teaching outcome expectancy refers to an individual's belief that his/her future students will learn science given factors external to the teacher (Finson, Riggs, \& Jesunathadas, 2000; Ramey-Gassert, Shroyer \& Staver, 1996).

The independent variables for this study included: (1) number of postsecondary science content courses taken; (2) prior science experiences; and (3) the science methods course. The science methods course was used a qualifier analyzed via $t$-test to compare the results from different sections of the science methods course taught at different times and by different professors. As a variable, however, it does not appear in the research questions. These variables are important because they encompass valuable aspects which are helpful to measure changes in science teaching self-efficacy. Bleicher (2004) reports that there is a significant difference in personal science teaching efficacy between groups of students that have taken different numbers of college science content courses. Preservice elementary teachers that reported having positive past experiences in science yielded higher personal science teaching efficacy than those that reported having negative past experiences in science classes (Bleicher, 2004). "All of these results would lead one 
to hypothesize that background variables such as gender, number of college science courses taken, and previous school science experiences could have associations with the self-efficacy preservice teachers" (Bleicher, 2004, p. 389).

Anderson (1997) suggested that methods courses are places where integration of philosophical, psychological, sociocultural, and subject matter perspectives are done in a holistic manner as well as being the launching pad for professional development and the foundation for a successful student teaching experience. It is within a constructivist structured science methods course that preservice elementary teacher candidates enrolled in that was formed basis for contextual change of this study.

Theoretical Framework

This study had two theoretical frameworks that integrate with each other to provide insight into the research questions. They were: (1) self-efficacy; and (2) response-shift bias.

\section{Self-Efficacy}

Bandura (1986) described self-efficacy as "beliefs in one's capabilities to organize and execute the courses of action required to manage prospective situations" (p.389). Self-efficacy is context-specific such that it evaluates the capability to perform a specific task (Plourde, 1999). Schunk (1991) suggests that self-efficacy is "an individual's judgment of his or her capabilities to perform given actions" (p.207).

The focus of Bandura's social cognitive construct of self-efficacy has been related to teaching and teacher preparation in several studies (Ashton, \& Webb, 1986; Bleicher \& Lindgren, 2005; Brand \& Wilkins, 2007; Carter \& Sottlile, 2002; Enochs \& Riggs, 1990, Finson, Riggs \& Jesunathadas, 2000; Gibson \& Dembo, 1984, Guskey, 1988; 
Johnston, 2003; Woolfolk \& Hoy, 1990). Research suggests teachers' who maintain high self-efficacy in the form of high expectations for themselves and their students yield students that obtain high achievement (Lockman, 2006; Wigfield, Galper, Denton, \& Seefeldt, 1999).

There are two major aspects of self-efficacy: (a) personal efficacy, and (b) outcome expectancy. Bandura $(1977,1986)$ distinguished between these two by arguing that personal efficacy refers to an individual's belief that he or she can do something to yield a specific outcome, while outcome expectancy infers an individual's conception that a specific action will produce a specific outcome. In regards to teaching, personal efficacy is known as teaching efficacy in which an individual believes he or she can be an effective teacher as well as pragmatically overcome barriers to student learning (Lockman, 2006). Lockman (2006) further contends that teacher outcome expectancy refers to a teacher's belief that he or she can effectively influence student learning.

Bandura $(1986,1997)$ asserted that there are four sources for self-efficacy information which provide insight into the nature of teaching and teacher training. These are: (a) mastery experiences; (b) physiological and emotional arousal; (c) vicarious experiences; and (d) social persuasion.

Mastery experiences, as described by Bandura (1997), is the most powerful source of efficacy information as it reflects successful past experiences that have contributed to an individual's expectation of future ability. Bandura (1996) describes physiological and emotional arousal as being associated with positive emotions that reflect confidence and self assurance as well as the expectation of future success. Schunk (1987) comments that individuals that relate and identify themselves with others through 
observable moments, or vicarious experiences, can lead to a belief that they too have the competence to be successful in similar situations. Social persuasion occurs when an individual experiences praise in the form of an expression of another's faith, usually from a superior or advisor, in their ability to successfully engage in a specific task (Bandura, 1997).

In terms of science education, Enochs and Riggs (1990) suggested that Bandura's notion of self-efficacy is delineated by teachers who believe in his or her ability to effectively teach science, as in personal science teaching efficacy; and further that effective science teaching can influence student learning of science, namely science teaching outcome expectancy.

\section{Response-Shift Bias}

In order to compare the scores from pre-test and post-test responses a common metric must exist between both scores (Cronbach \& Furby, 1970). Pre-test and post-test measures of self reporting assume that an individual's standard for measurement of the item being assessed will maintain consistency from one administration of the instrument to the other (Howard \& Dailey, 1979). If the common metric is somehow altered between assessments, the post-test scores would reflect this change. Howard \& Dailey (1979) referred to this as a response-shift. In an effort to minimize the distortion of the common metric, Howard and Dailey (1979) suggested to move the administration of the pre-test closer to the administration of the post-test, as it "is more likely that both ratings will be made from the same perspective and thus be free of response-shift bias" (p. 145). Howard, Ralph, Gulanick, Maxwell, Nance, and Gerber (1979) suggested using retrospective pre-tests to control for response-shift bias. Bray and Howard (1984) argued 
that "when there is a response-shift, the most powerful method of analysis, overall, is the retrospective pre/post test method"' (p. 781).

In regards to science teacher education, the response-shift bias and subsequent retrospective-test to minimize the bias is a method to encourage preservice elementary teacher candidates to reflect back on their entry to the methods course and the context from which they assessed their science teaching self-efficacy at that point. The changes in personal science teaching efficacy and science teaching outcome expectancy from the pre-test to the post-test will have different meaning as those changes originate from prior school science experiences whereas the changes shown from the retrospective-test and the post-test will be due to the methods course.

This study sought to quantitatively determine the difference in these contexts via retrospective-test/post-test perceptions of self-efficacy according to personal science expectancy and science teaching outcome expectancy among preservice elementary teachers when exposed to a science teaching methods course. To examine this more fully, 4 research questions were developed.

\section{Research Questions}

This study examined how a science methods course affected self-efficacy. The purpose of this study was to investigate perceptions of self-efficacy among preservice elementary teachers when exposed to a science methods course. Based on the purpose of the study, the following general research question was developed. How do retrospectivetest $\backslash$ post-test self-efficacy perceptions differ among preservice elementary science teachers when exposed to a teaching science methods course? From this, four specific 
research questions were developed to investigate the differences among the variables. The statistical analysis for each question will be described further in Chapter III.

Research Question 1: Is there a statistical difference in pre-test / retrospective-test scores for personal science teaching efficacy (PSTE) and science teaching outcome expectancy (STOE)?

Research Question 2: Are there statistically significant differential outcomes for changes in retrospective-test and post-test scores within personal science teaching efficacy (PSTE) and science teaching outcome expectancy (STOE) between preservice elementary teacher candidates who met the science content requirements for their degree and those that exceeded that number?

Research Question 3: Are there statistically significant differential outcomes for changes in retrospective-test and post-test scores within personal science teaching efficacy (PSTE) and science teaching outcome expectancy (STOE) between preservice elementary teacher candidates who perceived their prior school science experiences to be positive and those that perceived the experiences to be negative?

Research Question 4: Is there a statistically significant interaction of within PSTE and STOE subscale scores between number of postsecondary science content courses taken and perceptions of prior school science experiences?

\section{Definition of Terms}

Directly related to the purpose of the study are the definitions of key terms. The following terms are defined to provide clarity as to their meaning in the context of this study. The independent variables include: (1) number of postsecondary science content courses taken; (2) prior science experiences; and (3) the science methods course. The 
dependent variable is the change in science teaching self-efficacy as measured by the STEBI-B which identifies and measures two subscales that comprise science teaching self-efficacy: (1) personal science teaching efficacy; and (2) science teaching outcome expectancy.

\section{Independent Variables}

Number of postsecondary science content courses taken: The number of postsecondary science content courses taken as a construct is defined as being a count of the total number of science content courses enrolled and completed at the postsecondary level taught outside the department of education. For the purposes of this study, the operational definition is provided by having participants write the number of science content courses taken at the postsecondary level prior to the science methods course (Bleicher, 2004) in the blank space provided on the survey instrument. Respondents will then be sorted into two groups: (1) met science content course requirements; and (2) exceeded science content course requirements.

Prior school science experiences: Prior school science experiences are defined as positive or negative. For the purposes of this study the operational definition is provided by having participants select whether they consider their prior school science experiences to be positive or negative (Tosun, 2000) according to the choices provided on the survey instrument.

Science methods course: The science methods course is defined as the course in which science knowledge is blended with pedagogical knowledge to help train preservice teachers to be science teachers. For the purposes of this study the operational definition is the course named T\&L 470: Science in the Elementary School. This course is a 
requirement for graduation in the teacher education program with an emphasis in elementary level teaching.

\section{Dependent Variable}

The dependent variable for this study was the change in science teaching selfefficacy as measured by the STEBI-B. The STEBI-B contains two components; (1) personal science teaching efficacy (PSTE); and (2) science teaching outcome expectancies (STOE).

Science teaching self-efficacy: beliefs about science teaching that consist of both personal science teaching efficacy and science teaching outcome expectancy (Riggs, 1988).

Personal science teaching efficacy (PSTE): According to the PSTE, the construct definition is a teacher's belief regarding his or her own ability to teach science effectively (Enochs \& Riggs, 1990). The operational definition measures personal science teaching efficacy (PSTE) with 13 items of the 23 items on the STEBI-B. The items contain statements such as: "I will continually find better ways to teach"; and "I will typically be able to answer student science questions" (Enochs \& Riggs, 1990). Items on the instrument are scored via a 5 point Likert-scale that ranges from strongly agree to strongly disagree.

Science teaching outcome expectancy (STOE): According to the STOE, the construct definition of teacher's belief regarding is his or her own expectation that their science teaching will have a positive effect on future students such that the students will successfully learn science (Riggs, 1988). The operational definition measures science teaching outcome expectancy (STOE) with 10 items of the 23 items on the STEBI-B. The 
items on this subscale contain statements such as: "Students' achievement in science is directly related to their teacher's effectiveness in science teaching"; and "the inadequacy of a student's science background can be overcome by good teaching" (Enochs \& Riggs, 1990). Items on the instrument are scored via a 5 point Likert-scale that ranges from strongly agree to strongly disagree.

Science teaching efficacy belief instrument for prospective teachers (STEBI-B): The STEBI-B consists of the PSTE and the STOE. As a construct, the instrument is used to measure preservice elementary teacher candidates' personal science teaching efficacy and science teaching outcome expectancy as developed and validated by Enochs and Riggs (1990). Each of the 23 items as comprised by the PSTE and STOE on the instrument is scored via a 5 point Likert-scale that ranges from strongly agree to strongly disagree.

\section{Importance of the Study}

The importance of this study is that teacher preparation programs are under attack as they are considered to be producing inadequate elementary science teachers (NRC, 1996). This may be a result of preservice teacher candidates feeling challenged in their understanding of science and their confidence in basic science knowledge (Ellis, 2001). It may also reflect the inability of some science methods courses to help preservice elementary science teachers increase their science teaching self-efficacy. If teacher education programs are looking to better prepare elementary science teachers, it stands to reason that determining more insight into how methods courses affect science teaching self-efficacy would be a prudent step in the right direction. Watters and Ginns (1994) contended that the predilection of becoming an effective elementary science teacher is 
influenced by a preservice elementary teacher candidates' self-efficacy. Fulp (2002) noted that upon evaluation of the 2000 National Survey of Science and Mathematics Education: Status of Elementary School Science Teaching that fewer than $30 \%$ of elementary teachers report feeling well prepared to teach science. This is not encouraging.

It is vital that teacher education programs, in an effort to make a significant and permanent influence on the science teaching self-efficacy of preservice elementary teacher candidates, be aware of the far reaching repercussions of the courses and experiences preservice teachers engage within the preparation program (Lockman, 2006). In understanding better the context in which science teaching self-efficacy can increase, practical and theoretical assertions can then be made to further enhance the experiences and training of future science teachers.

\section{Summary}

The purpose of this study was to investigate how retrospective-test / post-test perceptions of science teaching self-efficacy differ according to personal science expectancy and science teaching outcome expectancy among preservice elementary teachers when exposed to a science teaching methods course. Johnston (2003) reports that, "many preservice teachers enter science methods courses judging themselves at that moment to be incapable of teaching science" (p. 2). If this is in fact the case, teacher education programs need to find ways better ways prepare preservice teachers before entering the methods class as it is often the last course on the preparation sequence. This study assessed whether preservice elementary science teacher candidates lack the appropriate context to have high science teaching self-efficacy prior to arriving in the 
science methods course, and superimpose the results over Bandura's (1977) notion that self-efficacy is contextually based. Further, this study identified if a statistically significant difference exits in STEBI-B scores on both subscales between retrospectiveand post-tests. A review of the literature addressing: perceptions of science in the elementary school; self-efficacy as a psychosocial construct; measurement of selfefficacy using the STEBI; defining self-efficacy in the context of this study; self-efficacy in teaching and teacher preparation; preservice science teacher education; bettering science content area knowledge; measurement of preservice teacher candidates scienceteaching self-efficacy; science methods courses as the vehicle to measure changes in science teaching self-efficacy; alternative interventions to measure science teaching selfefficacy; factors affecting science teaching self-efficacy; and response-shift bias and retrospective-testing, is presented in Chapter II. 


\section{CHAPTER II}

\section{REVIEW OF LITERATURE}

The purpose of this study was to investigate how retrospective-test / post-test perceptions of science teaching self-efficacy differ according to personal science expectancy and science teaching outcome expectancy among preservice elementary teachers when exposed to a science teaching methods course. The following chapter contains a review of the literature in twelve sections: (1) perceptions of science in the elementary school; (2) self-efficacy as a psychosocial construct; (3) measurement of selfefficacy using the STEBI; (4) defining self-efficacy in the context of this study; (5) self-efficacy in teaching and teacher preparation; (6) preservice science teacher education; (7) bettering science content area knowledge (8) measurement of preservice teacher candidates science-teaching self-efficacy; (9) science methods courses as the vehicle to measure changes in science teaching self-efficacy; (10) alternative interventions to measure science teaching self-efficacy; (11) factors affecting science teaching self-efficacy; and (12) response-shift bias and retrospective-testing.

\section{Perceptions of Science in the Elementary School}

Driver and Oldham (1986) provided insight and a voice in advocating for establishing better curriculum development in science in the light of an initiative from the United Kingdom called, “Children's Learning in Science Project”. In their work, Driver and Oldham (1986) described the dynamics of a constructivist approach to learning and 
the effectiveness of student learning it was intended to achieve. The article provided a glimpse into the condition of elementary school science curriculum and how it needed to change as the concerns for student epistemology were gaining steam and the call for better taught science lessons began to ring loud. Constructivist oriented learning was the answer to these calls and part of the impetus of reform in science teacher preparation as preservice elementary teacher candidates needed to be prepared to teach along this theoretical pedagogic line. This work is relevant to this dissertation study as it identified the call for constructivist learning in science classrooms 22 years ago, and how today there is still the same call. Teacher education programs have not yet fully embraced this notion, and are being scrutinized for graduating ineffective and inadequate science teachers as a result (NRC, 1996). The NRC (2000) continues to express concern about science teaching in the elementary school through an inquiry into the national science standards, and offers suggestions as to how teacher education programs can find new ways to improve science teacher candidates throughout their programs of study. One way is to have collaboration between education and science departments. This idea is further discussed in Chapter V.

Tilgner (1990), acknowledged the challenges facing science education at the elementary school, the elementary science teacher curriculum, and the factors affecting students' interest in science. Tilgner (1990) sought a solution to the perceived shortcomings of science teacher preparation programs and offered a thorough list of characteristics of effective elementary science programs to learn from and help modify the then current practices in science teacher development. The author noted however that preservice elementary teacher candidates seemed to have inefficient and alternative 
understandings in science, and even more concerning have little interest in teaching science. It is therefore not surprising that Claxton (1992) wrote his prognosis that the global condition of science teacher preparation and training was in crisis and teetering on the edge of collapse unless reform to science teacher preparation occurred swiftly as the then current standards of science education were failing the learners. Olson (2006) continued to share a concern about the condition of elementary science teacher preparation and practice. Olson's (2006) work focused on providing solutions that met now current understandings of teaching and learning, and the effectiveness of well prepared, science knowledge confident, and self-efficacious preservice elementary teacher candidates entering the field post-graduation as inservice teachers. While it appears that a dark cloud hangs over elementary level science teacher preparation and training programs, there is some light that provides hope in terms of reversing the mostly negative perception of the last 20 years by developing and employing exceptional science teachers at the elementary level. The aforementioned studies are relevant to this dissertation study as they provide the pillars from which the idea of holistically reforming science teacher education is built upon. One method that has been shown to improve the quality of science teaching at the elementary level is for teachers to have a stronger sense of their science teaching self-efficacy.

\section{Self-Efficacy, a Psychosocial Construct}

Science teaching self-efficacy is based upon Bandura's (1997) social cognitive theory of self-efficacy, which refers to one's perceived capabilities to execute actions that will produce given attainments. Science teaching self-efficacy is therefore ones perceived capabilities to teach science effectively and believe that such teaching will yield 
meaningful science learning for future students. The following paragraphs summarize the development of the concept of self-efficacy through the work of Bandura $(1977,1986$, 1994, 1996, 1997).

Bandura (1977) published "Self-efficacy: Toward a Unifying Theory of Behavioral Change" as a vehicle to introduce the theory that psychological procedures affect levels of self-efficacy. Bandura (1977) suggested that expectations of personal efficacy are derived from four sources of information which include: (1) performance accomplishments; (2) vicarious experiences; (3) verbal persuasion; and (4) psychological states. Bandura (1997) commented that performance accomplishments, or mastery experiences, refer to the level of success in past experiences that contribute to an individuals expectation of future ability in the same context. Bandura (1986) noted that vicarious experiences are how an individual can relate and identify with someone else during observable moments. Essentially, this refers to the idea that if someone else can be seen accomplishing a task or demonstrating a specific behavior, the person observing who can relate to the observed individual can accomplish the same tasks or demonstrate the same behaviors. Social or verbal persuasion manifests when someone of a higher ranking, or a more powerful position, expresses faith, praise, or confidence in another individual's ability to successfully participate in a specific task (Bandura, 1997). The psychological states of an individual, as a result of physiological and emotional sources of arousal, provide the basis from which confidence and self-assurance are coupled with the expectation of future success (Bandura, 1996).

Bandura (1977) argued that factors such as enactive, vicarious, exhortative, and emotive sources influence the cognitive processing of efficacy information. Further and 
relevant to this study is the idea that an effective science methods course within science teacher education programs can incorporate all four of these influences on self-efficacy. Research on this line is presented below in the science methods section. With these factors as parameters, Bandura (1977) developed various treatments to test his hypothesized relationship between perceived self-efficacy and behavioral changes. What this paper really did was introduce readers to the complex nature of self-efficacy through the perspective of sources that impact it and provocative treatments that can change it.

In publishing, Social Foundations of Thought and Action: A Social Cognitive Theory, Bandura (1986) promoted the idea that humans are capable of being selfregulating, self-reflecting, proactive, and self-organizing. This opposes the other psychosocial perspective that suggests that humans are reactive entities lead by changes and forces in the environment or driven by ulterior concealed inner impulses (Pajares, 2002). What this means is that humans have the ability to judge their behavior and identify how such behavior alters their environments. By acknowledging ones inherent personal factors and reflecting on them in relation to behavior, this information becomes the basis for future judgments and subsequent behavior. This advancement in the understanding of the human agency provides the foundation from which the more subtle aspects of self-efficacy, especially those relevant to this study, can be explored.

Bandura (1986) identified that the theoretical center of the social cognitive theory are self-efficacy beliefs in suggesting, "people's judgments of their capabilities to organize and execute courses of action required to attain designated types of performances" (p. 391). It is this quote that provides the link between Bandura's (1986) ideas and this study. People that believe in their abilities to accomplish tasks and prosper 
through challenges are the source from which continued effort and perseverance arise. If someone believes they can succeed in a given action, it is that confidence that becomes part of the motivation necessary to act to succeed. However, an absence of such belief, in the face of challenge and resistance, will result in minimal incentive to persevere or alter behavior as a mechanism to find personal accomplishment. In the arena of science teaching, if one believes they have the background and knowledge to teach science effectively, they will do so in real classrooms outside of the teacher education programs. However, if one lacks that belief and is concerned or fearful about their ability to teach science in the schools, there is little incentive to do so resulting in an ineffective science education for students.

Bandura (1986) proposed the two subcomponents that form self-efficacy; namely personal efficacy, and outcome expectancy. Personal efficacy is noted as being the belief in one's ability to behave or act in a way that will yield a specified outcome. For science teaching, this means the confidence that one could effectively teach science. Outcome expectancy refers to the notion that a specific outcome will arise as a result of a specific action. For science teaching, this means that a teacher would believe that future students will effectively learn science from their teaching of science.

The background of this study is framed around the perspective that not enough effective science teaching and learning is being done in the elementary stream. The question of why this occurs may be partially answered in considering the effects of science teaching self-efficacy during teacher education programs.

Self-Efficacy: The Exercise of Control (1997) further described the role of selfefficacy beliefs in the human agency in writing, "people's level of motivation, affective 
states, and actions are based more on what they believe than on what is objectively true" (p. 2). This quote points to the power of having a strong sense of self-efficacy. This work however holds deeper connection to teaching as Bandura (1997) contends that people with confidence can sometimes outperform those with advanced skill sets who suffer from self-doubt. Unfortunately, even an enormous amount of confidence in one's ability can result in success when the background information, knowledge and skills are absent. For teaching, this means that people with a good sense and understanding of science knowledge and pedagogic knowledge can embrace their energies to design, organize and implement effective science teaching as long as they have the confidence that they can do so. Conversely, someone with greater scientific and pedagogic knowledge may not be able to science teach effectively as they may have doubts to their ability to do so. However, without a comfortable amount of both scientific and pedagogic knowledge, an abundance of personal confidence will not be enough to effectively teach science. On this note, much research has been completed that relates science teaching self-efficacy with teaching.

Tschannen-Moran, Hoy and Hoy (1998) examined the conceptual groundwork and tools for measuring teacher efficacy. The purpose of the examination was to clarify the construct as well as improve methods for measuring it. Tschannen-Moran, et al. (1998) identified two competing ideas of teacher efficacy; one from Rotter's social learning theory (1966), and one from Bandura's social cognitive theory of self-efficacy (1977). Although the difference in perspective is pertinent for psychological frameworks and research, it is beyond the scope of, and relevance to, this study. The relevant aspect of this article is the overarching model that Tschannen-Moran et al. (1988) present. In 
this model, the authors suggested that teachers make efficacy decisions partially based on the results of assessing available resources and constraints in specific teaching contexts. The significant role of context is critical to the analysis of this dissertation study, as both personal efficacy and outcome expectancy subcomponents of self-efficacy, as well as the use of a retrospective-test, are based upon the influence context plays in assessing ones level of science teaching self-efficacy.

\section{Measurement of Self-Efficacy Using the STEBI}

Riggs (1988), in an unpublished dissertation, began the process of developing an instrument specifically designed to measure science teaching self-efficacy which incorporated Bandura's two theoretical constructs of PSTE and STOE. Within this research, Riggs (1988), aside from laying the foundation for developing the instrument used for data collection in this dissertation study, also provided clear descriptions of each of the constructs. Equally important and relevant to this study is that Riggs (1988) commented that in order to research science teaching self-efficacy, both constructs need to be examined.

Enochs and Riggs (1990) developed a measuring instrument for science teaching self-efficacy based on Riggs (1988) initial work. The instrument developed was the Science Teaching Efficacy Belief Instrument form B (STEBI-B). On the new version of the instrument, the original items geared towards assessing inservice science teachers' science teaching self-efficacy were converted to capture preservice science teachers' sense of science teaching self-efficacy. It is this reconfigured and more specialized instrument that was used as the data collection survey for this dissertation. Within the original study, Enochs and Riggs (1990) administered the STEBI initially to 71 inservice 
elementary science school teachers, then to 331 science teachers. A factor analysis of the responses identified two substantial factors; notably the PSTE and STOE components of science teaching self-efficacy. The factor analysis results agreed with those reported by Riggs (1988).

It was these papers that introduced the STEBI and STEBI-B. With the modifications made by Bleicher (2004) to remove extraneous and ambiguous words from two items, this instrument was selected for use in this dissertation and grounded in the literature.

\section{Defining Self-Efficacy in the Context of This Study}

In addition to Riggs (1988), and Enochs and Riggs (1990), Huinker and Madison (1997) provided insight into operational definitions for self-efficacy while investigating, among other items, the effects of methods courses on PSTE and STOE. The authors claimed that:

People who are seen themselves as efficacious set challenges for themselves and are more likely to persist in their efforts until they succeed. People who perceive themselves as inefficacious are more likely to shy away from difficult tasks and even abandon them in the face of obstacles. (p. 108)

This work is relevant to this dissertation study as it finds that effective methods courses have a positive influence on changing the levels of science teaching self-efficacy of preservice elementary teacher candidates which is addressed later in this chapter. More importantly, this research provides context in which science teaching self-efficacy can be defined.

Schunk (1991) described self-efficacy in providing a thorough overview of the psychosocial construct. Like Tschannen-Moran et al. (1998), Schunk (1991) described 
different perspectives of the related constructs to self-efficacy which include:

(1) perceived control; (2) outcome expectations; (3) perceived value; (4) attributions; and (5) self-concept. Schunk (1991) continued the study in capturing the resultant self-efficacy as a result of the effects of person variables like goal setting and information processing; and situation variables like models, feedback and rewards. This work is relevant to this study as it provides a global description of self-efficacy in suggesting that it is simply one's assessment of his or her capacity to perform specific actions (Schunk, 1991).

Ramey-Gassert, Shroyer, and Staver (1996) also contributed usable descriptions of PSTE and STOE in their investigation of factors that influence PSTE and STOE levels of preservice elementary teacher candidates. Using both qualitative and quantitative data collection, results of this study revealed that PSTE can be influenced by achievement in high quality science courses, professional development, supportive colleagues and administrators and access to resources and time. This investigation is relevant to this study as it provides insight into factors that might effect the changes in scores on the PSTE and STOE subscales as well as additional descriptions towards an understanding of what PSTE and STOE actually mean.

Johnston (2003) provided explanations as to what changes in levels of PSTE and STOE subscales mean from a pragmatic perspective. Here, Johnston (2003) identified high scores on the PSTE subscale to mean a strong belief in one's ability to teach science in a rich and effective way; while high scores on the STOE subscale denoted a high expectation that the practice of one's science teaching would elicit meaningful learning in students. It is these descriptive explanations that are relevant to this study as they helped 
focus the broad understandings of what each of the two science teaching self-efficacy components refer.

El-Deghaidy (2006) reported results of an investigation of Egyptian preservice teacher's levels of self-efficacy and self-image as science teachers. In this work, El-Deghaidy (2006) described the four main sources Bandura (1997) identified that impact self-efficacy. These include: (1) mastery experiences; (2) physiological and emotions states; (3) vicarious experiences; and (4) social persuasion. Further, the author described PSTE and STOE from a simplistic perspective such that PSTE defines confidence in the ability to teach science, and STOE refers to the confidence that future students will positively learn from the teaching. Schunk (1987) completed a metaanalysis of peer modeling research and within it comments that people who relate to others through vicarious experiences can result in those individuals developing a stronger sense of efficacy such that they too can be successful in a similar situation. This is a big part of peer teaching and observation during field placement and practicum. Finson, Riggs, and Jesunathadas (2000) sought to investigate the relationship between selfefficacy and perceptions of self as a science teacher among preservice elementary teacher candidates. The method used to collect the data was the Draw-A-Science-Teacher Teaching Checklist and the STEBI-B. The method and results of this work are irrelevant to study, yet the background definitions of variables are relevant.

The purpose of Bleicher and Lindgren's (2005) research was to examine the relationships between conceptual understanding and both PSTE and STOE subscales of science teaching self-efficacy developed within a constructivist based science methods course and variables that contribute to those changes. The theoretical framework of their 
study was constructivist learning theory and self-efficacy. Data was collected from 49 elementary preservice student teacher candidates. The results indicated that participation in the constructivist oriented science methods course increased perceptions of selfefficacy on both subscales and conceptual understanding. This suggests that increasing the number of science content courses preservice elementary teacher candidates may not be sufficient to increase science efficacy. Rather, it is the learning environment within such science content courses that makes the difference. Bleicher and Lindgren's (2005) work is relevant to this study as it helps focus the variables, from which context may be determined when assessing changes in perceptions of science teaching self-efficacy.

The works presented above are relevant to this dissertation study as they provide clear, yet varying, descriptions of self-efficacy, PSTE and STOE subcomponents, and how each term is delineated from results of using the STEBI-B. With theoretical and operational definitions in hand, the following section presents an overview of selfefficacy in teaching and teacher preparation.

\section{Self-Efficacy in Teaching and Teacher Preparation}

There has been much research conducted that relates self-efficacy and teaching, and teacher education and preparation. The following section provides a summary of key pieces that contributed to the development of this study.

Gibson and Dembo (1984) sought to develop an instrument to measure teacher efficacy while providing construct validation support to the individual differences in teaching effectiveness. Further, the authors examined the relationship between observable teacher behaviors and teacher efficacy. As a result, Gibson and Dembo (1984) developed a 30 item scale called the Teacher Efficacy Scale. A factor analysis of the responses 
found two substantial factors that correspond to Bandura's two tier factor model of selfefficacy; namely the PSTE and STOE. This piece of research is relevant to this study as it was one of the first studies to use the Bandura's two factor model of self-efficacy in relation to teaching.

Asthon and Webb (1986) developed Making a Difference: Teachers' Sense of Efficacy and Student Achievement. In the book, Ashton and Webb (1986) suggested that preservice elementary teacher candidates are ideal to study as teacher beliefs may be good predictors of future teaching behavior. What this means is that in identifying and understanding preserevice teacher self-efficacy beliefs, these may be used as predictors to gauge how these preservice teachers will teach once they become inservice teachers. This work was specifically aimed at science teaching which points to its relevance here.

Ashton and Webb's (1986) book is relevant to this study as it provides the underpinnings for doing science teaching self-efficacy study, especially in terms of valuing perspectives of self-efficacy as predictors for future teaching behavior.

The purpose of Guskey's (1988) work was to explore attitudes towards implementing new instructional practices. In this study of 120 teachers in a professional development program, Guskey (1988) determined that teachers that have a higher sense of teaching efficacy are more open to new pedagogic ideas for teaching and learning, and are more willing to put the needs of their students first and try innovative and different teaching and learning strategies to maximize meaningful learning. Allinder (1994) added commentary to exploring inservice teachers with high levels of teaching efficacy in studying direct and indirect instructional services. The results of that study indicated that teachers with a strong sense of teaching efficacy are more likely to be enthusiastic, better 
planned and more organized. These studies are relevant to this dissertation study as they provide possible characteristics which might exude from current preservice elementary teacher candidates once they become inservice teachers if the teacher education program as a whole can raise their levels of self-efficacy.

Woolfolk and Hoy (1990) examined the structure and meaning of efficacy amid preservice teachers. The authors then related the participant's efficacy to beliefs about control and motivation. The focus questions of this research were: (1) Is the structure of efficacy for prospective teachers the same as has been found for experienced teachers?; and (2) Are prospective teachers' beliefs about efficacy related to their orientations toward discipline, order, control, and motivation in schools? The results of this research found two independent aspects of efficacy; namely, teaching efficacy and personal efficacy. Like Gibson and Dembo (1984), these two dimensions are incorporated in this dissertation as PSTE and STOE. The interesting implication of Gibson and Dembo's (1984) results and of great relevance to this study is the comment that:

Prospective teachers with high teaching efficacy are more humanistic in their pupil control ideology than those with low teaching efficacy; however, the relationship exists only among prospective teachers who believe that they have the ability to make a difference in student achievement - that is, only among those who also have high personal efficacy. (p. 88)

Lockman (2006) studied preservice secondary teacher candidates in an attempt to explore teacher efficacy beliefs, beliefs regarding student learning, and the perceived role of the secondary science teacher. This research was conducted throughout a year long teacher preparation program. Results of the mixed-method study suggested that the year long teacher preparation program yielded increases in the levels of PSTE. Lockman (2006) also provided readers with descriptions of PSTE and STOE which are helpful in 
determining operational definitions for this dissertation. Lockman (2006) suggested that inservice teachers with a strong sense of self-efficacy, coupled with high expectations for themselves and their students promote high achievement from the students. This finding is relevant to this study as it suggests a future possible teaching outcome of preservice teachers who maintain a strong sense of self-efficacy once in the field.

Wigfield, Galper, Denton and Seefeldt (1999) studied 33 inservice grade 1 teachers' beliefs about: student ability; effort; sociability; participation in extracurricular endeavors; student achievement; and expectations for students' future studies. Wigfield et al. (1999) concluded that teachers who maintained high self-efficacy thought students could achieve more than they actually could. This conclusion is relevant to this dissertation as it suggests another trait of inservice teachers that hold high levels of selfefficacy in relation to student achievement. This comment, like Lockman's (2006) implications, are reasons to continue trying to improve the levels of self-efficacy in preservice elementary teacher candidates while enrolled in teacher preparation programs. The relevant results of the above studies to this dissertation study speak to the prediction of future teaching behavior, philosophy, and effectiveness based on levels of teaching efficacy. It is the positive attributes stemming from a strong sense of selfefficacy which are identified by the above research that teacher education programs seek to strengthen within their future teachers by helping to raise their levels of self-efficacy. Unfortunately, a high sense of self-efficacy during the preservice program does not always result in positive results once the preservice teacher candidate becomes an inservice teacher. 
Hoy and Spero's (2005) longitudinal study of preservice teachers from entry into teacher education programs through teaching in their own classrooms post-graduation found that although there was an increase in one's sense of self-efficacy during the teacher preparation program, there was also a significant decline in that same sense of self-efficacy during the first year of teaching. Hoy and Spero (2005) suggested a reason for this may be a lack of support received during that year. This research is significant to this dissertation study as it provides insight into what may happen in the real world of teaching post-graduation. Information of this nature should help drive the structuring of the teacher preparation programs such that preservice teachers can be informed of, and prepared for, this plausible outcome and be given resources and support strategies to handle it. This will aid beginning teachers in those challenging times during their first year and help minimize the reduction in teaching efficacy, as the results of maintaining a high level of self-efficacy are critical to success in teaching.

Brand and Wilkins (2007) sought to investigate the four sources that impact selfefficacy as suggested by Bandura (1994). The study explored preservice elementary teacher candidates' development into effective science teachers through enrolling and participating in a science and mathematics methods course designed for the elementary level. Brand and Wilkins (2007) researched how mastery experiences, vicarious experiences, social persuasions and stress reduction (Bandura, 1994) affected preservice elementary teacher candidates' levels of science teaching self-efficacy. Moreover, it was an opportunity to assess their methods course based on those parameters. Mastery experiences were determined to be the most influential of the sources affecting preservice elementary teacher candidates' sense of efficacy. This result is relevant to this 
dissertation study as it unites the sources impacting perceptions of one's efficacy and also contributes to the formulation of designing an effective and meaningful science methods course for preservice elementary teacher candidates which is described in the science methods course section below. The relationship between preservice science teacher education and self-efficacy is presented below.

\section{Preservice Science Teacher Education}

The intricate aspects of preservice science teacher education depend largely on the programs of study set out by Colleges of Education. Preservice elementary student teacher candidates at this Upper Midwest University are required to complete two science content courses with labs as the source of their science knowledge at the postsecondary level. The nature of the experiences and learning within these science content courses as an example of science teaching and learning plays a critical role in the preparation of future science teachers.

Ginns and Watters (1990) conducted a longitudinal study with the purpose of gaining insight into the personal and science teaching efficacy of preservice elementary teachers. Using a mix-method design including the administration of the science teaching efficacy belief instrument form B (STEBI-B) and conducting interviews, results suggested that teacher preparation programs as a whole do not appear to influence preservice elementary teachers' sense of science teaching self-efficacy, but do however significantly influence the beliefs of student epistemology and ability to learn of science. The apparent lack of change in personal science teaching self-efficacy may appear once preservice teachers have become inservice teachers. The implications of such a result are serious as they will likely decrease the effectiveness and richness of their future student 
science learning. Ginns and Watters (1990) work is relevant to this study as it identifies self-efficacy as a meaningful research topic as well as its relationship to the continuum of preservice teacher development and training towards becoming inservice teachers.

The purpose of Cochran, King and DeRuiter's (1991) work was to acknowledge the chasm between pedagogical knowledge and content knowledge, and provide a model for which pedagogical knowledge could be defined. The authors subsequently defined pedagogical knowledge as; "the manner in which teachers relate their pedagogical knowledge to their subject matter knowledge in the school context, for the teaching of specific students" (p. 1). The term pedagogical knowledge was then further broken down into four subcategories that included; knowledge of subject matter, knowledge of student, knowledge of the environmental contexts, and knowledge of pedagogy. The distinction between pedagogical knowledge and content knowledge is useful to this study as it identifies part of the foundation from which the science methods course, in which the participants of this study were enrolled in, could be developed. The other part of the foundation is the content knowledge that the preservice teachers learned in their postsecondary science content courses. Interestingly, Young and Kellogg (1993) and Duschl (1983) found that preservice elementary teacher candidates usually only enroll in and complete the required number of postsecondary science courses for their major. This is relevant as it provides insight into using the number of postsecondary science courses taken as a grouping variable for this study.

Tobias (1997) provides a strong voice for improving the nature of science teacher preparation within teacher education departments. The purpose of Tobias' (1997) work was to collate a review of the history and politics of teacher education. Within this work, 
the author compares and contrasts science education in science departments and mathematics education within mathematics departments. The results of this analysis elicited a call for improvements being made to science content area courses as they were appearing to be absent of efficient teaching and learning strategies. Tobias's (1997) work is relevant to this study as it integrates a call for improved pedagogy in the science content courses from which preservice science teachers will enroll with the suggestion that such an improvement will contribute to better science teaching of the future as preservice teachers will have a better grasp of science knowledge. Taken one step forward, such an improvement in science knowledge may subsequently lead to an increase in science teaching self-efficacy prior to arriving in the science methods course.

\section{Bettering Science Content Area Knowledge}

The purpose of Stotsky's (2006) work was to identify and describe the types of knowledge and skills preservice teacher candidates should have acquired in their teacher education programs. The author then argues that the wrong faculty members are held accountable for much of the core information needed to teach grade 5 through 12 . Stotsky (2006) presents three types of knowledge needed to become a teacher that includes:

(1) academic knowledge which is the subject area content knowledge in their field;

(2) generic professional knowledge and skills which is pedagogic knowledge; and

(3) license-specific professional knowledge and skills for teaching in the area of their licensure. The implications of this model suggest that much of the knowledge and skills needed to teach come from content area courses, not education based courses. Within this claim is the suggestion that better pedagogy in such courses would help develop stronger teachers as they would have acquired greater knowledge and skills in their subject area to 
be later combined with pedagogic knowledge within methods courses. This point is critical to this study as it lends support to the call for improving pedagogy in science content courses campus wide. The work concluded with an argument for teacher education reform being a campus wide endeavor, a concept that is deeply intertwined with the discussion in Chapter V of this dissertation.

Mestre (2001) provided a brief historical account of the cognitive research results relevant to the teaching and learning and postsecondary level physics content courses. Mestre's (2001) work superimposed these results over the current levels of which postsecondary physics courses are taught and learned by preservice teacher candidates. The results of this paper included a list of what the literature and research suggests bettering the preparation of preservice physics teachers. While the list provided by Mestre (2001) is designed for physics, the overall ideas presented have deeper meaning towards science teacher preparation as a whole as it identifies the need for pedagogical strategies in these science content courses to be more meaningful for students and their learning. This work is relevant to this dissertation study as it lends guidance to the pragmatic aspect of cross campus teacher education and preparation reform. All it takes is one department, like physics in this case, to encourage its professors to provide more opportunities for meaningful, deep, rich and complex learning to be constructed by students both part of and outside of the teacher education program. It is then that teacher education reform outside of the walls of the education building, like Stotsky (2006) suggested becomes possible. This is the hope that is discussed in Chapter V. 


\section{Measurement of Preservice Teachers' Levels of \\ Science Teaching Self-Efficacy}

Palmer (2001) provided a detailed record of research that aims to assess confidence levels and the perceived ability to teach science amongst preservice elementary teacher candidates. In citing these studies, Palmer (2001) noted the overwhelming sentiment that preservice elementary teacher candidates lack confidence in their ability to teach science, and worse yet, often dislike science. Palmer (2001) further investigated changes in preservice elementary teacher candidates' levels of confidence to teach science. Identified through interviews, Palmer (2001) determined factors that influenced a change from negative to positive attitudes and confidence within the teacher education program and methods courses. Palmer's (2001) paper has relevance to this study as it strengthens the resolve that preservice elementary teacher candidates have low science teaching self-efficacy, and that effective methods course are helpful in raising both the confidence and attitude towards science and science teaching.

Ramey-Gassert and Shroyer (1992), using the theoretical framework of selfefficacy, described methods for building science teaching confidence to help alleviate preservice elementary teacher candidates concerns of teaching science. The authors suggested that integrating technology, microteaching, cooperative learning, role modeling, and experiential learning are all vital aspects of a science methods course with the aim of elevating science teaching self-efficacy. Within this work, Ramey-Gassert and Shroyer (1992) discussed the interaction and interrelatedness of low science teaching self-efficacy, and science anxiety and attitudes towards science. One of the conclusions of this study is that without a healthy sense of personal science teaching self efficacy, 
preservce elementary teacher candidates are less likely to teach science at all when they are out in the field as their low science teaching self-efficacy and negative attitudes toward science will inhibit that endeavor. This work is relevant to this dissertation study as it helps construct the foundation of a rich and meaningful science methods course which is explored later in this chapter.

Scharmann and Hampton (1995) took one of the ideas noted by Ramey-Gassert and Shroyer (1992) and examined the influence of cooperative learning on the science teaching self-efficacy of preservice elementary teacher candidates. The results of this work identified the effectiveness of heterogeneous cooperative learning, as well as the positive impact a well organized and implemented science methods course has on levels of both PSTE and STOE subscales of science teaching self-efficacy. Scharmann and Hampton (1995) noted however that although well designed science methods courses help in this regard, many preservice elementary teacher candidates are none-the-less concerned about their ability to teach science once the teacher education and preparation program is completed. This concern, even thirteen years later, is still prevalent within preservice elementary teacher education and is relevant to this study as a result.

In Ellis's (2002) work to provide an overview of the professional standards of science teacher preparation programs, the author compared and contrasted the perceptions of the preservice teachers with the professional standards of the program. Through this study, Ellis (2002) examined the science teaching self-efficacy of the preservice elementary teachers and the concerns about their teaching of science to future students. Ellis (2002) concluded that many preservice elementary teacher candidates feel challenged by their limited understanding of science concepts and lack confidence in 
even the basic science knowledge they do possess. This conclusion is relevant to this study as it gives foresight into a possible root of preservice elementary teacher candidates' low levels of science teaching self-efficacy.

The purpose of Watters and Ginn's (1994) work was to explore prior and current science experiences and beliefs of preservice elementary teacher candidates. In this work, pre- and post-test psychometric instruments that evaluated science teaching self-efficacy, science related attitudes, interest in science teaching and preferred learning environments were administered. Some of the respondents were randomly selected to participate in interviews. While the statistical data provided no significant group differences in selfefficacy, interviews coupled with the numerical data provided the basis for Watters and Ginns (1999) to comment on causative factors that might influence the levels of preservice elementary teacher candidates' self-efficacy and related anxiety about science. The authors contended that the possibility of becoming an effective elementary science teacher is in fact related to preservice elementary teacher candidates' level of selfefficacy. This contention is relevant to this study as it speaks to the value of teacher education programs desired reform to help raise preservice elementary teacher candidates' levels of science teaching self-efficacy.

Appleton (2003) examined the transition between preservice to inservice for elementary teacher candidates. In this investigation, Appleton (2003) noted that preservice teacher candidates can be typically grouped to have the following characteristics: have low content knowledge in science; have had negative experiences in science; and regard themselves as language arts teachers that only sometimes dress up 
and play the part of a science teacher. This last trait is particularly concerning, and is part of the reason for beginning this dissertation study, which points to its relevance here.

Sadly, Fulp (2002), in a report for Horizon Research, found that in analyzing the 2000 National Survey of Science and Mathematics Education: Status of Elementary School Science Teaching, that there were some alarming trends. One of the most notable statistics was that fewer than $30 \%$ of elementary teachers reported feeling well prepared to teach science. Questions arise as to where those inservice teachers' science teaching self-efficacy went, or was it not there to begin with? In an effort to reduce this percentage, and put a qualified, prepared, confident, and self-efficacious science teacher in every elementary classroom, preservice elementary teacher candidates must leave teacher education programs with as high and strong a sense of self-efficacy as possible. This is the goal of science teacher preparation, and can be accomplished in many ways. One way is through effective science methods courses.

\section{Science Methods Courses}

In the semester or two before entering the student teaching phase of the teacher education program, elementary student teacher candidates typically enroll in a science methods course. The perceived function and strategic organization of the science methods course is critical in helping hone the craft of science teaching and encouraging a strong sense of science teaching self-efficacy.

Anderson (1997) provided useful insight into the nature of science methods courses from an operational definition perspective; and context within the total teacher education program perspective. The purpose of Anderson's study was to: (1) report research based definitions and ideas of the role and logistics of science methods courses; 
(2) construct a new definition that is integrates those purported in the literature; and

(3) provide suggestions into the implementation of such a new definition and

organizational definition of science methods courses while noting some pitfalls that may ensue. Data was derived and collected from published literature and research. Anderson noted that the literature promoted three different notions of what defined a science methods course. These include: (1) "a launching pad for a career-long process of professional development" (p. 269); (2) "foundation for a successful student teaching experience" (p. 269); and (3) "the linchpin of the teacher education program" (p. 269). Anderson (1997) noted that these three ideas are not mutually exclusive but rather the position from which developing an effective science methods course begins. The science methods course, Anderson (1997) advocated, must therefore be the, "foundation of a science teacher's professional development, both individually and programmatically" (p. 270). The implications from this study provide a new vision of the function science methods courses play in the larger role of teacher education programs. Anderson (1997) concluded that a science methods course:

...with a holistic orientation, a focus on integrating philosophical, psychological, sociocultural, and subject matter perspectives, and preparation for career-long professional development has the potential of integrating theoretical and practical dimensions of the program; ie. bridging the gap between theory and practice, between course work and student teaching. (p.270)

Anderson's (1997) research has relevance to this study as it provides context of the science methods course that the participants of this study are enrolled.

Kelly (2000) reported the theoretical and practical rationale for developing a constructivist based elementary science methods course, and the results of a four year study of this course. Kelly (2000) identified the benefits of developing learning centers, 
peer teaching experiences, and practical experiences with the learning styles of elementary students. This research adds to the mosaic of information that suggests that a holistic, constructivist-oriented science methods course can enhance pedagogical knowledge, science knowledge and increase science teaching self-efficacy. More importantly, Kelly (2000) suggested that a possible result of an effective science methods course is the transferring of the constructivist learning by preservice elementary teacher candidates to constructivist framed teaching once those candidates become inservice teachers. This theme is relevant to this dissertation as it identifies one of the goals for science teacher education through a pragmatic source like the science methods course.

The purpose of Carter and Sottile's (2002) work was to examine the critical factors that influenced dispositions of preservice elementary teacher candidates as a result of participating in a constructivist based science methods course. The results of the examination identified that the constructivist orientation increased the levels of science teaching self-efficacy amongst the preservice elementary teacher candidates. A relevant implication of this work to this dissertation study is the suggestion that improvement in science teaching self-efficacy, as a subsequence of a constructivist framed methods course, will be seen longitudinally when the preservice teachers become inservice teachers. This point is the reason for continued research and effort to reform science teacher education and preparation.

Johnston (2003) identified the relationship between constructivist based science methods course and levels of science teaching self-efficacy. More specifically, the study investigated how active learning and teaching style affected preservice elementary teacher candidates' beliefs and attitudes of science teaching. The results of the 
relationship analysis determined that well designed methods courses that incorporate hands-on activities with opportunities to construct new ideas about science intertwined with teaching and learning strategies had positive impact in elevating levels of science teaching self-efficacy. Johnston's (2003) article is relevant to this study as it lays the philosophic foundation from which the science methods course taught by the researcher and other member of the education department faculty in this study could be developed.

Bleicher and Lindgren (2005) studied the relationship between changes in levels of science teaching self-efficacy in relation to a constructivist oriented science methods course for preservice elementary teacher candidates. The authors found that hands-on activities, minds-on activities, and discussion were instrumental in increasing the levels of science teaching self-efficacy amongst the respondents. Bleicher and Lindgren (2005) suggested that these preservice teacher candidates would likely carry over the constructivist orientation of teaching and learning into their future classrooms.

Furthermore, the authors purported that it is not the number of science content courses a preservice teacher enrolls in, but the quality of the learning experience in that course that makes a difference in terms of science teaching self-efficacy. This suggestion is critical to this study as it implies the need for improved pedagogy within science content courses leading up to the science methods course.

Bleicher (2007) continued investigating changes in PSTE and STOE in preservice teacher candidates through the enrollment in a science methods course. In this research of 70 preservice teachers, Bleicher (2007) found that the extent of the relationship between science learning confidence and science teaching confidence requires more study. This 
contention of self-efficacy research provides insight into possible future research ideas. Moreover, Bleicher (2007) provides further interpretation of effective methods courses.

Bleicher and Lindgren (2005), and Bleicher's (2007) papers help to pragmatically organize the science methods course. This is especially helpful in an effort to integrate science knowledge with pedagogy knowledge within the science methods course used in this dissertation study.

\section{Measuring Science Teaching Self-Efficacy Through Alternative Interventions}

While investigating science methods courses and its effect on science teaching self-efficacy as a whole is one way to study changes in science teaching self-efficacy, there are other methods that seek insight into the same phenomenon. Jay (2000) reported on using modeling-microteaching as a specific intervention to affect levels science teaching self-efficacy. Using a pre-test and post-test method and employing the STEBI-B as the data collection instrument, Jay (2006) found that the modeling-microteaching component of the science methods course for preservice early childhood teacher candidates might be a positive factor for increasing scores on both PSTE and STOE subscales. Plourde (1999) also studied changes in science teaching self-efficacy using a different intervention than the science method course.

The purpose of Plourde's (1999) work was to investigate the effect of the student teaching semester on levels of PSTE and STOE of preservice elementary teacher candidates. Using a mix method technique which included interviews and the administration of the STEBI-B, data was collected and analyzed. The results of this investigation suggested that the student teaching semester did not have a statistically 
significant effect on PSTE scores, but did have a statistically significant effect on STOE scores. The relevance of this work to this dissertation study is profound as it identifies the effects of student teaching in terms of context for the STOE subscale. This is further discussed in Chapter Five.

Crowther (1999) examined the relationship between duration of science education practicum and the perceptions of science teaching self-efficacy of preservice elementary teacher candidates. The results of this study found that the placement of the practicum relative to when students enroll in the science methods course, as in before the practicum, during the practicum, or after the practicum, yielded qualitatively different levels of science teaching self-efficacy. This research is relevant to this dissertation study as it supports the discussion in Chapter Five regarding the value and positioning of the student teaching practicum in the overall chronology of the program of study within the teacher education program.

Jay (2000), Plourde (1999), and Crowther (1999) are relevant to this study as they identify the robust research opportunities available for studying changes in science teaching self-efficacy from varying perspectives and interventions.

\section{Factors Affecting Science Teaching Self-Efficacy}

The purpose of Mulholland, Dorman, and Odgers's (2004) study was to investigate science teaching efficacy of 314 preservice elementary teachers using the STEBI-B. The variables used for grouping in the analysis were gender and high school science subjects. The authors researched two questions in their study; (1) did the number of high school science subjects taken have an effect on levels of science teaching selfefficacy?; and (2) did the particular high school science subjects have an effect on levels 
of science teaching self-efficacy? The results indicated that neither the number of subject of high school science courses had an effect on either PSTE or STOE. This work is relevant to this study as it provides insight into the value of prior school science experiences as a useful descriptive variable. If it is not the number or subject area of the high school science courses, then it may in fact be the quality of experiences in those courses. As such, one of the grouping variables within this study was selected to be the perceptions of prior school science experiences.

The purpose of Young and Kellogg's (1993) study was to compare the experiences of preservice elementary teachers and other nonscience majors with science majors within science and mathematic training. The results indicated that although both groups of participants received roughly equal training in both subject areas, there was a noticeable difference in the attitudes and beliefs towards science between the groups. Young and Kellogg (1993) reported that, "elementary teachers' attitude toward science warrants concern" (p. 279). Appleton (1995) reiterates this concern.

Appleton (1995), in response to calls by teacher educators in Australia to provide more science area units in the science methods courses, studied the changes in perceptions of science teaching self-efficacy pre and post a methods courses that contained only minimal amount of science content. The results, as reported by Appleton (2005), suggested that the need for more science knowledge within the science methods course is substantiated. What this means is that methods courses need a careful blend of pedagogical knowledge and content knowledge. This contrived union will help increase the levels of science teaching self-efficacy amongst preservice elementary teachers. It is 
implications from this work that helped focus the nature of the science methods course from which the respondents of this study enrolled.

Young and Kellogg (1993), Appleton (1995) both coupled with Olson's (2006) paper which states the same worry, has relevance to this study as they speak to the continuing anxiety regarding preservice elementary teachers' levels of science teaching self-efficacy and how this may translate into elementary classrooms post-graduation. More specifically, what these referenced studies have provided is the foundation from which this study has been developed. There is great need to improve the training and preparation of preservice elementary science teachers, from both the content area courses as well as the methods courses.

The notion of improving preservice teacher candidates' levels of self-efficacy has become a popular research focus. The purpose of Palmer's (2006) paper was to investigate the sources of self-efficacy in an elementary level science methods course. Using formal and informal surveys as the data collection tool, Palmer (2006) deduced that the main source of self-efficacy was cognitive pedagogical mastery. While the reported result is not directly relevant to this study, the background from which Palmer's (2006) work was developed is relevant. Palmer (2006) identified the overwhelming position that many preservice elementary teachers have low science teaching selfefficacy. Unfortunately, this is not a new theme in this literature review.

Schoon and Boone (1998), and Moore and Watson (1999), both studied the effects of increasing the number of postsecondary science courses in preservice elementary teacher candidates' programs of study on level's of science teaching selfefficacy. The results from both studies identified that such an increase had little or no 
effect on changes in science teaching self-efficacy as a whole. However, Bleicher (2004) and Bleicher and Lindgren (2005) have shown that the number of science courses taken does effect the PSTE subscale but not the STOE subscale. These results are significant to this study as they provide the basis from which using the number of postsecondary science courses taken as a grouping variable becomes possible.

The perception of prior school science experiences was examined by Tosun (2000) as a source of information for guiding reform of preservice teacher education. Tosun (2000) reported that within the interview process, descriptors used by preservice teacher candidates to reflect previous school science experiences were overwhelmingly negative. These sentiments, more so than achievement in these courses, had great impact on influencing levels of science teaching self-efficacy.

These findings are relevant to this study as they identify the influence of perceptions of prior school science experiences on levels of science teaching selfefficacy. This is important as it provides insight into the context from which the pre-test results of the STEBI-B can be seen through.

Bleicher (2004) re-examined the internal validity and reliability of the STEBI-B as an instrument for measuring science teaching self-efficacy. In the analysis, six descriptive variables were examined for relationships with PSTE and STOE. The background variables were; (1) age; (2) ethnicity; (3) teaching experience; (4) gender; (5) number of science courses taken; and (6) previous school science experience. Age, ethnicity and teaching experience showed no relationship to either PSTE or STOE. Gender, number of science courses taken, and previous school science experience demonstrated a relationship with the PSTE subscale, but not the STOE subscale. 
These results are relevant to this dissertation study as it provides insight into background variables that could be used as independent variables. In acknowledging the realities of the convenience sample selected for respondents in this dissertation study, using gender as a background variable was not viable as there simply are not enough male preservice elementary teacher candidates to carry out statistical analyses without violating the assumptions of ANOVA. The number of postsecondary science courses taken, and the perception of school science experiences were selected as useful grouping variables for this study.

Cantrell, Young and Moore (2003) sought to examine self-efficacy beliefs of preservice elementary teacher candidates at different stages during their programs of study. This longitudinal study, which included data collection using questionnaires which included the STEBI-B during an introductory class, a methods course, and post-student teaching, added to the growing body of research intended to identify, “...the correlates and factors related to the development of self-efficacy in preservice teachers" (p. 178). The variables considered included gender, prior school science experiences, and science teaching time. Cantrell et al. (2003) found that an effective methods course had significant success in raising the preservice candidates' levels of science teaching selfefficacy. Prior school science experiences in this case were determined by number of years in high school science and participation in extracurricular science experiences. These subcategories of what constitutes a prior school science experiences are relevant to this study as they provide insight into the complexity of how to place parameters that enables an assessment of prior school science experiences. 
The above section of this chapter provided an overview of the relevant factors that influence science teaching self-efficacy. While most of the studies involved the use of the STEBI-B via a pre-test and post-test administration methodology, this dissertation utilizes a different methodology. As aforementioned, self-efficacy as a whole is context driven. As such, this dissertation proposes that the measurement of science teaching selfefficacy should also be contextual, and therefore accounting of the response-shift bias inherent in measuring change need occur. The following section provides a review of response-shift bias and the relationship to retrospective-testing. It is this from this section that the methodology used in this dissertation arises.

\section{Response-Shift Bias and Retrospective-Testing}

Response-shift bias refers to a change in the underlying scale from which assessments are made. The purpose of Cronbach and Furby's (1970) work was to examine the notion of basefree measures of changes, and other kinds of differences of scores from a statistical perspective. The authors commented that while "a persistent puzzle in psychometrics is the "measurement of change"" (p. 68), in order to compare scores from a pre-test to those of a post-test, the common metric must exist between those scores.

Linn and Slinde (1977) argued that the comparisons of pre-test to post-tests include the assumption that, "the scale unit must be same at both points in time" (p. 124). However, the purpose of most interventions, like the science methods course in this study, is to change the participants understanding or awareness of a given topic or concept. This study included a change in awareness of perceived science teaching self-efficacy. The change in awareness, and thus the underlying metric of how 
participants assess their levels of science teaching self-efficacy has therefore changed. In this study, upon completion of the course, students are more aware of how much they now understand about science teaching and their respective capabilities within it in relative to what they thought the knew upon entry to the course and the prior self assessment done on the pre-test. This is the response-shift bias. In an effort to keep the underlying metric the same, a retrospective-test can be used as the comparison benchmark for the post-test. This concept is relevant to this study as it is the underpinnings of the method used for data collection.

Howard and Dailey (1979) discussed the effects of self-reporting and the possibility of data contamination if a common metric does not exist resulting in an instrument effect called the response-sift bias. Howard and Dailey (1979) examined the results of a response-shift bias on the assessment of a training program for developing interviewers. In their recommendations, the authors suggested that moving the pre-test closer to the post-test would help minimize the response-shift bias. The notion of moving the data collection administrations closes to each other was furthered by Howard, Ralph, Gulanick, Maxwell, Nance and Gerber (1979) through investigating evaluations of five interventions. Through the analysis, Howard et al. (1979) suggested using a retrospectivetest to improve the internal validity of evaluations when of self-reporting on results of interventions. Bray and Howard (1984), in their examination of graduate teaching assistants' behavior, beliefs about teaching and ratings of effectiveness by their students suggested using a retrospective-test to reduce the response-shift bias when self-reporting. Bray and Howard (1984), advocated for continued and future use of retrospective-testing in the field of education. While the results of these studies are not relevant to this 
dissertation, what is relevant is the development and layout of the theoretical framework of response-shift bias. Cantrell (2003) advanced the use of retrospective-testing as a means to handle response-shift bias in the context of examining science teaching self-efficacy.

Cantrell's (2003) purpose was to investigate the differences in science teaching efficacy pre-test and retrospective-test scores against post-test scores. The theoretical framework for this study was self-efficacy and response shift bias, the same as it is for this dissertation study. Data was collected from preservice student teacher candidates using the Science Teaching Efficacy Belief Instrument (STEBI-B). Pre-tests, retrospective-tests and post-tests were administered. Results of Cantell's (2003) study identified a statistically significant change in levels of science teaching self-efficacy from pre-test to post-test comparisons in the PSTE subscale but not the STOE subscale. Further, a statistically significant change in the retrospective-test to post-test comparison, for both subscales was determined. The implications of Cantrell's (2003) study suggest that retrospective-testing has a valid and theoretically grounded place in educational research where traditional pre-test to post-test comparisons have been made. This research is relevant to this study as it provides literature based support for the method chosen to assess and place in context the changes of science teaching self-efficacy of preservice elementary student teacher candidates.

\section{Summary}

There is a perception of ineffective and inadequate quality regarding elementary level teaching and learning of science, as well as the quality of new teachers graduating from teacher education and preparation programs. The calls for reform of elementary 
science curricula and teaching methods have been placed for over two decades. In this time, research has been done to determine possible areas for improvement within teacher education programs to minimize the perception of inadequate elementary science teachers. One area that has been fruitful in research relative to attempting to improve the effectiveness of preservice elementary science teacher candidates becoming inservice teachers is Bandura's psychosocial construct of self-efficacy. Self-efficacy, in simplistic, everyday terms refers to the confidence one has in their ability to do something. The construct can be split into two components namely personal efficacy and outcome expectancy. In this forum, science teaching self-efficacy refers to a preservice elementary teacher candidate's confidence in their ability to effectively teach science (PSTE) and have students effectively learn science from their teaching (STOE). There has been an abundance of research in this area as Bandura's model is well suited to science education. In an effort to measure a change in science teaching self-efficacy, the science teaching efficacy belief instrument form B (STEBI-B) which captures the PSTE and STOE of preservice teachers was selected as the data collection instrument as it is widely used for research in this area.

Within the plethora of research uniting science teacher education and science teaching self-efficacy, the evident trends were used to develop the foundation of this study. Effective science methods courses were mostly found to increase levels of science teaching self-efficacy among preservice elementary teacher candidates. The number of postsecondary science courses taken, as well as the perception of prior school science experiences has been studied as viable grouping variables for analysis, and therefore the reason why they were selected for independent variables of this study. 
The methodology for administering the STEBI-B in this dissertation, however, is different than most studies of science teaching self-efficacy that preceded it. In reading and considering the intricacies of self-efficacy in terms of context being a prominent and highly influential aspect of one's sense of self-efficacy, it was only fitting to research a method that keeps context of responses in line as well. As such, the notion of responseshift bias in terms of maintaining a common metric between measurement or evaluation administrations became appropriate. In administering a retrospective-test in addition to the traditional pre-test and post-test administrations of the instrument, the context from which preservice elementary teacher candidates could assess their science teaching selfefficacy could be maintained. This small but significant variation on the methodology of measuring a change in science teaching self-efficacy separates this study from others.

The literature review provided a general background of the call and necessity to reform science teacher education, and the steps being taken to accomplish that task. One method to improving both the quality of teacher education programs and of the preservice teachers graduating from those programs is by acknowledging the value of a strong sense of science teacher self-efficacy among preservice teacher candidates and developing that sense throughout the teacher education program. The commitment to bolster the science teaching self-efficacy of preservice elementary teacher candidates is the responsibility of the entire campus, not only the science methods professors. This study sought evidence to place science teaching self-efficacy of preservice elementary teacher candidates in context. Chapter Three will present the methodology used in this study to seek insight into the research questions posed in Chapter I. 


\section{CHAPTER III}

\section{METHODOLOGY}

The methodology used to examine self-efficacy among preservice elementary teachers is described in this chapter. After a restatement of the purpose, this chapter will outline: (1) the research design; (2) the participants; (3) the instrumentation; (4) the pilot test; (5) data analysis; (6) the assumptions of the study; and (7) the delimitations and limitations of the study.

The purpose of this study was to investigate how retrospective-test / post-test perceptions of science teaching self-efficacy differ according to personal science expectancy and science teaching outcome expectancy among preservice elementary teachers when exposed to a science teaching methods course. The dependent variable was change in self-efficacy. Self-efficacy comprises two subareas: (1) personal science teaching efficacy; and (2) science teaching outcome expectancy. The independent variables were: (1) number of postsecondary science content courses taken; (2) prior science experiences; and (3) a science methods course.

\section{Research Design}

This study employed the Science Teaching Efficacy Belief Instrument (STEBI-B) as the means to collect data. The survey was administered in the elementary stream science methods course for a pre-test on the first day of class August 22/23, 2007. On November 7/8, 2007, the STEBI-B was administered once for a post-test and once for a 
retrospective-test. The surveys were distributed in class and returned to the researcher once completed. The purpose of the survey was explained to the participants on the first administration of the test, and contact information was given at that time. Participants were asked to voluntarily participate in the study and that there were no academic implications for participating or not participating. The survey contained 23 items that are structured on a 5-point Likert-scale from $1=$ strongly disagree to $5=$ strongly agree. Individuals will be coded numerically as 1,2, 3, 4 by last name. Each individual was randomly assigned a number. This was done to help ensure confidentiality in that the numbers did not correspond to names in the alphabet, such as 1 did not correspond to someone's name beginning with " $\mathrm{A}$ " and 2 did not correspond to someone's name beginning with "B". Class lists of student names were obtained. Each student was assigned a random number and surveys were distributed to students according to that number. For the post-test and retrospective-test, each student was provided the instrument with the same number they had for the pre-test. Confidentiality was ensured in that numbers did not correspond in sequential order to the alphabetical order of names. Only the researcher had access to the coding for data entry and analysis. The coding list was stored in a locked cabinet along with completed survey instruments.

Retrospective-Testing

Administering a retrospective-test is a method used to minimize the response-shift bias by recalibrating ones underlying metric (Aiken \& West, 1990, Cantrell, 2003). A metric "refers to the numbers that the observed measures taken on when describing individuals' standings on the construct of interest" (Blanton \& Jaccard 2006, p. 27). For the dimension of self-efficacy on the STEBI-B the metric ranges from the lowest possible 
rating of 1 to the highest possible rating of 5 , where 5 represents high self-efficacy. This study utilized the retrospective-test method to have participants reflect on their perceptions of their science teaching self-efficacy upon arrival in the science methods course. This was done to compare their perceptions as identified on the pre-test with those identified on the retrospective-test, as well as to determine their change in science teaching self-efficacy to the post-test . The information provided by this approach provided insights into the context in which preservice elementary teachers assess their perceptions of their science teaching self-efficacy prior to entering the science methods course. Students were able to compare how they originally thought about their science teaching self-efficacy to what they thought about their science teaching self-efficacy at the end of the methods course. Therefore, this approach allowed the researcher to understand how well students thought they were prepared to teach science before the first day and after the completion of the science methods course, as well as how they think they will teach science in their own classrooms of the future.

\section{The Methods Course}

There are two sections of the elementary science methods course offered each semester an upper Midwest university. The preservice elementary teacher candidates from both sections were invited to participate in this study. The survey results from a pilot study from the spring semester of the same course were also used in this study. The researcher ran analyses with the results of the pilot study included as well as excluded. The reason for this was to determine that there were no measurable differences between the courses of each semester. If the results did change, the scores from the pilot study 
would have been excluded from this study. This however was not the case, as can be seen in the descriptive results presented in Chapter IV.

There was a different professor for each section, yet both have organized the course together and share curriculum and teaching philosophies. An analysis of both sections and the pilot section was done for this study. If there was a significant difference in the results between the Fall 2007 sections it might indicate a difference in teaching methods and subsequent impact on the preservice student teacher candidates perceptions of science teaching self-efficacy. If there was a significant difference in results, the section for which the researcher did not teach would have been excluded and the results from the pilot test would have been included as the researcher taught that class. The results of this analysis are presented in Chapter IV.

Both professors aimed to model a constructivist approach to teaching and learning (Bleicher \& Lindgren, 2005; Tobin \& Tippins, 1993). In these classes, teacher candidates were provided opportunities to hone their craft of science teaching through: reflection of their own learning, abilities, and ideas; inquiry and discovery based activities to sharpen their science contents understandings and conceptions; collaborative events that included discussion of experiences and content meaning; and creative project development and construction to communicate key science concepts through effective means.

\section{Participants}

The population for this study was preservice science elementary teacher candidates enrolled in a methods science courses within teacher education programs. The sample for this study consists of the undergraduate students enrolled in the elementary stream science methods course at a upper Midwest university during Fall 2007. There 
were 51 students enrolled for the Fall of 2007 and 18 completed the pilot study. The preservice elementary teaching candidates involved in this study were seniors and in their second to last semester in their teacher education programs. The methods course was intended as the capstone science methods course before students go to field experience and then student teaching.

\section{Convenience Sampling}

The sample for this study was a convenience sample. A convenience sample refers to a data-providing group that serves as the basis for inferential statements by its readily available status relative to the researcher (Huck, 2008). For this study the participant preservice teacher candidates are representative of the greater population of preservice teacher candidates as teacher education programs are fairly similar in course requirements and programs of study. Therefore, although chronology of courses taken and timing of student teaching may vary between teacher preparation programs, preservice teachers enrolled in science methods courses have had many of the same pedagogical content courses and science content courses in their programs of study. As such, their training and thus learning experiences relevant to this study are similar for students nationally. Because of this, this sample of students is likely to be representative for the constructs measured in this study, making the preservice elementary teachers in this study representative of preservice elementary teachers nationally.

The Teaching and Learning department provides licensing requirements for teachers as set by accreditation boards and areas of federal and state government. Since 1883, the upper Midwest university has offered Teacher Education programs. The department supports undergraduate through graduate level programs with intensive, 
intellectually stimulating, challenging, integrated study. Teacher education for preparation to teach at all levels encourages students to assume initiative and independence in their learning while developing personal and professional commitments ad competence. The Teacher Education program is accredited by the North Central Association of Teacher Education (UND Academic Catalog, 2005). Upon arrival in the elementary science methods course, students have completed at least " 2 science courses with corresponding labs" (p. 174). The science methods course is described as, "a survey of teaching strategies, materials, and resources appropriate for promoting science inquiry in elementary classrooms" (p. 179).

\section{Instrumentation}

The Science Teaching Efficacy Belief Instrument (STEBI-B) is a 23 item survey structured on a 5-point Likert-scales ranging from strongly disagree to strongly agree. The survey was developed by Enochs and Riggs (1990) based on Bandura's psychosocial construct of self-efficacy to aid in early detection of low self-efficacy levels in preservice elementary teacher candidates. The instrument is presented in Appendix A. The survey was designed as a one page instrument that could measure both aspects of science teaching self-efficacy. The two aspects measured are: (1) Personal science teaching efficacy and (2) Science teaching outcome expectancy.

The first aspect the survey measures is personal science teaching efficacy (PSTE). This subscale contains 13 items, including numbers: $2,3,5,6,8,12,17,18,19,20,21$, 22 , and 23 . Items $3,6,8,17,19,20,21$, and 23 are reverse scored. The reliability coefficient on the original development and administration of the STEBI-B as determined by Enochs and Riggs (1990) was .90. Examples items of this subscale of PSTE include; 
item 8 , "I will generally teach science ineffectively", and item 22 , "When teaching science, I will usually welcome student questions."

The second aspect of the survey measures science teaching outcome expectancy (STOE). This subscale contains 10 items; including numbers: 1, 4, 7, 9, 10, 11, 13, 14, 15 , and 16. Items 10 and 13 are reversed scored. The reliability coefficient of this subscale on the original development and administration of the STEBI-B as determined by Enochs \& Riggs (1990) was .76. Examples of items on this subscale of STOE include; item 11, "When a low-achieving child progresses in science, it is usually due to extra attention given by the teacher", and item 14, "The teacher is generally responsible for the achievement of students in science".

\section{Pilot Study}

A pilot test of this study was conducted during the Spring of 2007 with one of two sections of the science methods class. The survey was part of a class research project for partial fulfillment of credit for graduate level statistics course where the investigator was a student. As a graduate teaching assistant (GTA) teaching the science methods course a convenient intact sample for the pilot study was available. The STEBI-B was administered on the first day of class as the pre-test on January 9, 2007, and the retrospective-test and post-test were administered on the final day of class on April 3, 2007. Each survey took approximately 15 minutes to complete. Students chose confidential codes of their own which they kept in their binder to be used on the post-test and retrospective-test surveys. The researcher kept a copy of the codes, not knowing who they belong to for future reference for students. The completed surveys and code sheet were stored in a locked cabinet in the researcher's office. The class had 18 students of 
which sixteen were female. The STEBI-B was given as originally developed by Enochs \& Riggs (1990) with the removal of the word "some" from items 10 and 13 as, "these two items showed a qualitative difference in wording compared to the other 21 items on the STEBI-B" (Bliecher, 2004, p. 387).

\section{Data Analysis}

There were two main parts to this study that required separate descriptions within the data analysis. The first part comprised the analysis of all respondents to determine if a significant statistical difference exits between pre-test and retrospective-test scores. The pilot study, as well as Cantrell (2003) suggested that a significant statistical difference did in fact exist. The second part comprised an analysis of the changes in self-efficacy from retrospective-test to post-test scores once the science methods course had been completed. To determine what the statistical findings mean in terms of practical applications, Cohen's effect sizes were calculated. The results of these calculations are presented in Chapter IV. A list of the research questions, as well as the analysis methods are presented below.

Research Question 1: Is there a statistical difference in pre-test / retrospective-test scores for personal science teaching efficacy (PSTE) and science teaching outcome expectancy (STOE)?

Analysis: One paired $t$-test for all respondents was used to determine if changes in scores on each subscale were statistically different between the pre-test and the retrospective-test. A Type I error rate of .05 was used as the judgment criteria. The scales are conceptually independent. 
Research Question 2: Are there statistically significant differential outcomes for changes in retrospective-test and post-test scores within personal science teaching efficacy (PSTE) and science teaching outcome expectancy (STOE) between preservice elementary teacher candidates who met the science content requirements for their degree and those that exceeded that number?

Research Question 3: Are there statistically significant differential outcomes for changes in retrospective-test and post-test scores within personal science teaching efficacy (PSTE) and science teaching outcome expectancy (STOE) between preservice elementary teacher candidates who perceived their prior school science experiences to be positive and those that perceived the experiences to be negative?

Analysis for both Research Question 2 and 3: This is a within and between groups design. The changes in scores were calculated on the within factor, and a $2 \mathrm{X} 2$ Analysis of variance (ANOVA) for main effects was used to statistically analyze these research questions. The subscales of PSTE and STOE were treated as conceptually independent and analyzed at that level with a Type I error rate of .05 used as the judgment criteria. As is reported in the Course Catalog, students enrolled in the elementary science methods course en-route to a Bachelor's of Science in Early Childhood Education must have taken at least 2 postsecondary science content courses. Using this as a theoretical justification, there were two levels associated with number of postsecondary science courses taken, these were: (1) "met science content course requirements"; and (2) "exceeded science content course requirements". "Met science content course requirements" means the preservice elementary teacher candidate has taken 2 science content courses, while those within the "exceeded science content course requirements" have taken at least 3 science 
content courses. Preservice elementary teacher candidates were also grouped on their reported perceptions of their prior school science experiences. The groups included:

(1) positive; and (2) negative.

For research question 2, the null hypothesis was:

$\mathrm{H}_{0}: \mu_{\mathrm{M}}=\mu_{\mathrm{E}}$

The alternative hypothesis was:

$\mathrm{H}_{1}: \mu_{\mathrm{M}} \neq \mu_{\mathrm{E}}$

Where: $\mu_{\mathrm{M}}$ is the mean of the "met science content course requirements" group; and $\mu_{\mathrm{E}}$ is the mean of the "exceeded science content course requirements" group.

For research question 3, the null hypothesis was:

$\mathrm{H}_{0}: \mu_{\mathrm{P}}=\mu_{\mathrm{N}}$

The alternative hypothesis was:

$\mathrm{H}_{1}: \mu_{\mathrm{P}} \neq \mu_{\mathrm{N}}$

Where: $\mu_{\mathrm{p}}$ is the mean of the "positive school science experiences" group; and $\mu_{\mathrm{N}}$ is the mean of the "negative school science experiences" group.

Research Question 4: Is there a statistically significant interaction of within PSTE and STOE subscale scores between number of postsecondary science content courses taken and perceptions of prior school science experiences?

Analysis: This research question was analyzed using an ANOVA for a 2-way interaction between number of postsecondary science content courses taken and perceptions of prior school science experiences. A Type I error rate of .05 was used as the decision criteria. For research question 4, the null and alternative hypotheses were: 
$H_{0}: \Psi=\mathrm{w}_{1} \mu_{\mathrm{MP}}+\mathrm{w}_{2} \mu_{\mathrm{MN}}+\mathrm{w}_{3} \mu_{\mathrm{EN}}+\mathrm{w}_{4} \mu_{\mathrm{EP}}=0$

$H_{1}: \Psi \neq 0$

Where: $\mu_{\mathrm{MP}}$ is the mean of the "met requirements for postsecondary science content courses taken and report a positive perception of prior school science experiences" group, $\mu_{\mathrm{MN}}$ is the mean for the "met requirements for postsecondary science content courses taken and report a negative perception of prior school science experiences" group, $\mu_{\mathrm{EN}}$ is the mean of the "exceeded requirements for postsecondary science content courses taken and report a negative perception of prior school science experiences" group, and $\mu_{\mathrm{EP}}$ is the mean of the "exceeded requirements for postsecondary science content courses taken and report a positive perception of prior school science experiences" group.

Assumptions of the Study

\section{General Assumptions}

For this study, it is assumed that: (1) the data will be clean to interpret; (2) there will be normal distribution among the residuals; (3) respondents will understand the survey and answer honestly to the items; (4) the administration of the survey conformed to protocol set out by the researcher and the Institutional Research Board (IRB).

\section{Specific Assumptions}

In the following section, the assumptions and repercussions of violations for each statistic used in this study are discussed.

$t$-Test

There are two types of $t$-tests used in this study. Independent sample $t$-tests compare the means of two groups, like the different sections of the science methods course that participated in this study. The assumptions for using an independent sample $t$ - 
tests include: (1) the population distributions are normal; (2) independent observations; and (3) equal distributions. (Statsoft, 2007)

Paired sample $t$-tests compare data that are related to each other, like the pre-test, post-test and retrospective-tests performed in this study. The assumptions for using a paired sample $t$-test include: (1) the population distribution is normal; and

(2) independent observations. (Cronk, 2004)

ANOVA

Mertler and Vannatta (2005) identify three assumptions to using the analysis of variance (ANOVA). These are:

(1) The observations within each sample must be randomly sampled and must be independent of one another; (2) the distributions of scores on the dependent variable must be normal in the population from which data were sampled; and (3) the distributions of scores on the dependent variable must have equal variances. (p. 74)

Failure to meet the assumptions of the ANOVA may arise as a result of violating the homogeneity of variance (Mertler \& Vannatta, 2005). Normal distribution was tested by examining skewness and kurtosis of the residuals. The results of these analyses are presented in Chapter Four.

\section{Delimitations}

1. This study confined itself to the quantitative results of the changes in perceptions of science teaching self-efficacy as ascertained from preservice elementary teacher candidates enrolled in a science methods class at an upper Midwest university in the Fall term of 2007. 
2. Some of the preservice elementary teacher candidates may have chosen to not participate in this study which would have decreased the sample size.

3. This study focused on the perceptions of science teaching self-efficacy of preservice elementary teacher candidates and did not account for perceptions of instructors of the methods course, or any other persons who could have influenced students' perceptions.

\section{Limitations}

1. The convenience sampling procedure decreased the generalizability of the findings to all preservice elementary teacher candidates.

2. The study is limited to one semester's results of pre-tests, post-tests and retrospective-tests from an upper Midwest university.

3. The study is limited as some participants, due to absence or uncontrollable factors may not complete all surveys. Only the scores from participants who completed all three surveys were included in the final data set. All other data would have been removed as incomplete.

4. There were no set criteria as to what constitutes a positive or negative perception of prior school science experiences.

Summary

The purpose of this study was to investigate how retrospective-test / post-test perceptions of science teaching self-efficacy differ according to personal science expectancy and science teaching outcome expectancy among preservice elementary teachers when exposed to a science teaching methods course. This study used data collected from three administrations of the STEBI-B. SPSS 14.0 was used as the source 
of data analysis to perform $t$-tests, and an ANOVA to determine if a change in perceptions of science teaching self-efficacy had occurred over the course of the science methods course. Chapter IV will present the results of the research questions' analysis. 


\section{CHAPTER IV}

\section{RESULTS}

The results of the analysis used to examine self-efficacy among preservice elementary teachers are described in this chapter. The purpose of this study was to investigate how retrospective-test / post-test perceptions of science teaching self-efficacy differ according to personal science expectancy and science teaching outcome expectancy among preservice elementary teachers when exposed to a science teaching methods course.

Preservice elementary teacher candidates were asked to respond to statements reflecting their science teaching self-efficacy using the Science Teaching Expectancy Belief Instrument (STEBI-B). The survey was administered three times using pre-test, post-test and reflective-test methodology. The 23-item instrument contains a Likert-scale with a 1 to 5 range of "strongly disagree" to "strongly agree". A higher score indicated a stronger sense science teaching self-efficacy.

This chapter will present: (1) survey response rate data; (2) assumptions of the study; (3) descriptives relevant to the study; (4) instrument reliability; and (5) research question results.

\section{Survey Response Rate}

The instrument was administered to sixty-nine pre-service elementary teachers. The convenience sample was chosen as all the pre-service elementary teachers were 
enrolled in an elementary stream science methods course at an upper Midwest university. There was a $100 \%$ response rate as all students participated in the study in each phase. Therefore the number of participants for statistical analysis is $N=69$.

\section{Assumptions}

\section{Skewness and Kurtosis}

To test for normal distribution for both different of scores in both PSTE and STOE subscales, skewness and kurtosis statistics were calculated and presented in Table 1.

Table 1. Descriptive Statistics for Residuals of Changes in Scores in PSTE and STOE Subscales.

Skewness and Kurtosis Statistics Calculations

\begin{tabular}{|c|c|c|c|c|c|}
\hline \multirow[t]{2}{*}{ Residual } & \multirow[t]{2}{*}{$\begin{array}{c}\text { Std. } \\
\text { Deviation } \\
\text { Statistic }\end{array}$} & \multicolumn{2}{|c|}{ Skewness } & \multicolumn{2}{|c|}{ Kurtosis } \\
\hline & & Statistic & Std. Error & Statistic & Std. Error \\
\hline $\begin{array}{l}\text { Residual for changes in } \\
\text { scores on PSTE }\end{array}$ & .52 & -.92 & .29 & .93 & .57 \\
\hline $\begin{array}{l}\text { Residual for changes in } \\
\text { scores on STOE }\end{array}$ & .50 & -.23 & .29 & .38 & .57 \\
\hline
\end{tabular}

Univariate skewnesses and kurtosis were found to be acceptable within the range of $+/-1.0$ (Bollen, 1989) for the residual change in score of PSTE, with skewness $Z=-.92$, kurtosis $Z=.93$, and for the residual change in score of STOE, with skewness $Z=-.23$, kurtosis $Z=.38$. 


\section{Descriptives of Changes in Scores on Each Subscale}

Changes in scores on both PSTE and STOE subscales were analyzed for descriptive information. The results are presented in the tables below.

\section{Changes in PSTE Subscale}

With an $\mathrm{N}=69$, the mean change in scores on the PSTE subscale was .62 with a standard error of .07. The median change in score was .61 with a variance of .35 and standard deviation of .59 . The minimum change in score was -1.0 with a maximum of 1.9 and a subsequent range of 2.9. As shown on Table 2, the mean for the pre-test score was 3.7; the mean for the post-test score was 4.1; and the men for the retrospective score was 3.5. Thus the difference in scores between the pre-test and post-test was .4, while the difference in scores between the retrospective-test and post-test was .6.

Table 2. Descriptive Data for Changes in Scores in PSTE Subscale.

Descriptives

Subscale

Statistic

Std. Error

Mean .62

.07

Variance

.35

PSTE Difference of Scores

Std. Deviation

.59

Minimum

$-1.0$

Maximum

1.9

Range

2.9 
Table 3. Descriptive Data for Changes in Scores in STOE Subscale.

Descriptives

Statistic

Std. Error

STOE Difference of

Scores

$\begin{array}{lr}\text { Mean } & .44 \\ \text { Median } & .40 \\ \text { Variance } & .26 \\ \text { Std. Deviation } & .51 \\ \text { Minimum } & -1.0 \\ \text { Maximum } & 1.8 \\ \text { Range } & 2.8\end{array}$

\section{Changes in STOE Subscale}

With an $\mathrm{N}=69$, the mean change in scores on the STOE subscale was .44 with a standard error of .06 . The median change in score was .40 with a variance of .26 and standard deviation of .51 . The minimum change in score was -1.0 was a maximum of 1.8 and a subsequent range of 2.8. As shown on Table 5, the mean for the pre-test score was 3.7; the mean for the post-test score was 4.0; and the mean for the retrospective score was 3.5. Thus the difference in scores between the pre-test and post-test was .30, while the difference in scores between the retrospective-test and post-test was .50.

Descriptives Relevant to the Study

This section will report the descriptive statistics relevant to the study, in the following sequence: (1) descriptive statistics of the pre-test, post-test, and retrospectivetest; (2) descriptive statistics of the respondents; and (3) descriptive statistics of both classes when compared to each other. 


\section{Descriptive Statistics of the PreTest, PostTest, \\ and Retrospective-Test}

The STEBI-B instrument used in this study has two subscales, PSTE and STOE within in the survey items. The descriptive data for each of the subscales during each of the writings is presented below.

Table 4. Descriptive Statistics of the Subscales for Each Test Administration.

\begin{tabular}{lccccc}
\hline & \multicolumn{5}{c}{ Descriptive Statistics } \\
& N & Minimum & Maximum & Mean & Std. Deviation \\
& & & & & \\
& 69 & 2.1 & 5.0 & 3.7 & .71 \\
PSTE (Pre-test) & 69 & 2.6 & 5.0 & 3.7 & .56 \\
STOE (Pre-test) & 69 & 2.5 & 5.0 & 4.1 & .54 \\
PSTE (Post-test) & 69 & 2.7 & 5.0 & 4.0 & .55 \\
STOE (Post-test) & 69 & 2.0 & 4.5 & 3.5 & .49 \\
PSTE (Retrospective-test) & 69 & & & & \\
& 69 & 2.7 & 4.7 & 3.5 & .44 \\
STOE (Retrospective-test) & 69 & & & & \\
\hline
\end{tabular}

Pre-test $(N=69)$

The PSTE scores had a minimum of 2.1 and maximum of 5.0 with a mean of 3.7 and standard deviation of .71. The STOE scores had a minimum of 2.6 and maximum of 5.0 with a mean of 3.7 and standard deviation of .56 . 
Post-test $(N=69)$

The PSTE scores had a minimum of 2.5 and maximum of 5.0 with a mean of 4.1 and standard deviation of .54. The STOE scores had a minimum of 2.7 and maximum of 5.0 with a mean of 4.0 and standard deviation of .55 .

Retrospective-test $(N=69)$

The PSTE scores had a minimum of 2.0 and maximum of 4.5 with a mean of 3.5 and standard deviation of .49. The STOE scores had a minimum of 2.7 and maximum of 4.7 with a mean of 3.5 and standard deviation of .44 .

\section{Descriptives of Respondents}

Preservice-elementary student teacher candidates were grouped in the following categories: (1) those that met the required number of post-secondary science courses taken, and those that exceeded that requirement; and (2) those perceived their school science experiences as positive, and those that perceived their school science experiences as negative. Each of these groupings were analyzed for descriptive statistics relevant to this study.

Met or Exceeded Required Number of Post-secondary Science Courses Taken

With a total $N=69, n=22(32 \%)$ of respondents met the requirement of completing two post-secondary science courses while $n=47(68 \%)$ exceeded the departmental requirement for graduation. The skewness of the group was determined to be $Z=-1.0$ with standard error .29 , and kurtosis $Z=-.97$ with standard error $=.57$. 


\section{Perception of School Science Experiences}

With a total $\mathrm{N}=69, \mathrm{n}=23(33 \%)$ of respondents reported having negative perception of their school science experiences while $n=47(67 \%)$ reported positive perceptions. The skewness of the group was determined to be $Z=-1.4$ with standard error .29 , and kurtosis $\mathrm{Z}=-.04$ with standard error $=.57$.

Table 5. Descriptive Statistics for Changes in Subscale Scores Between RetrospectiveTest and Post-Test.

Requirement Perception Positive Negative

$$
\mathrm{n}=12
$$

Met Requirement

For change in PSTE score: For change in PSTE score:

$$
M=0.61, S D=0.42 \quad M=1.3, S D=0.74
$$

For change in STOE score: For change in STOE score:

$$
M=0.34, S D=0.32 \quad M=0.62, S D=0.56
$$

Exceeded

Requirement

$$
\mathrm{n}=34
$$

For change in PSTE score:

$$
M=0.42, S D=0.48
$$

For change in STOE score

$$
M=0.39, S D=0.49
$$

$$
\mathrm{n}=13
$$

For change in PSTE score:

$$
M=0.67, S D=0.58
$$

For change in STOE score:

$$
M=0.55, S D=0.66
$$




\section{Descriptives for Each Grouping Per Subscale}

Descriptive statistics were calculated for each grouping along each of the subscale scores.

Table 6. Descriptive Statistics of Independent Variables.

\begin{tabular}{|c|c|c|c|c|c|c|c|c|}
\hline \multirow[b]{2}{*}{ Variable } & \multirow[b]{2}{*}{$\mathrm{N}$} & \multirow[b]{2}{*}{ Mean } & \multirow[b]{2}{*}{$\begin{array}{c}\text { Std. } \\
\text { Deviation }\end{array}$} & \multirow[b]{2}{*}{ Variance } & \multicolumn{2}{|c|}{ Skewness } & \multicolumn{2}{|c|}{ Kurtosis } \\
\hline & & & & & Statistic & $\begin{array}{l}\text { Std. } \\
\text { Error }\end{array}$ & Statistic & $\begin{array}{l}\text { Std. } \\
\text { Erro }\end{array}$ \\
\hline Requirement & 69 & .72 & .45 & .20 & -1.0 & .29 & -.97 & .57 \\
\hline Perception & 69 & .78 & .42 & .17 & -1.4 & .29 & -.04 & .57 \\
\hline
\end{tabular}

\section{Change in PSTE Scores Per Grouping}

Ten $(n=10)$ or $15 \%$ of all respondents reported having only met the required amount of post-secondary courses taken and had negative perceptions regarding their school science experiences had a mean change in score of 1.3 and standard deviation of .74 on the PSTE subscale. Twelve $(n=12)$ or $17 \%$ of all respondents reported having only met the required amount of post-secondary courses taken and had positive perceptions regarding their school science experiences had a mean change in score of .61 and standard deviation of .42 on the PSTE subscale. The total $(n=22)$ mean change in score on the PSTE subscale for all respondents that only met the required number of postsecondary science courses taken was .91 with a standard deviation of .66 .

Thirteen $(n=13)$ or $19 \%$ of all respondents reported having exceeded the required amount of post-secondary courses taken and had negative perceptions regarding their school science experiences had a mean change in score of .67 and standard deviation of .58 on the PSTE subscale. Thirty-four $(n=34)$ or $49 \%$ of all respondents reported having 
exceeded the required amount of post-secondary courses taken and had positive perceptions regarding their school science experiences had a mean change in score of .42 and standard deviation of .48 on the PSTE subscale. The total $(n=47)$ mean change in score on the PSTE subscale for all respondents that exceeded the required number of post-secondary science courses taken was .49 with a standard deviation of .52

Twenty-three $(n=23)$ or $33 \%$ of all respondents who reported a negative perception of their school science experiences had a mean change in score on the PSTE subscale of .93 with a standard deviation of .71 . Forty-seven $(n=47)$ or $67 \%$ of all respondents who reported a positive perception of their school science experiences had a mean change of score on the PSTE subscale of .47 with a standard deviation of .47 .

\section{Change in STOE Scores per Grouping}

Ten $(n=10)$ or $15 \%$ of all respondents reported having only met the required amount of post-secondary courses taken and had negative perceptions regarding their school science experiences had a mean change in score of .62 and standard deviation of .56 on the STOE subscale. Twelve $(n=12)$ or $17 \%$ of all respondents reported having only met the required amount of post-secondary courses taken and had positive perceptions regarding their school science experiences had a mean change in score of .34 and standard deviation of .32 on the STOE subscale. The total $(n=22)$ mean change in score on the STOE subscale for all respondents that only met the required number of post-secondary science courses taken was .47 with a standard deviation of .46 .

Thirteen $(n=13)$ or $19 \%$ of respondents reported having exceeded the required amount of post-secondary courses taken and had negative perceptions regarding their school science experiences had a mean change in score of .68 and standard deviation of 
.58 on the PSTE subscale. Thirty-four $(n=34)$ or $49 \%$ of respondents reported having exceeded the required amount of post-secondary courses taken and had positive perceptions regarding their school science experiences had a mean change in score of .42 and standard deviation of .48 on the PSTE subscale. The total $(n=47)$ mean change in score on the STOE subscale for all respondents that only met the required number of post-secondary science courses taken was .43 with a standard deviation of .54 .

Twenty-three $(n=23)$ or $33 \%$ of all respondents who reported a negative perception of their school science experiences had a mean change in score on the STOE subscale of .58 with a standard deviation of .61 . Forty-seven $(n=47)$ or $67 \%$ of all respondents who reported a positive perception of their school science experiences had a mean change of score on the STOE subscale of .38 with a standard deviation of .45 .

\section{Comparison of Class Sections}

A comparison of sections ' 6 ' and ' 7 ' of classes the survey was administered in was completed via independent sample t-test to determine if any statistically significant mean difference existed between each of the sections. This analysis is necessary as it speaks to the influence of the instructors on the results. There was no evidence to suggest that the instructors statistically differently influenced the levels of science teaching selfefficacy of the preservice elementary teacher candidates.

Pre-test Results. For the PSTE subscale, section $6(n=25)$ had a mean score of 3.6 , standard deviation of .79 and standard error mean of .16 . Section $7(n=26)$ recorded a mean score of 3.7 , standard deviation of .75 and standard error mean of .15 . The net difference of score was .03 , with a standard error difference of .22 . There was no 
evidence to suggest that section 6 had a statistically different mean than section 7 as $(t(49)=.15, p>.05)$

For the STOE subscale, section $6(n=25)$ had a mean score of 3.7 , standard deviation of .59 and standard error mean of .12 . Section $7(n=26)$ recorded a mean score of 3.9, standard deviation of .57 and standard error mean of .11. The net difference of score was .17 , with a standard error difference of .16 . There was no evidence to suggest that section 6 had a statistically different mean than section 7 as $(t(49)=1.1, p>.05)$.

Post-test Results. For the PSTE subscale, section $6(\mathrm{n}=25)$ had a mean score of 4.3 , standard deviation of .34 and standard error mean of .07 . Section $7(n=26)$ recorded a mean score of 4.3 , standard deviation of .50 and standard error mean of .10 . The net difference of score was -.03 , with a standard error difference of .12 . There was no evidence to suggest that section 6 had a statistically different mean than section 7 as $(t(49)=-.27, p>.05)$

For the STOE subscale, section $6(n=25)$ had a mean score of 4.0 , standard deviation of .45 and standard error mean of .09 . Section $7(n=26)$ recorded a mean score of 4.1, standard deviation of .60 and standard error mean of .12. The net difference of score was .13, with a standard error difference of .15 . There was no evidence to suggest that section 6 had a statistically different mean than section 7 as $(t(49)=.85, p>.05)$. Retrospective-test Results. For the PSTE subscale, section $6(\mathrm{n}=25)$ had a mean score of 3.5 , standard deviation of .44 and standard error mean of .09 . Section $7(n=26)$ recorded a mean score of 3.6, standard deviation of .46 and standard error mean of .09 . The net difference of score was .08, with a standard error difference of .13 . There was no 
evidence to suggest that section 6 had a statistically different mean than section 7 as $(t(49)=.65, p>.05)$.

For the STOE subscale, section $6(n=25)$ had a mean score of 3.5 , standard deviation of .54 and standard error mean of .11 . Section $7(n=26)$ recorded a mean score of 3.5, standard deviation of .39 and standard error mean of .08. The net difference of score was -.02 , with a standard error difference of .13 . There was no evidence to suggest that section 6 had a statistically different mean than section 7 as $(t(49)=-.12, p>.05)$. Table 7. Group Statistics of Team 6 and TEAM 7 during Fall 2007 Semester.

\begin{tabular}{|c|c|c|c|c|c|}
\hline Subscale & TEAM & $\mathrm{N}$ & Mean & $\begin{array}{c}\text { Std. } \\
\text { Deviation }\end{array}$ & $\begin{array}{c}\text { Std. Error } \\
\text { Mean }\end{array}$ \\
\hline PSTE (Pre-test) & $\begin{array}{l}\text { TEAM } 7 \\
\text { TEAM } 6\end{array}$ & $\begin{array}{l}26 \\
25\end{array}$ & $\begin{array}{l}3.7 \\
3.6\end{array}$ & $\begin{array}{l}.75 \\
.79\end{array}$ & $\begin{array}{l}.15 \\
.16\end{array}$ \\
\hline STOE (Pre-test) & $\begin{array}{l}\text { TEAM } 7 \\
\text { TEAM } 6\end{array}$ & $\begin{array}{l}26 \\
25\end{array}$ & $\begin{array}{l}3.9 \\
3.7\end{array}$ & $\begin{array}{l}.57 \\
.59\end{array}$ & $\begin{array}{l}.11 \\
.12\end{array}$ \\
\hline PSTE (Post-test) & $\begin{array}{l}\text { TEAM } 7 \\
\text { TEAM } 6\end{array}$ & $\begin{array}{l}26 \\
25\end{array}$ & $\begin{array}{l}4.3 \\
4.3\end{array}$ & $\begin{array}{l}.50 \\
.35\end{array}$ & $\begin{array}{l}.10 \\
.07\end{array}$ \\
\hline STOE (Post-test) & $\begin{array}{l}\text { TEAM } 7 \\
\text { TEAM } 6\end{array}$ & $\begin{array}{l}26 \\
25\end{array}$ & $\begin{array}{l}4.1 \\
4.0\end{array}$ & $\begin{array}{l}.60 \\
.45\end{array}$ & $\begin{array}{l}.12 \\
.09\end{array}$ \\
\hline PSTE (Retrospective-test) & $\begin{array}{l}\text { TEAM } 7 \\
\text { TEAM } 6\end{array}$ & $\begin{array}{l}26 \\
25\end{array}$ & $\begin{array}{l}3.6 \\
3.5\end{array}$ & $\begin{array}{l}.46 \\
.44\end{array}$ & $\begin{array}{l}.09 \\
.08\end{array}$ \\
\hline STOE (Retrospective-test) & $\begin{array}{l}\text { TEAM } 7 \\
\text { TEAM } 6\end{array}$ & $\begin{array}{l}26 \\
25\end{array}$ & $\begin{array}{l}3.5 \\
3.5\end{array}$ & $\begin{array}{l}.39 \\
.54\end{array}$ & $\begin{array}{l}.08 \\
.11\end{array}$ \\
\hline
\end{tabular}

Comparison of Spring and Fall

A comparison of Spring 2007 and Fall 2007 sections of classes the survey was administered in was completed via independent sample $t$-test to determine if any 
statistically significant difference existed. This analysis was necessary as it provides insight into if there was any evidence to suggest that once this project was proposed as dissertation work if the instructors' influenced the students levels of science teaching self-efficacy any more or less than in the Spring semester. There was no evidence to suggest any difference in scores from each of the semesters.

Pre-test Results. For the PSTE subscale, Spring $2007(\mathrm{n}=18)$ had a mean score of 3.9, standard deviation of .46 and standard error mean of .11. Fall $2007(n=51)$ recorded a mean score of 3.7, standard deviation of .76 and standard error mean of .11 . The net difference of score was .28, with a standard error difference of .19 . There was no evidence to suggest that Spring 2007 had a statistically different mean than Fall 2007 as $(t(67)=1.5, p>.05)$

For the STOE subscale, Spring $2007(n=18)$ had a mean score of 3.6, standard deviation of .41 and standard error mean of .10 . Fall $2007(n=51)$ recorded a mean score of 3.8, standard deviation of .58 and standard error mean of .08 . The net difference of score was -.23 , with a standard error difference of .15 . There was no evidence to suggest that Spring 2007 had a statistically different mean than Fall $2007(t(67)=-1.5, p>.05)$.

Post Test Results. For the PSTE subscale, Spring $2007(\mathrm{n}=18)$ had a mean score of 4.0, standard deviation of .42 and standard error mean of .10 . Fall $2007(n=51)$ recorded a mean score of 4.1, standard deviation of .31 and standard error mean of .04. The net difference of score was -.06 , with a standard error difference of .09 . There was no evidence to suggest that Spring 2007 had a statistically different mean than Fall 2007 as $(t(67)=-.69, p>.05)$ 
For the STOE subscale, Spring $2007(n=18)$ had a mean score of 3.9, standard deviation of .44 and standard error mean of .10 . Fall $2007(n=51)$ recorded a mean score of 4.1, standard deviation of .52 and standard error mean of .07. The net difference of score was -.18 , with a standard error difference of .14 . There was no evidence to suggest that Spring 2007 had a statistically different mean than Fall $2007(t(67)=-1.3, p>.05)$.

Retrospective Test Results. For the PSTE subscale, Spring $2007(\mathrm{n}=18)$ had a mean score of 3.4, standard deviation of .59 and standard error mean of .14. Fall 2007 $(n=51)$ recorded a mean score of 3.5 , standard deviation of .45 and standard error mean of .06 . The net difference of score was -.14 , with a standard error difference of .13 . There was no evidence to suggest that Spring 2007 had a statistically different mean than Fall 2007 as $(t(67)=-1.1, p>.05)$.

For the STOE subscale, Spring $2007(n=18)$ had a mean score of 3.7, standard deviation of .34 and standard error mean of .08 . Fall $2007(n=51)$ recorded a mean score of 3.5, standard deviation of .47 and standard error mean of .07 . The net difference of score was .16 , with a standard error difference of .12 . There was no evidence to suggest that Spring 2007 had a statistically different mean than Fall $2007(t(67)=1.3, p>.05)$. Comparison of Researcher's Classes

A comparison of Spring 2007 and Fall 2007 classes in which the researcher was the instructor for the class where the survey was administered was completed via independent sample $t$-test to determine if any statistically significant difference existed between each of the sections. The reason for this analysis is to determine if the researcher biased the sample once it was accepted for the dissertation study. There is no evidence to suggest that that was the case. 
Pre-test results. For the PSTE subscale, Spring $2007(\mathrm{n}=18)$ had a mean score of 3.9, standard deviation of .46 and standard error mean of .11 . Fall $2007(n=26)$ recorded a mean score of 3.7, standard deviation of .75 and standard error mean of .15. The net difference of score was .26, with a standard error difference of .20. There was no evidence to suggest that Spring 2007 had a statistically different mean than Fall 2007 as $(t(42)=.19, p>.05)$

Table 8. Group Statistics of Spring 2007 and Fall 2007 Semesters.

\begin{tabular}{|c|c|c|c|c|c|}
\hline Subscale & TEAM & $\mathrm{N}$ & Mean & $\begin{array}{c}\text { Std. } \\
\text { Deviation }\end{array}$ & $\begin{array}{l}\text { Std. Error } \\
\text { Mean }\end{array}$ \\
\hline \multirow[t]{2}{*}{ PSTE (Pre-test) } & Spring 2007 & 18 & 3.9 & .46 & .11 \\
\hline & Fall 2007 & 51 & 3.7 & .76 & .11 \\
\hline \multirow{2}{*}{ STOE (Pre-test) } & Spring 2007 & 18 & 3.6 & .41 & .10 \\
\hline & Fall 2007 & 51 & 3.8 & .58 & .08 \\
\hline \multirow[t]{2}{*}{ PSTE (Post-test) } & Spring 2007 & 18 & 4.0 & .42 & .10 \\
\hline & Fall 2007 & 51 & 4.1 & .31 & .04 \\
\hline \multirow[t]{2}{*}{ STOE (Post-test) } & Spring 2007 & 18 & 3.9 & .44 & .10 \\
\hline & Fall 2007 & 51 & 4.1 & .52 & .07 \\
\hline \multirow[t]{2}{*}{ PSTE (Retrospective-test) } & Spring 2007 & 18 & 3.4 & .59 & .14 \\
\hline & Fall 2007 & 51 & 3.5 & .45 & .06 \\
\hline \multirow[t]{2}{*}{ STOE (Retrospective-test) } & Spring 2007 & 18 & 3.7 & .34 & .08 \\
\hline & Fall 2007 & 51 & 3.5 & .48 & .07 \\
\hline
\end{tabular}

For the STOE subscale, Spring $2007(n=18)$ had a mean score of 3.8, standard deviation of .41 and standard error mean of .10 . Fall $2007(n=26)$ recorded a mean score of 3.9, standard deviation of .57 and standard error mean of .11 . The net difference of score was -.31 , with a standard error difference of .16 . There was no evidence to suggest 
that Spring 2007 had a statistically different mean than Fall 2007 as $(t(42)=-2.0, p>$ $.05)$.

Post-test results. For the PSTE subscale, Spring $2007(\mathrm{n}=18)$ had a mean score of 4.0, standard deviation of .42 and standard error mean of .10 . Fall $2007(n=26)$ recorded a mean score of 4.0, standard deviation of .31 and standard error mean of .06 . The net difference of score was -.02 , with a standard error difference of .11 . There was no evidence to suggest that Spring 2007 had a statistically different mean than Fall 2007 as $(t(42)=-.16, p>.05)$

For the STOE subscale, Spring $2007(n=18)$ had a mean score of 3.9, standard deviation of .44 and standard error mean of .10 . Fall $2007(n=26)$ recorded a mean score of 4.2 , standard deviation of .58 and standard error mean of .11. The net difference of score was -.27 , with a standard error difference of .16 . There was no evidence to suggest that Spring 2007 had a statistically different mean than Fall 2007 as $(t(42)=-1.7, p>$ $.05)$.

Retrospective-test results. For the PSTE subscale, Spring $2007(\mathrm{n}=18)$ had a mean score of 3.4, standard deviation of .59 and standard error mean of .14. Fall 2007 $(n=26)$ recorded a mean score of 3.6, standard deviation of .46 and standard error mean of .09 . The net difference of score was -.18 , with a standard error difference of .16. There was no evidence to suggest that Spring 2007 had a statistically different mean than Fall 2007 as $(t(42)=-1.1, p>.05)$

For the STOE subscale, Spring $2007(n=18)$ had a mean score of 3.7, standard deviation of .34 and standard error mean of .08. Fall $2007(n=26)$ recorded a mean score of 3.5, standard deviation of .39 and standard error mean of .08 . The net difference of 
score was .16 , with a standard error difference of .12 . There was no evidence to suggest that Spring 2007 had a statistically different mean than Fall 2007 as $(t(42)=1.4, p>.05)$. Table 9. Group Statistics of Spring 2007 and Fall 2007 Semesters for Researchers Taught Sections.

\begin{tabular}{|c|c|c|c|c|c|}
\hline Subscale & TEAM & $\mathrm{N}$ & Mean & $\begin{array}{c}\text { Std. } \\
\text { Deviation }\end{array}$ & $\begin{array}{l}\text { Std. Error } \\
\text { Mean }\end{array}$ \\
\hline \multirow[t]{2}{*}{ PSTE (Pre-test) } & Spring 2007 & 18 & 3.9 & .46 & .11 \\
\hline & Fall 2007 & 26 & 3.7 & .75 & .15 \\
\hline \multirow[t]{2}{*}{ STOE (Pre-test) } & Spring 2007 & 18 & 3.8 & .41 & .10 \\
\hline & Fall 2007 & 26 & 3.9 & .57 & .11 \\
\hline \multirow[t]{2}{*}{ PSTE (Post-test) } & Spring 2007 & 18 & 4.0 & .42 & .10 \\
\hline & Fall 2007 & 26 & 4.0 & .31 & .06 \\
\hline \multirow[t]{2}{*}{ STOE (Post-test) } & Spring 2007 & 18 & 3.9 & .44 & .10 \\
\hline & Fall 2007 & 26 & 4.2 & .58 & .11 \\
\hline \multirow[t]{2}{*}{ PSTE (Retrospective-test) } & Spring 2007 & 18 & 3.4 & .59 & .14 \\
\hline & Fall 2007 & 26 & 3.6 & .46 & .09 \\
\hline \multirow[t]{2}{*}{ STOE (Retrospective-test) } & Spring 2007 & 18 & 3.7 & .34 & .08 \\
\hline & Fall 2007 & 26 & 3.5 & .39 & .08 \\
\hline
\end{tabular}

\section{Instrument Reliability}

The Science Teaching Expectancy Belief Instrument Form B (STEBI-B) which has 23 items has two subscales: a) Personal Science Teaching Efficacy (PSTE); and b) Science Teaching Outcome Expectancy (STOE). The PSTE subscale contained 13 questions, while the STOE accounted for 10 questions. For each administration of the instrument, Cronbach's alpha was determined for the entire set of items as well as each 
subscale independently. Reliability will be judged against .70 which is the lowest general acceptable level (Orcher, 2007).

\section{Reliability of Entire Instrument}

The entire instrument containing 23 items $(n=23)$ was evaluated using Cronbach's alpha. Overall, as in the three times the survey was administered $(N=69, n=$ $69)$, alpha $=.93$. For the pre-test $(N=69, n=23)$, alpha $=.92$. For the post-test $(N=69$, $\mathrm{n}=23)$, alpha $=.90$. For the retrospective-test $(\mathrm{N}=69, \mathrm{n}=23)$, alpha $=.79$. All of these results suggest instrument reliability as alpha $>.70$.

Table 10. Instrument Reliability Statistics Based on Administration Time for All Items.

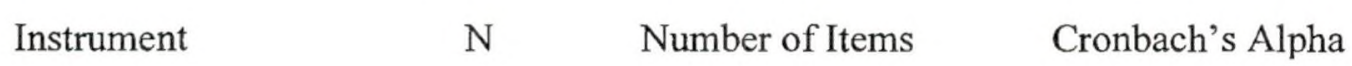

\begin{tabular}{lccc} 
Overall & 69 & 69 & .93 \\
Pre-test & 69 & 23 & .92 \\
Post-test & 69 & 23 & .90 \\
Retrospective-test & 69 & 23 & .79 \\
\hline
\end{tabular}

\section{Reliability of PSTE Subscale}

The PSTE subscale contained 13 of the 23 items on the instrument. The PSTE subscale was evaluated using Cronbach's alpha as a whole and each time the instrument was administered. Overall, as in the three times the survey was administered $(N=69, n=$ 39), alpha $=.90$. For the pre-test $(\mathrm{N}=69, \mathrm{n}=13)$, alpha $=.91$. For the post-test $(\mathrm{N}=69$, 
$\mathrm{n}=13)$, alpha $=.89$. For the retrospective-test $(\mathrm{N}=69, \mathrm{n}=13)$, alpha $=.85$. All of these results suggest instrument reliability as alpha $>.70$.

Table 11. Instrument Reliability Statistics Based on Administration Time for PSTE Subscale.

Instrument N N N Nonbach's Alpha

Overall PSTE

Pre-test PSTE

Post-test PSTE

Retrospective-test PSTE
69

69

69

69
39

13

13

13
.90

.91

.89

.85

\section{Reliability of STOE Subscale}

The STOE subscale contained 10 of the 23 items on the instrument. The PSTE subscale was evaluated using Cronbach's alpha as a whole and each time the instrument was administered. Overall, as in the three times the survey was administered $(N=69, n=$ $30)$, alpha $=.91$. For the pre-test $(N=69, \mathrm{n}=10)$, alpha $=.88$. For the post-test $(\mathrm{N}=69$, $\mathrm{n}=10)$, alpha $=.85$. For the retrospective-test $(\mathrm{N}=69, \mathrm{n}=10)$, alpha $=.75$. All of these results suggest instrument reliability as alpha $>.70$. 
Table 12. Instrument Reliability Statistics Based on Administration Time for STOE Subscale.

Instrument N Number of Items Cronbach's Alpha

$\begin{array}{lccc}\text { Overall STOE } & 69 & 30 & .91 \\ \text { Pre-test STOE } & 69 & 10 & .88 \\ \text { Post-test STOE } & 69 & 10 & .85 \\ \text { Retrospective-test STOE } & 69 & 10 & .75\end{array}$

\section{Research Question Results}

The purpose of this study was to investigate how retrospective-test / post-test perceptions of science teaching self-efficacy differ according to personal science expectancy and science teaching outcome expectancy among preservice elementary teachers when exposed to a science teaching methods course. Four research questions were proposed to focus the direction of the study. The research questions sought information on the difference between the pre-test and retrospective-test results, as well as identify interaction and main effects of the independent variables including number of post-secondary science courses taken and perception of previous school science experiences on the dependent variable of a change in self efficacy.

Research Question 1: Is there a statistical difference in pre-test / retrospective-test scores for personal science teaching efficacy (PSTE) and science teaching outcome expectancy (STOE)? Tables 17 and 18 show the results of the analysis. 
A paired-sample $t$-test was used to analyze the data for this research question. A Type I error rate of .05 was used as the criteria to decide if the results of the pre-test were statistically different than the results of the retrospective-test for each subscale.

Table 13. Paired Sample Statistics for Pre-Test and Retrospective-Test Scores.

Mean N Std. Deviation Std. Error Mean

$\begin{array}{llllll}\text { Pair 1 } & \text { PSTE (Pre-test) } & 3.7 & 69 & .70 & .08 \\ & \text { PSTE } & 3.5 & 69 & .49 & .06 \\ \text { (Retrospective-test) } & & & & \\ \text { Pair 2 } & \text { STOE (Pre-test) } & 3.7 & 69 & .56 & .07 \\ & \text { STOE } & 3.5 & 69 & .44 & .05 \\ & \text { (Retrospective-test) } & & & & \end{array}$

Table 14. Paired Sample Test Results for Pre-test and Retrospective-test Scores

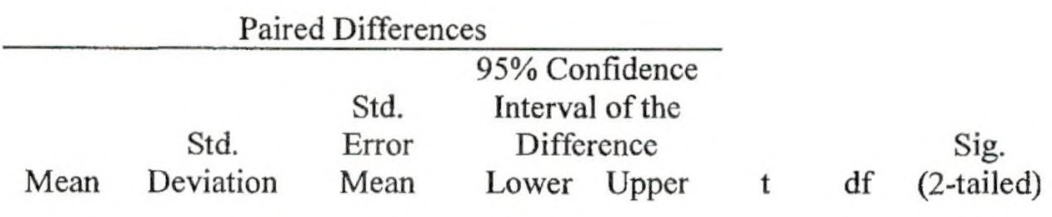

PSTE (Pre-test) -

Pair 1 PSTE (Retrospectivetest)

STOE (Pre-test) test)

$.24 \quad .80$

Pair 2 STOE (Retrospective- $\quad .17 \quad .57$

$.10 \quad .05$

$.07 \quad .03$
.44

$\begin{array}{lll}2.5 & 68 & .01\end{array}$

Personal science teaching efficacy (PSTE) is a teacher's belief regarding his or her own ability to teach science effectively (Enoch's \& Riggs, 1990) as defined as a construct in the Definitions of Terms section in Chapter one. It was then measured 
operationally in 13 of the 23 items on the STEBI-B instrument with a 5-point Likert scale.

PSTE subscale results were determined from the pre-test and retrospective-test. The pre-test mean $(\mathrm{N}=69)$ was 3.7 with standard deviation of .71 and standard error mean of .08 . The retrospective-test mean $(\mathrm{N}=69)$ was 3.8 with a standard deviation of .49 and standard error mean of .06 . The net mean difference of score was .24 with standard deviation of .80 and standard error mean of .10 . There is evidence to suggest that mean of the pre-test scores was statistically different than the mean of the retrospective-test scores as $(t(68)=2.5, p<.05)$

Science teaching outcome expectancy (STOE) reflects a teacher's belief regarding his or her own expectation that their science teaching will have a positive effect on future students such that the students will successfully learn science (Riggs, 1988) as defined as a construct in the Definitions of Terms section in chapter one. It was then measured operationally in 10 of the 23 items on the STEBI-B instrument with a 5-point Likert scale.

STOE subscale results were determined from the pre-test and retrospective-test. The pre-test mean $(\mathrm{N}=69)$ was 3.7 with standard deviation of .56 and standard error mean of .07 . The retrospective-test mean $(\mathrm{N}=69)$ was 3.5 with a standard deviation of .44 and standard error mean of .05 . The net mean difference of score was .17 with standard deviation of .57 and standard error mean of .07 . There is evidence to suggest that mean of the pre-test scores was statistically different than the mean of the retrospective-test scores as $(t(68)=2.5, p<.05)$ 
The results of the analysis indicated a statistically significant difference for both PSTE and STOE subscales in the pre-test and retrospective-test results as $p<.05$. In other words, preservice elementary science teacher candidates self reported a lower level of self-efficacy on the retrospective-test than on the pre-test.

Research Question 2: Are there statistically significant differential outcomes for changes in retrospective-test and post-test scores within personal science teaching efficacy (PSTE) and science teaching outcome expectancy (STOE) between preservice elementary teacher candidates who met the science content requirements for their degree and those that exceeded that number? Tables 15 and 16 show the results of the analysis.

A 2X2 univariate ANOVA was used to analyze the data for main effects of number of postsecondary science courses on both the PSTE and STOE subscales. A Type I error rate of .05 was used as the judgment criteria.

Table 15. Tests of Between-Subjects Effects for Changes of Scores on PSTE Subscale.

\begin{tabular}{lll} 
Source & $\begin{array}{c}\text { Type III Sum } \\
\text { of Squares }\end{array}$ df $\quad$ Mean Square \\
\hline
\end{tabular}
Sig. 


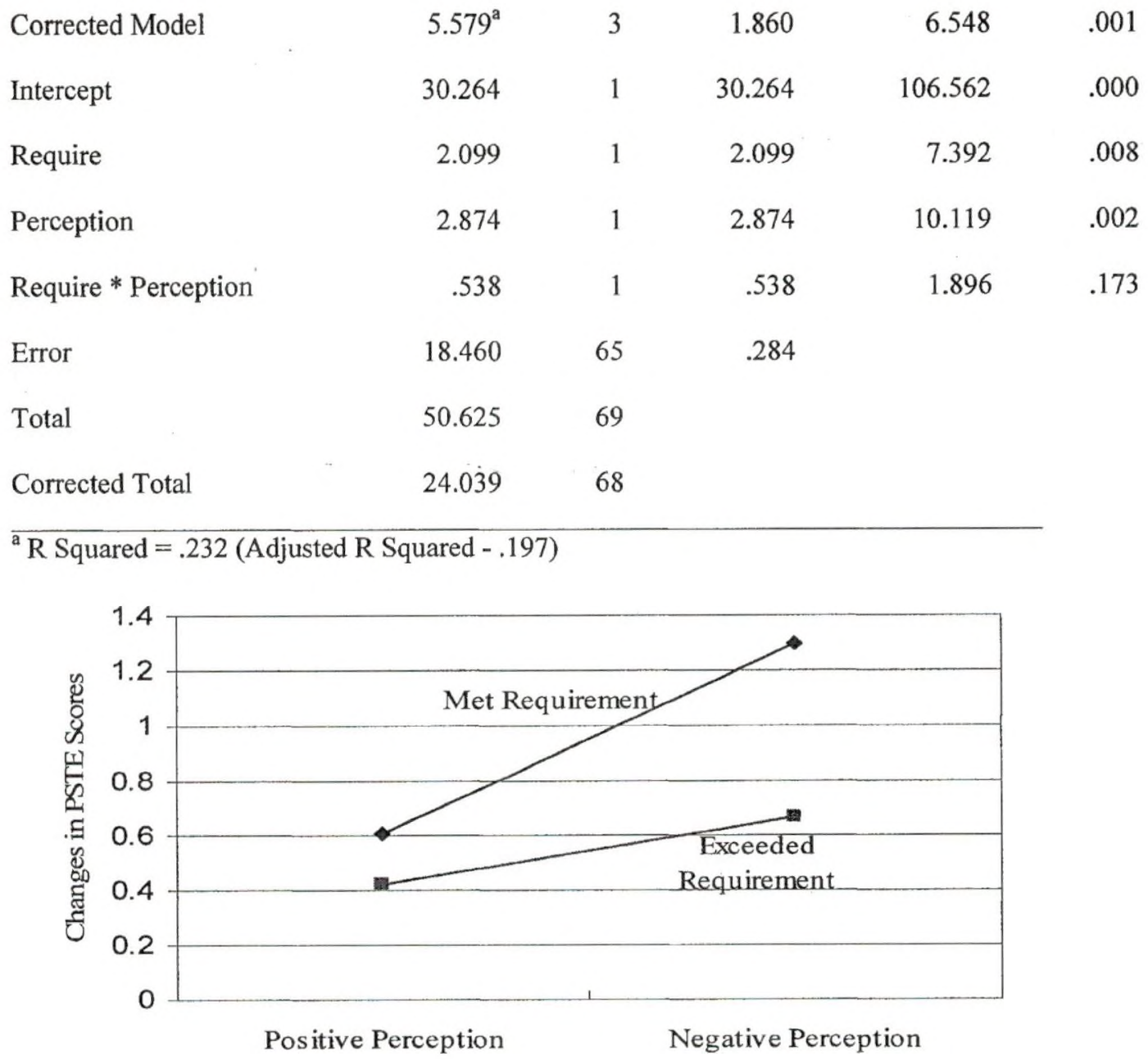

Figure 2. Interaction graph of changes in PSTE subscale scores.

Table 16. Tests of Between-Subjects Effects for Changes of Scores on STOE Subscale.

Type III Sum

Source of Squares df Mean Square F Sig. 


\begin{tabular}{|c|c|c|c|c|c|}
\hline Corrected Model & $.666^{\mathrm{a}}$ & 3 & .222 & .839 & .478 \\
\hline Intercept & 12.5 & 1 & 12.5 & 47.0 & .00 \\
\hline Require & .002 & 1 & .002 & .008 & .930 \\
\hline Perception & 648 & 1 & .648 & 2.45 & .122 \\
\hline Require * Perception & .053 & 1 & .053 & .198 & .657 \\
\hline Error & 17.2 & 65 & .265 & & \\
\hline Total & 31.5 & 69 & & & \\
\hline Corrected Total & 17.9 & 68 & & & \\
\hline
\end{tabular}

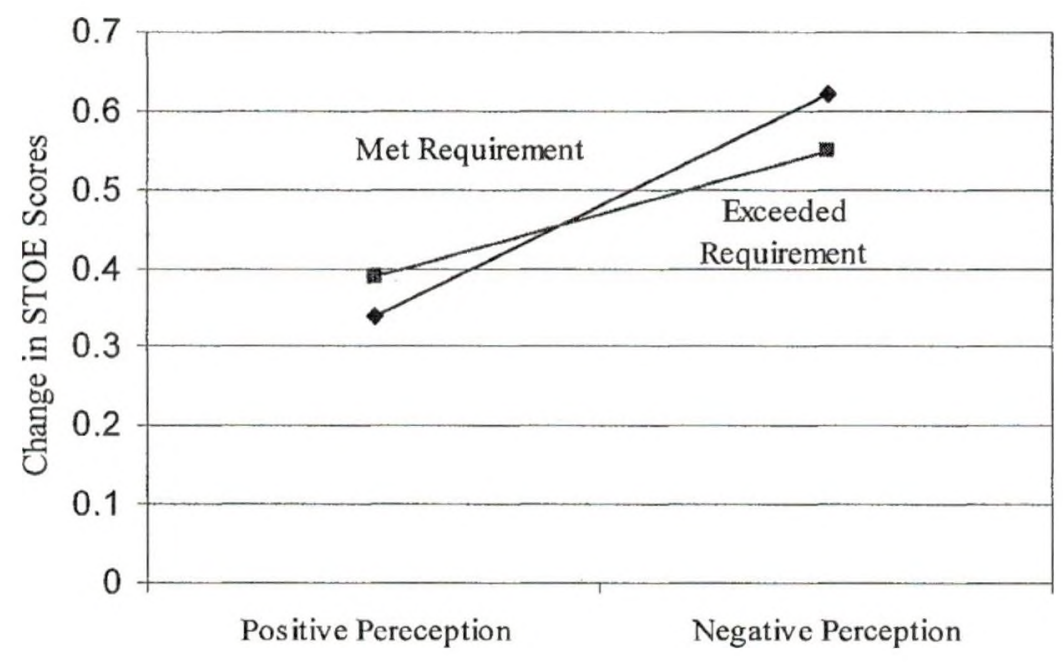

Figure 3. Interaction graph of changes in STOE subscale scores.

The number of post-secondary science content courses taken as a construct is defined as being a count of the total number of science content courses enrolled and completed at the post-secondary level taught outside the department of education 
(Bleicher, 2004). This independent variable was operationally measured by having participants write the number of science content courses taken at the post-secondary level in the blank space provided on the survey instrument.

Main effects were determined from the post-test and retrospective-test. Of the 69 students, 22 respondents (32\%) reported having only completed 2 postsecondary science courses and therefore only met the requirements necessary in their program of study to graduate. Forty-seven respondents (68\%) reported exceeding the required number of postsecondary courses taken. The ANOVA tests of between-subjects effects on the change in PSTE scores found a significant main effect of this independent variable $(F(1,65)=7.4, p<.05)$. There is no evidence to suggest a main effect of number of postsecondary science courses taken on the change of STOE scores $(F(1,65)=.008$, $\mathrm{p}>.05)$. In other words, the number of postsecondary science courses taken had an effect on how student teacher candidates perceived their future ability to teach science, but did not have an effect on if they thought future students would adequately learn science as a result of their teaching.

Research Question 3: Are there statistically significant differential outcomes for changes in retrospective-test and post-test scores within personal science teaching efficacy (PSTE) and science teaching outcome expectancy (STOE) between preservice elementary teacher candidates who perceived their prior school science experiences to be positive and those that perceived the experiences to be negative? Tables 15 and 16 above present the results. 
A 2 X2 univariate ANOVA was used to analyze the data for main effects of perceptions of prior school science experiences on both the PSTE and STOE subscales. A Type I error rate of .05 was used as the judgment criteria.

Prior school science experiences may be defined in terms of being positive or negative (Tosun, 2000). For the purposes of this study the operational definition is provided by having participants select whether they consider their prior school science experiences to be positive or negative according to the choices provided on the survey instrument. This independent variable was operationally measured by having participants write the number of science content courses taken at the post-secondary level in the blank space provided on the survey instrument.

Main effects were determined from the post-test and retrospective-test. Of the 69 students, 23 respondents (33\%) reported having negative perceptions of their prior school science experiences. Forty-six respondents (67\%) reported positive perceptions of their prior school science experiences. The ANOVA tests of between-subjects effects on the change in PSTE scores found a significant effect of this independent variable $(F(1,65)=$ $10, p<.05)$. There is no evidence to suggest a main effect of number of postsecondary science courses taken on the change of STOE scores $(F(1,65)=2.5, p>.05)$. In other words, a positive or negative perception of prior school science experiences had an effect on how student teacher candidates perceived their future ability to teach science, but did not have an effect on if they thought future students would adequately learn science as a result of their teaching. 
Research Question 4: Is there a statistically significant interaction of within PSTE and STOE subscale scores between number of post-secondary science content courses taken and perceptions of prior school science experiences?

A 2X2 univariate ANOVA was used to analyze the data for interaction effects of number of postsecondary science courses and perception of prior school science experiences on both the PSTE and STOE subscales. A Type I error rate of .05 was used as the judgment criteria.

Interaction effects were determined from the post-test and retrospective-test. There is no evidence to suggest a statistically significant interaction effect between the independent variables on the change in PSTE scores $(F(1,65)=1.9, p>.05)$. There is also no evidence to suggest a statistically significant interaction between the independent variables on the change in STOE scores $(F(1,65)=.20, p>.05)$. In other words, there was no evidence to suggest that the interaction of the number of postsecondary science courses taken and the perception of prior school science experiences had an effect on either the PSTE or STOE subscales of self-efficacy.

\section{Conclusion}

A report of the survey response rate, assumptions of the study, descriptive statistics, instrument reliability calculations and results of research questions were presented in this chapter. With a $100 \%$ survey response rate $(\mathrm{N}=69)$; each test was determined to be reliable as each administration of the STEBI-B instrument yielded a Cronbach's alpha of $>.70$.

Independent sample $t$-tests showed no evidence for a significant difference in scores between the Spring 2007 and Fall 2007 classes, nor in a comparison between each 
of the instructors classes. Evidence did not suggest a statistically significant difference in scores between each of the researcher's sections.

A paired sample $t$-test provided evidence to suggest that there was statistically significant difference in mean change of scores between the pre-test and retrospectivetest.

A series of $2 \times 2$ univariate ANOVA calculations suggested that the number of postsecondary science courses taken each had a statistically significant main effect on the PSTE subscale but not on the STOE subscale. Further, there was no evidence of a statistically significant interaction effect of each of the independent variables on the change of scores in either the PSTE or STOE subscales.

Pragmatically, the change in scores between the retrospective test and the posttest was determined by calculating the Cohen effect size. The measurement for effect size indicates the practical significance (Huck, 2008) of the results in terms of answering the question, what do these results actually mean? For changes in scores on the PSTE subscale using the retrospective-test mean of 3.5 and standard deviation of .49 with posttest mean of 4.1 and standard deviation of 0.54 , Cohen's $d=1.1$. For changes in scores on the STOE subscale using the retrospective-test mean of 3.5 and standard deviation of .44 with post-test mean of 4.0 and standard deviation of .55 , Cohen's $d=.93$. The Cohen (1998) effect size is therefore considered to be large for changes in both subscales as both results exceeded .80 . This result suggests that the changes in scores on both subscales were practically significant, as well as statistically significant. How these changes of score on each subscale relate to the 1 to 5 Likert-scale on the STEBI-B from which the raw scores were reported is discussed in Chapter V. 
A discussion of the aforementioned results as well as suggested implications and directions for future research are provided in Chapter V. 


\section{CHAPTER V \\ SUMMARY, DISCUSSION, CONCLUSIONS, AND RECOMMENDATIONS FOR FUTURE RESEARCH}

With an increasing concern regarding the current quality of elementary level science teaching (NRC, 1996) and the ability of new teacher education graduates to temper that trend, efforts are needed to improve the science teaching self-efficacy of preservice elementary teacher candidates. Preservice elementary teacher candidates must leave teacher education programs with a greater belief in their ability to teach science. This study examined how a science methods course affected their science teaching selfefficacy. The purpose of this study was to investigate perceptions of self-efficacy among preservice elementary teachers when exposed to a science methods course. This chapter will include: (1) an overall summary of the study and findings; (2) a discussion of the findings; (3) conclusions; and (4) recommendations for future research.

\section{Summary}

In Spring 2007 and Fall 2007 sessions an upper Midwest university, preservice elementary teacher candidates enrolled in a science methods course participated in this study. The course was organized to progress through a constructivist, inquiry based learning framework (Bleicher \& Lindgren, 2005) where students actively participated in the teaching and learning of science. Two of the three sections of this course in which teacher candidates participated in this study were taught by the researcher, with one 
section taught by a science education faculty member in the department. Preservice teacher candidates enrolled in these classes were provided a plethora of opportunities to engage in science experiences designed to enhance their understanding of science teaching and bolster their science teaching self-efficacy. The experiences included: hands-on inquiry based activities; projects that creatively expressed science concepts using technology; and peer teaching. Teacher candidates were also given assignments and asked to participate in activities that were designed to increase their science teaching selfefficacy by making them more confident in their science knowledge and skills. It was these assignments and experiences that would hopefully lead to a more confident science teacher-to-be, which would manifest once outside of the teacher education program and in the teaching profession.

Data were gathered from three administrations of an isomorphic instrument. The Science Teaching Expectancy Belief Instrument form B (STEBI-B) contained 23 items scored on a 5 point Likert-scale, ranging from "strongly disagree" to "strongly agree". Items on the instrument asked participants to respond to statements regarding their science teaching self-efficacy. The survey instrument contains two subscales; Personal Science Teaching Efficacy (PSTE); and Science Teaching Outcome Expectancy (STOE). The PSTE subscale captured teacher candidates' beliefs about their ability to teach science, while the STOE reflected the beliefs of having future students learn adequately from their science teaching. The instrument was administered on the first day of class, as well as twice on the last day of class. The reason for the dual administration on the final day was that one was considered a post-test, while the other was used as a retrospectivetest. In administering the instrument in this manner, changes in the perceptions of self- 
efficacy among preservice elementary teacher candidates when exposed to a science methods course could be described.

The following pages will present and discuss the findings related to the research questions as ascertained by this study. This section will include a discussion of the statistical analysis of the data as compared and contrasted with findings existent in the literature.

\section{Discussion}

Research Question 1: Is there a statistical difference in pre-test / retrospective-test scores for personal science teaching efficacy (PSTE) and science teaching outcome expectancy (STOE)?

The purpose of using the retrospective-test was to minimize the response-shift bias that occurs when the common metric was altered between measurements (Howard \& Dailey, 1979). In this study, a preservice teacher candidates' understanding of the nature of science teaching and their roles in it have changed from entry of the science methods course to the exit. In order to justify using a retrospective-test / post-test method to compare and discuss changes in science teaching self-efficacy in research questions 2,3 , and 4, a comparison of means between the initial pre-test and the retrospective-test was needed. A paired sample $t$-test was used to determine a statistically significant difference in the pre-test versus retrospective-test mean scores with judgment criteria of alpha $<.05$. The statistical findings, as presented in Chapter Four, provide evidence to suggest a significant difference of scores between the pre-test and retrospective-test on both PSTE and STOE subscales. This agrees with Cantrell's (2003) findings in comparing the subscales. What the findings reveal is that upon entry into the science methods course, 
preservice elementary teacher science candidates had a significantly inflated perception of their science teaching self-efficacy than they thought they did when asked to reflect on their pre-test level of self-efficacy at the course completion. Some implications of this result are presented below.

The difference in scores between the pre-test and the retrospective-test reflects a change in metric. Olson (2006) reports that preservice elementary teacher candidates feel more like English teachers than science teachers. Mulholland, Dorman, and Odgers (2004), and Tosun (2000) suggest that the negative attitudes towards science and science teaching are a result of negative prior school science experiences. This sentiment reflects the confidence and perception of science ability that the preservice elementary teacher candidates have upon entry to the methods course. However, after thirteen weeks of constructivist framed inquiry based learning about science and science teaching, it seems that a change in perception of the nature of science teaching and learning and one's teaching role in it has occurred. Appleton (2005) reports that effective methods courses can increase a preservice teacher candidates' confidence in his or her ability to teach science. This may be true as the metric for which science teaching self-efficacy is measured has changed.

The results of this question can be explained using the following example based on Cantrell (2003). Upon completing the pre-test STEBI-B on the first day of a methods class, a teacher candidate reports a score of 3 on an item on the survey, on the scale of 1 to 5 , where 1 represents low science teaching self-efficacy and 5 represents high science teaching self-efficacy. The reason for this score is that the teacher candidate felt confident in her ability to respond accurately to student questions and concerns as the teacher 
candidate had been successful in her postsecondary science content courses. The student then completes 13 weeks of the methods course, where she was instructed by a professor deeply rooted in a constructivist pedagogical philosophy. The instructor organized the course to challenge teacher candidates' understandings of science knowledge and encouraged the integration of such knowledge with effective and pragmatic applications of pedagogical theory. During the methods course, the teacher candidate developed, prepared, and peer taught lessons and incorporated a series of anticipated student questions to give greater depth to her lesson. Upon course completion, the STEBI-B was administered again and this teacher candidate realized that although she knew much more about how to teach science and the complexities and intricacies of it, she still had much to learn. As such, she scored herself as 3 on the same 5 point scale. She clearly now has a different perspective than she did when taking the pre-test, but the net change on this item on the instrument is apparently zero. The teacher candidate was unaware that she had artificially exaggerated her self-efficacy on the pre-test as the context at that point was much different than her current context for responding to the items on the STEBI-B. Although the student had increased her science teaching self-efficacy over the duration of the methods course, the traditional pre-test / post-test score would suggest that no increase in self-efficacy had occurred at all. This result is not accurate.

The context in which she now wrote the post-test vastly changed from when she responded on the pre-test. This disparity reflects a changing underlying metric, yet the underlying metric of the STEBI-B did not change. To keep the underlying metric of the individual consistent across the time in which the pre-test and post-test are completed, a practical method is to employ a retrospective-test. Here, the teacher candidate would 
respond as to what she should have responded in terms of self-efficacy on the pre-test during the first day of the methods course, knowing what she now knows about teaching science. If the teacher candidate reflects back on her understanding of teaching science and her growth within that understanding, she would respond to the self-efficacy item as a 2. As a result, the net change in science teaching self-efficacy between the retrospective-test and the post-test is 1 . This may be both statistically and pragmatically, in terms of effect size, significant on a 5 point scale. Here, it is therefore clear that the context in self-assessing one's self-efficacy is critical to any ideas drawn from it.

The issue of context is critical to this study as it places the preservice elementary teacher candidates' responses in perspective. This context identifies a low level of perceived science teaching self-efficacy en-route to the science methods course which is traditionally taken in the Senior year of undergraduate study in the teacher preparation program. In an effort to prepare better the elementary science teachers of tomorrow, we need them to arrive in the science methods course with a higher perception of science teaching self-efficacy. This is a challenge, but can be done. An outline of how to pragmatically make this a reality is presented in the conclusions section below.

Research Question 2: Are there statistically significant differential outcomes for changes in retrospective-test and post-test scores within personal science teaching efficacy (PSTE) and science teaching outcome expectancy (STOE) between preservice elementary teacher candidates who met the science content requirements for their degree and those that exceeded that number?

The statistical findings analyzed through a $2 \mathrm{X} 2$ ANOVA, as presented in Chapter Four, provide evidence of a significant difference of scores between the retrospective-test 
and post-test on the PSTE but not the STOE subscale. The judgment criterion for this analysis was alpha $<.05$. What this means is that there is evidence here to suggest that the number of postsecondary science content courses taken has a significant main effect on the PSTE subscale but not on the STOE subscale. These results coincide with Bleicher (2004) who reported that the number of postsecondary science courses did have a significant association with the PSTE subscale but not the STOE subscale. Some implications of this result are presented below.

The result for the PSTE subscale seems logical as those students who have taken more postsecondary science courses would likely be engaged by its material more so than a student who is enrolled in the courses to simply check boxes off from their programs of study. There are several variables that may contribute to why someone would enroll in further postsecondary science courses. Some of these may be: enjoyment of the nature of science; pre-requisites for a different degree; license or certificate; social reasons; and general interest in science as a field of research and study. As noted in the recommendations for future research later in this chapter, this would be an ideal place for qualitative interviews to determine some of the reasons for exceeding the number of postsecondary science courses required to graduate and intertwine them with statistical data from the STEBI-B. The data of this study indicates that whether or not a preservice elementary teacher candidate met or exceeded the number of science courses required to graduate has a main effect on his / her sense of personal science teaching efficacy. This may be because more science knowledge and skills as learned in the extra postsecondary science courses may result in a greater confidence of ability to teach science. While it would be easy then to suggest that requiring more science content courses be taken in 
one's program of study would be a sure fire way to increase levels of science teaching self-efficacy, that has been shown to not be the case.

In the grand scheme of better preparing teacher candidates to be science teachers, requiring teacher candidates to take more science content courses is not the answer (Moore \& Watson, 1999; Schoon \& Boone, 1998). Palmer (2005) asserts that enrollment in more courses does not necessarily result in better science teachers candidates. Rather it is the quality of the instruction and learning environment in the postsecondary science content courses that make a difference. Organizing and delivering better and more engaging inquiry based science courses at the undergraduate level will go a long way to help develop improved science teachers of tomorrow. Etkina, Mestre \& O'Donnell (2005) suggest that if postsecondary level science content courses for elementary preservice teachers were taught through inquiry based methods, preservice teachers would then be simultaneously immersed in pedagogical training and content learning; and then this student-centered instructional approach may then be carried forward by the preservice teacher once in a classroom of their own. Further, these constructivist, inquiry based courses might expand positive science experiences into strong beliefs about science as a whole which may effect their pedagogic choices of the future. It is reported that student beliefs about science have great influence on their future instructional behavior (Plourde, 2003; Thompson, 1992; Tobin, Tippins \& Gallard, 1994).

The absence of a significant main effect on the STOE also seems logical as students have yet to be in a classroom as a student teacher. In taking the science methods course in the semester before graduation and the student teaching experience, the preservice elementary teacher candidates have no context in which to assess how 
theoretical future students will react to their science teaching. It is this point that needs to be addressed. Universities across the North America have varying structures for placing teacher candidates in classrooms as student teachers. Some universities have students in real classrooms from acceptance in the teacher education program while others do not place their teachers until mid-Senior year. In placing students out in the field from entry in the program, teacher candidates are able to begin seeing the nature and dynamics of the teaching world while learning the theoretical positions that are supposed to guide teaching and learning. In this way, preservice teacher candidates can then superimpose learned material from their coursework over the experiences as student teachers in classrooms. Beeth and Adadan (2006) contend that field experiences are the vehicle in which preservice teachers apply acquired pedagogical knowledge from their coursework. Much research has been done to describe the effects school-based experiences have on teacher preparation (Moore, 2003; Roth \& Tobin, 2001).

Conversely, in having teacher candidates wait until the end of their program before venturing into a real classroom as a student teacher, students will have their subject area courses and pedagogical courses completed. Shoon and Sandoval (1997) report that preservice teachers in traditional programs complete their university methodology coursework and then enter the field experience. At this point, preservice teacher candidates can infuse the learned theories of pedagogy with the content and knowledge that they possess into a more complex student teaching experience. There are pros and cons to both chronologies.

In terms of this study, however, preservice teacher candidates do not have a context to base a change in their perceptions of their science teaching outcome 
expectancies as they have yet to experience classroom teaching from the other side of the desk. Once again, it is the contexts, or in this case lack of real life teaching context, from which they assess their levels of science teaching self-efficacy that seem to influence their responses.

Research Question 3: Are there statistically significant differential outcomes for changes in retrospective-test and post-test scores within personal science teaching efficacy (PSTE) and science teaching outcome expectancy (STOE) between preservice elementary teacher candidates who perceived their prior school science experiences to be positive and those that perceived the experiences to be negative?

Tosun (2000) used interviews to collate a list of descriptors used by preservice elementary teacher candidates to characterize their prior school science experiences. Tosun (2000) noted that the descriptors were overwhelmingly negative and influenced science teaching self-efficacy. The results of this study, as determined by a $2 \mathrm{X} 2$ ANOVA with a judgment criterion of alpha $<.05$ and presented in Chapter Four, indicate that the perception of prior school science experiences have a significant main effect on the PSTE subscale, while it does not have a significant main effect on the STOE subscale. Prior school science experiences that were positive seemed to result in a higher perception of personal science teaching self-efficacy, which agree with the same results reported by Bleicher (2004). Some implications of this result are presented below.

Several studies report that there is a correlation between perceptions of prior school experiences and self-efficacy (Jarret, 1999; Palmer, 2002; Tosun, 2000). These perceptions however can be influenced by an efficient science methods course that includes well conceived and executed learning experiences (Bleicher \& Lindgren, 2005; 
Ramey-Gassert \& Shroyer, 1992). The science methods course that the respondents of this survey were enrolled in aimed to provide opportunities for such learning experiences as well as be fun and engaging so to touch an affective sense of learning. Both instructors of the course deliberately planned and orchestrated activities to enhance the learning experience. The activities, like peer teaching, science inquiry experiments, and science concepts movies, were designed to engage the students. However, this is not necessarily the process and aim for which science content courses are designed, organized, and implemented. It is in this dichotomy between course design and implementation that may be the reason for this main effect. While the research suggests that perceptions of prior school science experiences can be influenced in a science methods course, it is curious as to why a preponderance of negative perceptions are carried into the science methods course in the first place. Etkina, Mestre, and O'Donnell (2005) provide a description of the disparity of intended goals and the actual student learning that occurs in postsecondary science classrooms in terms of teaching strategies and learning, as well as make suggestions how to remedy them. A detailed suggestion, using Mestre's (2001) recommendations is provided below in the conclusions section.

What may also contribute to the statistical significance of this variable is that preservice elementary teacher candidates have an array of reasons for selecting and identifying themselves as having positive or negative perceptions of prior school science experiences in this survey. It is suspected that these have more to do with the quality of learning experiences within these courses than they do with courses themselves as courses are the umbrellas that envelop the vanes of significant learning experiences. Fink (2003) describes significant learning experiences as those that: engage students; have 
high energy levels; result in significant change; and have value in student's lives. These characteristics vary from course to course which may influence a positive or negative perception of prior school science experiences.

The lack of significant main effect on the STOE subscale is likely a reflection of the preservice teacher candidate's absence of experience in a real classroom which was discussed above.

These results, more so than the effect of the quantity of postsecondary science content courses, reveal a grey area in the understanding of Bandura's two-component theory for self-efficacy; namely the PSTE and STOE subscales. There is an absence in the literature of the conceptual details of the PSTE and STOE (Bleicher \& Lindgren, 2005; Tschannen-Moran 1998). The PSTE subscale is conceptually more defined as it speaks to one's personal sense of self-efficacy, while the STOE is less clear. Bleicher and Lindgren (2005) suggest that:

...in the context of studies involving preservice elementary teacher methods course experiences, the conceptualization of outcome expectancy as "personalexternal (Tschannen-Moran et al.) seems to us to be a close match to how our preservice teachers expressed their developing sense that their teaching might make a difference to student learning. (p. 220)

This again reflects a need for context. Bandura's self-efficacy is context guided, and the preservice teacher candidates, when responding to the STEBI-B, had minimal context when it came to the STOE subscale as they had little to base their conceptualization of the outcomes expectancy upon. Like Tosun (2000), it is suggested here that in an effort to increase results on the STOE subscale, preservice teacher candidates need to actively participate in frequent field experiences throughout their program of study. 
Research Question 4: Is there a statistically significant interaction of within PSTE and STOE subscale scores between number of postsecondary science content courses taken and perceptions of prior school science experiences?

As statistically reported in Chapter IV and shown in the Figures 2 and 3, the interaction graphs of the data identify no evidence of significant interaction between the variables of meeting the required number of postsecondary courses and the perception of prior school science experiences on either of the PSTE and STOE subscales. Although these variables have been analyzed through a correlation matrix (Bleicher, 2007), they have not been analyzed strictly through interaction effects using ANOVA. It is in this research question that a limitation of the dissertation appears. Some implications of this result are presented below.

A perception of prior school science experience, like any other perception, is relative to the observer. As such, assume there are two students, student A and student B. Student A might have a positive perception of prior school science experiences because the professor of the course was humorous, while student B may report a positive perception on prior school science experiences because class was only once a week. Tosun (2000) suggests however that achievement is not an influencing factor in how students perceive their prior school science experiences, but negative feelings towards those experiences carry the heavy weight. In this study, there is no clear set of attributes or conditions that are used to determine if a prior school science experience is positive or negative.

A further possible reason for the lack of significant interaction is the varying courses that students may have taken in order to meet or exceed the science content 
course requirements for their program of study. As defined in the Course Catalog (University of North Dakota, 2005), students are required to take 2 science courses with labs. While a partial list is given as to what may count towards this requirement, the actual list is diverse including courses of different levels of difficulty and focus. Some courses are more science content driven than others, while others are more focused on basic science knowledge. Furthermore, depending on the type of professor and teaching style of courses, the experiences in those courses could be very different. The differences of the professors may be measured in terms of their relation to the scholarship of teaching. Trigwell, Martin, Benjamin and Prosser (2000) propose a four dimensional model for the scholarship of teaching that includes the following attributes a professor who engages in the scholarship of teaching can be measured by;

- The extent to which they engage in scholarly contributions of others, including the literature of teaching and learning of a general nature, and particularly that in their discipline;

- The focus of their reflection to their own teaching practice and the learning of students within the context of their own discipline: whether it is unfocused, or whether it is asking what do I need to know and how do I find out;

- The quality of the communication and dissemination of aspects of practice and theoretical ideas about teaching and learning in general and teaching and learning within their discipline; and

- Their conceptions of teaching and learning: whether the focus of their activities is on student learning and teaching or mainly on teaching.

Each professor is different, and so is each student. How a student interacts with the coursework and professor will elicit different perceptions of the experience. This is the nature of education for all subject areas in all grade levels. Students are individuals and are unique. Due to an absence of strict criterion to assess and differentiate between a 
positive or negative perception of prior school science experiences, it is therefore difficult to expect a consistency in these descriptive responses, and thus a significant interaction of these variables.

While the research questions for this study focused on determining whether a statistically significant main and / or interaction effect existed between variables, there is another area of significance that needs to be addressed. The practical significance of the results speaks to the actual pragmatic manifestation of the changes in science teaching self-efficacy on each of the PSTE and STOE subscales. More specifically, how did the upward change in science teaching self-efficacy affect the preservice elementary teacher candidate in the science methods course? The significance of the study applies in several practical areas.

The significance of study applies in several practical areas. First, the PSTE from retrospective-test to post-test went from a mean of 3.5 to a mean of 4.1 . This change means that where respondents were generally uncertain how they positioned themselves within the framework of science teaching self-efficacy, they now generally agreed with the statements made on the STEBI-B. The practical side of this result may be identified in the selection and development of peer teaching lessons by preservice elementary teacher candidates in the science methods course. Selection of the topic and concept to teach within the peer teaching lesson is made solely by the preservice teacher. There is a great spectrum in topic choices ranging from the content areas of science, to levels of difficulty and intricacy of the concepts. There is also a wide disparity in the level and challenge of the activities used to engage learners in those concepts. A stronger sense of PSTE may have encouraged preservice elementary teacher candidates to select a more challenging 
and complex peer teaching topic and related activities to share with their colleagues as opposed to a more superficial and basic concept with shallow activities. The choice to present a richer science topic, lesson, and set of activities may be a result of having a stronger sense in their abilities to effectively teach the science concept as a whole. This sentiment is what the PSTE refers.

Second, the change in score on the STOE from retrospective-test to post-test went from a mean of 3.5 to 4.0. Like PSTE, the STOE change of scores identified that where respondents were generally uncertain how they positioned themselves within the framework of science teaching self-efficacy, they now generally agreed with the statements made on the STEBI-B. The practical side of this result may be identified in the Discovery Center creation and presentation. One activity of the science methods course used in this study is for preservice elementary science teachers to create science discovery centers and take them to a local elementary school to engage young students in a diverse plethora of science activities. In preparation for this activity, preservice teacher candidates were asked to consider developing a center that provided a meaningful learning opportunity for the students who would visit their center in the coming weeks. The positive change in STOE perspective may be demonstrated in how the preservice teacher candidates organized, planned, and created their centers as now they may have had a greater sense of what they could do to make the learning opportunity of the upcoming student participants that much more meaningful, engaging, and rich. This speaks entirely to their sense of how future students could learn from their science teaching, specifically in this case as preservice teachers presenting their self-made Discovery Center. This is, by definition, what the STOE means. 
It was however beyond the scope of this study to ascertain data that would provide deeper insight into these ideas for practical manifestation as a result of the changes in scores on PSTE and STOE subscales. This short discussion however provides the basis from which future research possibilities can be derived. Such recommendations are found later in this Chapter.

\section{Conclusions and Recommendations}

The future of science education rests in the hands of the teacher candidates currently enrolled in Departments of Education on campuses across North America. Despite rigorous programs of study, exceptional teacher education faculty, and teacher candidate ability, the National Research Council (NRC) (1996) reports that teacher preparation programs fail to prepare science teachers adequately that effectively teach science. The NRC makes a very humbling assertion, especially to members of the academe associated with science teacher education. It is therefore the purpose of this discussion regarding this study to: (1) identify the tenets of science teacher education methods courses that are suggested to be inadequate; (2) provide suggestions to enhance those programs in a holistic manner; and (3) to report why these suggestions will remain mostly dormant propositions unless serious changes to the factors that influence promotion among faculty occur.

Current standards in science education, among other recommended outcomes, solicit science teachers to create classroom environments that foster rich student scientific inquiry and concept development. Students in such an environment will, "design, investigate, represent data, construct models, talk science, build shared meaning, and argue about ideas and evidence" (Smith \& Anderson, 1999, p. 773). In order to facilitate 
this environment and perhaps more importantly to maintain it, a teacher must have a well developed set of blended pedagogical knowledge with scientific knowledge. It appears that the absence of either of these knowledge bases significantly inhibits the making of such a classroom environment plausible and viable. Teacher education methods courses are usually one of the capstone courses that interweave discipline knowledge and teaching knowledge preceding the final student teaching experience. Although designed with the best intentions, teacher candidates do not always match their learning with the goals set out by the professors of methods courses. The dichotomy between a professors planned goals and what students actually learn becomes noticeably apparent when teacher candidates are no longer teacher candidates but rather employed teachers.

Olson (2006) reports that current research indicates elementary science teaching practices do not promote meaningful science learning. In other words, the literature suggests that the pedagogical choices made by elementary science teachers do not engage students in significant science learning experiences. Further, the practices teachers demonstrate once in the field are inconsistent to those taught in teacher preparation programs. This is seems inconsistent with the efforts made by science methods courses to improve science teaching self-efficacy and the results presented in the literature like Kelly (2000), or Carter and Sottile (2002). While there are several possible interrelated variables that likely contribute to this claim, the most significant one is a fundamental deficiency of deep and complex science content knowledge, and a lack of efficient and engaging science learning as a whole. Being an instructor of the science methods courses for four semesters, it seems that many students enrolled in this course lack the necessary science knowledge to interweave it with pedagogical knowledge to form the skill set 
needed to create and maintain the aforementioned scientific classroom atmosphere. In short, their science teaching self-efficacy is exceedingly low. Appleton (2003) notes that elementary teacher education candidates typically have had negative experiences with science, low content knowledge in science, and do not see themselves as science teachers but rather language arts teachers. If this is true, science methods courses have innate and predetermined parameters that seriously inhibit the development of effective science teaching from teacher candidates once they enter classrooms of their own. It is unfortunate however that public opinion assigns responsibility of these ineffective teachers to professors of methods courses and does not take a more global perspective that might identify that responsibility should be shared for this perceived failure. What is more disconcerting is that the dominant theme of the literature, regardless of whom is at fault, is that teacher preparation programs fail on both the pedagogical strategies and content area knowledge levels (Duran, McArthur \& Van Hook, 2004; Fort, 1993; McDermott, 1990).

Accountability for teacher candidate preparation is a charged issue with serious implications. Stotsky (2006) argues that different faculty members need to be accountable for different aspects of the entity known as teacher education. This includes deep and rich academic content learning from the disciplines as well as thorough pedagogical information from the faculty of education. However fair or not, pedagogical faculty at most higher education settings are held responsible for academic content knowledge as well. Stotsky (2006) suggests that reform by restructuring the coursework allocations within the undergraduate program, as well as working collaboratively with discipline area faculty would enhance the programs of study and generate more adequately prepared 
science teachers. Furthermore, it means that postsecondary science content courses should help reinforce a positive experience in science by making the material engaging and meaningful. This idea is not foreign. The NRC (2000) provides guidelines towards collaboration between faculties of education and those of science when they describe the characteristics of teacher education in science and math as follows:

...involve collaborative endeavors developed and conducted by scientists, mathematicians, education faculty, and K-12 teachers.

...help prospective teachers to know well, understand deeply, and use effectively and creatively the fundamental content and concepts of the disciplines they will teach.

...unify, coordinate, and connect content courses in science and mathematics with methods courses and field experiences.

...integrate science education theory with actual teaching practice, and knowledge from science and mathematics teaching experience with research on how people learn science and mathematics.

...welcome students into the professional community of educators and promote a professional vision of teaching by providing opportunities for experience and future teachers to assume new roles. (p. 68)

Carr (2002) captures the strength of the proposed relationship between science and education departments in describing the partnerships that exist between the multiple stakeholders within the university. While wonderful partnerships based on holistic ideals are starting to form, pragmatic guidelines to do so are more difficult to establish.

Mestre (2001) identifies a set of desirable attributes for physics courses, which preservice science teacher candidates have and will continue to enroll in, and that would significantly help prepare future science teachers at all levels. These include:

1) Physics content and pedagogy should be integrated,

2) Construction and sense making of physics knowledge should be encouraged 
3) The teaching of content should be a central focus

4) Ample opportunities should be available for learning 'the process of doing science'

5) Ample opportunities should be provided for students to apply their knowledge flexibly across multiple contexts

6) Helping students organize content knowledge according to some hierarchy should be a priority

7) Qualitative reasoning based on physics concepts should be encouraged

8) Metacognitive strategies should be taught to students, and,

9) Formative assessment should be used frequently to monitor students' understanding and to help tailor instruction to meet students' needs.

Mestre (2001) argues that physics teacher education requires a closer examination to prepare physics teacher candidates better in their journey to become physics teachers. This examination and subsequent modification of pedagogical methods content area professors could utilize would help reform discipline courses to provide the foundation for rich and complex learning. This learning is what is missing when teacher candidates appear in their final methods courses. Without this vital piece it is difficult to help teacher candidates learn specific methods of science pedagogy as they cannot connect the science piece with the teaching piece. Etkina et al. (2005) remind us that this does not always need to be the case as constructivist, inquiry based courses can connect these pieces. Further, the methods and content area courses that teacher candidates enroll in should be rooted in successful strategies for teaching and learning as this will act as a model, and thus contribute to helping reduce the number of ineffective science teacher candidate graduates from departments of education. 
While these suggestions manifest from literature, observation, and personal insight, it is curious as to why more content specific professors do not embrace these suggestions and employ more of them. The reason why these suggestions remain dormant rather than being implemented is sadly rather clear. Powell, (2003), as cited in Duran et al. (2004), states the answer in suggesting, "Transforming traditional learning environments is a lofty goal in a system where excellence in teaching is not a significant factor for career advancement" (p. 156). Perhaps what this means is that there is little or no real incentive for professors in the disciplines to improve their teaching to include Mestre's (2001) recommendations as that may take time and energy from other critical areas of the professoriate in the form of research and service. Essentially, as long as the course and student evaluations are generally positive, and there are no instances of violations of academic freedom, or poor choices in one's faculty conduct, there is no reason to improve or modify teaching technique or style to engage more students, as there is no real reward, neither promotional nor financial, for doing so. While the professoriate may be moving away, only slightly perhaps, from the idiom of 'publish or perish', it still seems to hold much truth. Despite this, however, significant efforts are reported (Atkinson, 2001) and intended to reverse this trend and reward excellence in teaching as well as scholarship of research.

What this means in the greater picture of higher education is that excellence in teaching is, albeit slowly, becoming a valued activity. More specifically, this suggests that upon the promotion and advancement horizon, there will be external remuneration for professors improving their pedagogy and classroom environments to foster greater student learning. This paradigmatic shift will help the science teachers of tomorrow be 
better prepared in their science background as the postsecondary science content courses will be better taught, which they can then blend with pedagogy knowledge in methods courses before entering the teaching profession.

Teacher candidates who are not engaged in the learning process, at any of the postsecondary levels in either education or discipline area courses, leave our programs with, "little more than shallow understandings, weak connections between big ideas, trivial knowledge, unchallenged naïve conceptions of how the natural world operates, and an ability to apply knowledge in new settings" (Craven \& Penick, 2001, p. 1). This is not the ideal level for which teacher candidates should emerge from our programs. It is thus not surprising why we, as a nation, reportedly lack quality science teachers, especially at the elementary level.

Etkina, et al. (2005), Mestre (2001), and Stotsky (2006) all provide suggestions to which content area professors could improve their pedagogy, and in turn, help better prepare the teachers of tomorrow. It is truly a collaborative effort to accomplish this goal, as both discipline area faculty members as well as education area faculty need to be accountable for their roles in developing teacher candidates.

With a changing higher education landscape on the horizon in which teaching quality and ability are valued as much as research ideals and service hours, due in part to the foresight of Boyer's Scholarship Reconsidered (1990), cross-campus improvement in teaching will not only improve the education of all students, but will significantly better prepare science teacher candidates. Thus the NRC and the general public will hopefully no longer worry or contend that science teacher education and preparation in America is inadequate. 


\section{Recommendations for Future Research}

In the new arena of significant political influence on the education of our children through mandates like the No Child Left Behind legislation, teacher education programs are becoming more publicly accountable for preparing teacher candidates to understand and carry out the new directions and focus of education in the United States. It is thus the responsibility of universities as a whole, including but not limited to teacher education programs, and specifically the professors of methods courses, to prepare better the aspiring teachers. It is within this framework that the following recommendations are provided.

The university as a holistic enterprise has the responsibility to maximize student learning and teacher preparation efficiently. Courses must match intended learning outcomes with assessments, and demonstrate consistency in delivering content that is engaging and meaningful. These criteria are not limited only to pedagogy based courses found in the education department. Both teacher educators and content area educators need to organize and carryout their classes to best prepare current students and the teachers of the future.

Teacher educators and subject area educators, specifically in the area of science education, need to be aware of the low levels of science teaching self-efficacy of the preservice elementary teacher candidates. An awareness of this may help to begin the process to radically change the mentality of postsecondary science teaching and in turn help to alleviate some of the excess anxiety and low level of confidence reported in the literature by preservice elementary teacher candidates arising from enrolling in such classes. Courses that are structured to be inquiry based, constructivist in nature, that 
meander through pedagogical strategies governed by the ideals of good pedagogy will go far into making science content more meaningful and valuable to the students. These changes will help reduce the negative perceptions of school science experiences and perhaps even strengthen the positive perceptions. Asking students to enroll in more science content courses is not the answer to raising preservice teachers' levels of science teaching self-efficacy. Providing richer science content instruction is part of the answer to accomplishing that. Teacher educators as well as content area educators need to be versed in educational research and the suggestions for effective pedagogy within it as from that, useful strategies and ideas can be discussed.

In terms of future research, the primary recommendation is to track the trajectory of preservice elementary teacher candidate's levels of science teaching self-efficacy throughout their program, from admission into the program to graduation and beyond. This longitudinal study will help determine areas in which growth towards being a science teacher are either stifled, constant or promoted. From this determination, a deeper analysis as to what makes these trends occur can be obtained and subsequently used as the basis for reforming future teacher education programs.

Two major considerations for future research in this area arise from limitations of this study. It is suggested to develop a consistent set of criteria to reduce any confusion regarding what constitutes a positive or negative perception of prior school science experiences. Further, the sample size needs to be larger. Since there are so few males in the preservice elementary stream, it is difficult to obtain enough data to use gender as a statistically viable variable. It is interesting, based on other studies like Bleicher (2004), as to how this variable might interact with the other variables in this study. 
Another possible area for future research would be to continue this study with a larger sample size which includes preservice elementary teacher candidates at other institutions. As this is a national problem, then it seems that a larger study would provide better evidence to strengthen and perhaps reform the organization and structure of science teacher preparation programs.

A study that would seem fruitful as future research would include one to covary teaching styles. If a professor of a science methods course employs a subject-centered approach compared to a professor whom designs the course from a learner-centered approach, the student learning experience and subsequent change in levels of science teaching self-efficacy may be affected.

In recognizing that prior school science experiences relate to science teaching self-efficacy, a further study that contrasts which specific postsecondary science content courses and labs were taken would help explore this variable. Integrating the reasons for choosing those courses and them with the perceptions of prior school science experiences might then provide a richer understanding of how these variables interact.

Using a mixed-method technique to interweave statistical data with interview responses seems to a possible next step to this dissertation study as it would provide more information as to how the selected grouping variables affect other descriptive variables. For example, gaining insight into why students enroll in more postsecondary science content courses might provide complimentary ideas as to why evidence suggested that this variable had a main effect on PSTE. Further interviews may provide the insight from which data based claims could be made about the practical significance of increasing 
ones level of science teaching self-efficacy and that manifests in the teacher education program among preservice teacher candidates.

\section{Conclusion}

In an effort to improve our science teacher candidates' preparation and level of science teaching self-efficacy, we need take a more holistic look at their overall program of study. Preservice elementary teacher candidates should have experiences in postsecondary science courses leading up to the methods courses that are positive, meaningful and engaging, regardless of the number of postsecondary science content courses taken. This will help raise their levels of science teaching self-efficacy. An increase in this psychosocial construct will allow for greater growth in the methods course and hopefully a sustained level of science teaching self-efficacy once out in the real classrooms post-graduation. To do this, teacher education departments need the assistance of other science departments and professors to unify in their philosophy of teaching and learning such that students are taught with effective teaching strategies to maximize science learning opportunities and experiences. This is a circular argument however, that needs departments to buy in. More effective science content teaching in the required courses for preservice teachers will generate more confident science teachers-tobe. These teachers will go to the field and teach students who will arrive in those same courses years in the future. Better prepared and more capable science students at the elementary level will progress to a higher quality of science students upwards on the academic ladder en route to postsecondary science courses which the original changes occurred. It is then that the fruits of this change to effective teaching cross-campus will manifest. Preservice elementary science teacher candidates' level of science teaching 
self-efficacy, as seen by the results of this study and supported in the literature, can increase through science methods courses. Imagine however what additional progress could be made if the level of personal science teaching efficacy (PSTE) and science teaching outcome expectancy (STOE) upon arrival to the methods course were already that much higher, and what that could mean to an improved quality of science teaching and learning in the elementary schools across North America. 
APPENDICES 
Appendix A

Demographic Grouping Questions

CHANGES IN PRESERVICE ELEMENTARY TEACHERS' PERSONAL SCIENCE TEACHING EFFICACY AND SCIENCE TEACHING OUTCOME EXPECTANCIES: THE INFLUENCE OF CONTEXT

Code:

Demographic questions:

1. Male

Female (check one)

2. How many postsecondary science content courses have you taken?

3. You perceive your prior school science experiences to be:

Positive Negative (check one)

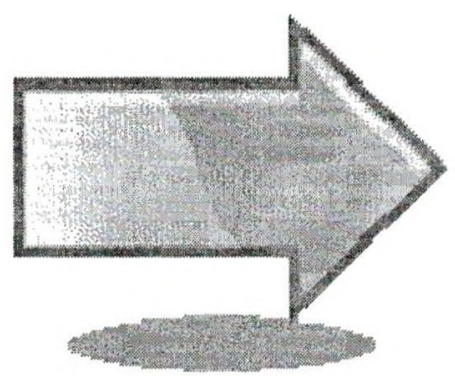

Please turn over..... 


\section{Appendix B \\ The STEBI-B Instrument Used for Data Collection}

Please indicate the degree to which you agree or disagree with each of the following statements below by circling the appropriate letters to the rights of each statement.

$\mathrm{SA}=$ Strongly Agree, $\mathrm{A}=$ Agree, $\mathrm{UN}=$ Uncertain, $\mathrm{D}=$ Disagree, $\mathrm{SD}=$ Strongly Disagree

\begin{tabular}{|c|c|}
\hline Statement & Response \\
\hline $\begin{array}{l}\text { 1. When a student does better than usual in science, it is often because } \\
\text { the teacher exerted a little more effort. }\end{array}$ & SA A UN D SD \\
\hline 2. I will continually find better ways to teach science. & SA A UN D SD \\
\hline $\begin{array}{l}\text { 3. Even if I try hard, I will not teach science as well as I will most } \\
\text { subjects. }\end{array}$ & SA A UN D SD \\
\hline $\begin{array}{l}\text { 4. When the science grades of students improve, it is often due to their } \\
\text { teacher having found a more effective teaching approach. }\end{array}$ & SA A UN D SD \\
\hline 5. I know the steps necessary to teach science concepts effectively. & SA A UN D SD \\
\hline 6. I will not be very effective in monitoring science experiments. & SA A UN D SD \\
\hline $\begin{array}{l}\text { 7. If students are underachieving in science, it is most likely due to } \\
\text { ineffective science teaching. }\end{array}$ & SA A UN D SD \\
\hline 8. I will generally teach science ineffectively. & SA A UN D SD \\
\hline $\begin{array}{l}\text { 9. The inadequacy of student's science background can be overcome by } \\
\text { good teaching. }\end{array}$ & SA A UN D SD \\
\hline $\begin{array}{l}\text { 10. The low science achievement of students cannot generally be } \\
\text { blamed on their teachers. }\end{array}$ & SA A UN D SD \\
\hline $\begin{array}{l}\text { 11. When a low achieving student progresses in science, it is usually } \\
\text { due to extra attention given by the teacher. }\end{array}$ & SA A UN D SD \\
\hline $\begin{array}{l}\text { 12. I understand science concepts well enough to be effective in } \\
\text { teaching elementary science. }\end{array}$ & SA A UN D SD \\
\hline $\begin{array}{l}\text { 13. Increased effort in science teaching produces little change in } \\
\text { students' science achievement. }\end{array}$ & SA A UN D SD \\
\hline $\begin{array}{l}\text { 14. The teacher is generally responsible for the achievement of students } \\
\text { in science. }\end{array}$ & SA A UN D SD \\
\hline $\begin{array}{l}\text { 15. Student's achievement in science is directly related to their teacher's } \\
\text { effectiveness in science teaching. }\end{array}$ & SA A UN D SD \\
\hline $\begin{array}{l}\text { 16. If parents comment that their child is showing more interest in } \\
\text { science, it is probably due to the performance of their child's teacher. }\end{array}$ & SA A UN D SD \\
\hline $\begin{array}{l}\text { 17. I will find it difficult to explain to students why science experiments } \\
\text { work. }\end{array}$ & SA A UN D SD \\
\hline 18. I will typically be able to answer student's science questions. & SA A UN D SD \\
\hline 19. I wonder if I will have the necessary skills to teach science. & SA A UN D SD \\
\hline $\begin{array}{l}\text { 20. Given a choice, I will not invite the principal to evaluate my science } \\
\text { teaching. }\end{array}$ & SA A UN D SD \\
\hline $\begin{array}{l}\text { 21. When a student has difficulty understanding a science concept, I will } \\
\text { usually be at a loss as to how to help the student understand it better. }\end{array}$ & SA A UN D SD \\
\hline 22. When teaching science, I will usually welcome student questions. & SA A UN D SD \\
\hline 23. I do not know what to do to turn students on to science. & SA A UN D SD \\
\hline
\end{tabular}




\section{REFERENCES}

Aiken, L. S., \& West, S. G. (1990). Invalidity of true experiments: Self-report pretest bias. Evaluation Review, 14(4), 374-390.

Anderson, R. D. (1997). The science methods course in the context of the total teacher education experience. Journal of Science Teacher Education, 8(4), 269-282.

Appleton, K. (1995). Student teachers' confidence to teach science: Is more science knowledge necessary to improve self-confidence? International Journal of Science Education, 17(3), 357-369.

Appleton, K. (2003). How do beginning primary school teachers cope with science? Toward an understanding of science teaching practice. Research in Science Education, 33, 1-25.

Ashton, P. T., \& Webb, R. B. (1986). Making a difference: Teachers' sense of efficacy and student achievement. New York: Longman.

Atkinson, M. P. (2001). The scholarship of teaching and learning: Reconceptualizing scholarship and transforming the academy. Social Forces, 79(4), 1217-1230.

Bandura, A. (1977). Self-efficacy: Toward a unifying theory of behavioral change. Psychological Review, 84, 191-215.

Bandura, A. (1986). Social foundations of thought and action: A social cognitive theory. Englewood Cliffs, NJ: Prentice-Hall.

Bandura, A. (1996). Self-efficacy in changing societies. New York: Cambridge University Press.

Bandura, A. (1997). Self-efficacy: The exercise of control. New York: W. H. Freeman.

Bandura, A. (2000). Self-efficacy: Foundation of agency. In W. Perring, \& A. Gorb (Eds.), Control of human behavior, mental processes, and consciousness. (pp. 17-33). Mahwah, NJ: Lawrence Erlbaum.

Beeth, M. E., \& Adadan, E. (2006). The influences of university-based coursework on field experience. Journal of Science Teacher Education, 17(2), 103-120.

Blanton, H., \& Jaccard, J. (2006). Arbitrary metrics in psychology. American Psychologist, 61(1), 27-41. 
Bleicher, R. E. (2004). Revisiting the STEBI-B: Measuring self-efficacy in preservice elementary teachers. School Science and Mathematics, 104(8), 383-391.

Bleicher, R. E. (2007). Nurturing confidence in preservice elementary science teachers. Journal of Science Teacher Education, 18(6), 841-860.

Bleicher, R. E., \& Lindgren, J. (2005). Success in learning science and preservice science teaching self-efficacy. Journal of Science Teacher Education, 16, 205-225.

Bollen, K. (1989). Structural equations with latent variables. New York: Wiley.

Boyer, E. L. (1990). Scholarship reconsidered: Priorities of the professoriate. Princeton, New Jersey: Carnegie Foundation for the Advancement of Teaching.

Brand, B. R., \& Wilkins, L. M. (2007). Using self-efficacy as a construct for evaluating science and mathematics methods courses. Journal of Science Teacher Education, 18, 297-317.

Bray, J. H., \& Howard, G. S. (1980). Methodological considerations in the evaluation of a teacher-training program. Journal of Educational Psychology, 72(1), 62-70.

Bray, J. H., Maxwell, S. E., \& Howard, G. S. (1984). Methods of analysis with responseshift BIAS. Educational and Psychological Measurement, 44(4), 781-804.

Cantrell, P. (2003). Traditional vs. retrospective pretests for measuring science teaching efficacy beliefs in preservice teachers. School Science and Mathematics, 103(4), 177-185.

Cantrell, P., Young, S., \& Moore, A. (2003). Factors affecting science teaching efficacy of preservice elementary teachers. Journal of Science Teacher Education, 14, 177-192.

Carr, K. (2002). Building bridges and crossing borders: Using service learning to overcome cultural barriers to collaboration between science and education departments. School Science and Mathematics, 102(6), 285-298.

Carter, W., \& Sottile, J. M. (2002). Changing the "ecosystem" of preservice math and science methods classes to enhance students' social, cognitive, and emotional development. Paper presented at the annual meeting of the Eastern Educational Research Association, Sarasota, FL.

Claxton, G. (1992). Why science education is failing. New Scientist, 133(1804), 45-46.

Cochran, K. F., King, R. A., \& DeRuiter, J. A. (1993). Pedagogical content knowledge: A tentative model for teacher preparation. Journal of Teacher Education, 44, 263272 . 
Cohen, J. (1988). Statistical power analysis for the behavioral sciences (2nd edition ed.). Hillsdale, NJ: Erlbaum.

Craven, J. A., \& Penick, J. (2001). Preparing new teachers to teach science: The role. Electronic Journal of Science Education, 6(1), 1-9.

Cronbach, L. J., \& Furby, L. (1970). How we should measure "change" - or should we? Psychological Bulletin, 74(1), 68-80.

Cronk, B. C. (2004). How to use SPSS (3rd ed.). Glendale, CA: Pyrczak Publishing.

Driver, R., \& Oldham, V. (1986). A constructivist approach to curriculum development in science. Studies in Science Education, 13, 105-122.

Duran, L. B., McArthur, J., \& Van Hook, S. (2004). Undergraduate students' perceptions of an inquiry-based physics course. Journal of Science Teacher Education, 15(2), $155-171$.

Duschl, R. A. (1983). The elementary level science methods course: Breeding ground of an apprehension toward science? A case study. Journal of Research in Science Teaching, 20(8), 745-754.

El-Daghaidy, H. An investigation of pre-service teacher's self-efficacy and self-image as a science teacher in Egypt. Asia-Pacific Forum on Science Learning and Teaching, 7(2), May 7, 2007.

Ellis, J. D. (2001). A dilemma in reforming science teacher education: Responding to students' concerns or striving for high standards. Journal of Science Teacher Education, 12(3), 253-276.

Enochs, L., \& Riggs, I. M. (1990). Further development of an elementary science teaching efficacy belief instrument: A preservice elementary scale. School Science and Mathematics, 90, 694-706.

Etkina, E., Mestre, J. P., \& O'Donnell, A. (2005). The impact of cognitive revolution on science teaching and learning. In J. M. Royer (Ed.), The cognitive revolution in educational psychology (pp. 119-164). Greenwich, Connecticut: Information age publishing.

Finson, K., Riggs, I. M., \& Jesunathadas, J. The relationship of science teaching selfefficacy and outcome expectancy to the draw-A science-teacher-teaching checklist. Proceedings of the 1999 Annual International Conference of the Association for the Education of Teachers in Science Greenville, NC. 123-133.

Fort, D. C. (1993). Science shy, science savvy, science smart. Phi Delta Kappan, 74, 674-681. 
Fulp, S. L. (2002). Status of elementary school teaching. Chapel Hill, North Carolina: Horizon Research, Inc.

Gibson, S., \& Dembo, M. H. (1984). Teacher efficacy: A construct validation. Journal of Educational Psychology, 76, 569-582.

Ginns, I. S., \& Watters, J. J. (1990). A longitudinal study of preservice elementary teachers' personal and science teaching efficacy (Research/Technical No. ED 404 127)

Guskey, T. R. (1988). Teacher efficacy, self-concept, and attitudes toward the implementation of instructional innovation. Teaching \&Teacher Education, 4(1), 63-69.

Howard, G. S., \& Dailey, P. R. (1979). Response-shift bias: A source of contamination of self-report measures. Journal of Applied Psychology, 64(2), 144-150.

Howard, G. S., Ralph, K. M., Gulanick, N. A., Maxwell, S. E., Nance, D., \& Gerber, S. L. (1979). Internal validity in pretest-posttest self-report evaluations and reevaluation of retrospective pretests. Applied Psychological Measurement, 16, 129-135.

Hoy, A. W., \& Spero, R. B. (2005). Changes in teacher efficacy during the early years of teaching: A comparison of four measures. Teacher and Teacher Education, 21, 343-356.

Huck, S. W. (2008). Reading statistics and research (5th ed.). United States of America: Allyn and Bacon.

Huinker, D., \& Madison, S. K. (1997). Preparing efficacious elementary teachers in science and mathematics: The influence of methods courses. Journal of Science Teacher Education, 8(2), 107-126.

Jarrett, O. S. (1999). Science interest and confidence among preservice elementary teachers. Journal of Elementary Science Education, 11(1), 49-59.

Jay, J. S. (2000). Preservice early childhood teachers' science teaching self-efficacy: The effects of a modeling-microteaching intervention. Unpublished $\mathrm{PhD}$, University of Missouri - Columbia.

Johnston, J. D. (2003). Active learning and preservice teacher attitudinal change.

Kelly, J. (2000). Rethinking the science methods course: A case for content, pedagogy, and informal science education. International Journal of Science Education, 22, 755-777. 
Linn, R. L., \& Slinde, J. A. (1977). The determination of the significance of change between pre- and posttesting periods. Review of Educational Research, 47(1), 121-150.

Lockman, A. S. (2006). Changes in teacher efficacy and beliefs during a one-year teacher preparation program. Unpublished $\mathrm{PhD}$, The Ohio State University.

McDermott, L. C. (1990). A perspective on teacher preparation in physics and other sciences: The need for special science courses for teachers. American Journal of Physics, 58, 734-742.

Mertler, C. A., \& Vannatta, R. A. (2001). Advanced and multivariate statistical methods practical application and interpretation. Los Angeles: Pyrczak Publishing.

Mestre, J. P. (2001). Implications of research on learning for the education of prospective science and physics teachers. Physics Teacher, 36(1), 44-51.

Moore, J. J., \& Watson, S. B. (1999). Contributors to the decision of elementary education majors to choose science as an academic concentration. Journal of Elementary Science Education, 11, 37-46.

Moore, R. (2003). Reexamining the field experiences of preservice teachers. Journal of Teacher Education, 54, 31-42.

Mulholland, J., Dorman, J. P., \& Odgers, B. M. (2004). Assessment of science teaching efficacy of preservice teachers in an Australian university. Journal of Science Teacher Education, 15(4), 313-331.

Mulholland, J., \& Wallace, J. (2000). Beginning elementary science teaching: Entryways to different worlds. Research in Science Education, 30, 151-171.

National Research Council. (1990). Fulfilling the promise: Biology education in the nations schools. Washington, D.C: National Academy Press.

National Research Council. (1996). National science education standards. Washington, D.C: National Academy Press.

National Research Council. (2000). Inquiry in the national science education standards: A guide for teaching and learning. Washington, D.C.: National Academy Press.

Olson, J. K. (2006). Toward an understanding of elementary science teacher preparation and practice. Unpublished manuscript.

Orcher, L. T. (2007). Conducting a survey: Techniques for a term project. Glendale, CA: Pyrczak Publishing. 
Palmer, D. (2001). Factors contributing to attitude exchange among preservice elementary teachers. Science Teacher Education, 86(122), 138.

Palmer, D. (2002). Factors contributing to attitude exchange amongst preservice elementary teachers. Science Education, 86(1), 122-138.

Palmer, D. (2006). Durability of changes in self-efficacy of preservice primary teachers. International Journal of Science Education, 28(6), 655-671.

Palys, T. (1997). Research decisions. quantitative and qualitative perspectives (2nd ed.). Toronto, Canada: Harcourt Brace \& Company.

Plourde, L. A. (1999). Preservice elementary teachers' personal science teaching efficacy and science teaching outcome expectancies: The influence of student teaching. Unpublished $\mathrm{PhD}$, University of Hawai'i at Manoa.

Plourde, L. A. (2002). Elementary science education: The influence of student teaching where it all begins. Education, 123(2), 253-261.

Powell, K. (2003). Spare me the lecture. Nature, 425, 234-236.

Ramey-Gassert, L., \& Shroyer, M. G. (1992). Enhancing science teaching self-efficacy in preservice elementary teachers. Journal of Elementary Science Education, 4, 26-34.

Ramey-Gassert, L., Shroyer, M. G., \& Staver, J. R. (1996). A qualitative study of factors influencing science teaching self-efficacy of elementary level teachers. Science Education, 80, 283-315.

Riggs, I. M. (1988). The development of an elementary teachers' science teaching efficacy belief instrument. Unpublished $\mathrm{PhD}$, Kansas State University.

Roth, W. M., \& Tobin, K. (2001). Learning to teach: Science as practice. Teacher and Teacher Education, 17, 741-762.

Rotter, J. B. (1966). Generalized expectancies for internal versus external control of reinforcement. Psychological Monographs: General \& Applied., 80(1), 1-28.

Scharmann, L. S., \& Hampton, C. O. (1995). Cooperative learning and preservice elementary teacher science self-efficacy. Journal of Science Teacher Education, 6(3), 125-133.

Schoon, K. J., \& Boone, W. J. (1998). Self-efficacy and alternative conceptions of science of preservice elementary teachers. Science Education, 82, 553-568. 
Schoon, K. J., \& Sandoval, P. A. (1997). The seamless field experience model for secondary science teacher preparation. Journal of Science Teacher Education, $8(2), 127-140$.

Schunk, D. H. (1987). Peer models and children's behavioral change. Review of Educational Research, 57(2), 149-174.

Schunk, D. H. (1991). Self-efficacy and academic motivation. Educational Psychologist, 26(3-4), 207-231.

Smith, D. C., \& Anderson, C. W. (1999). Appropriating scientific practices and discourses with future elementary teachers. Journal of Research in Science Teaching, 36(7), 755-776.

StatSoft, Inc. (2007). Electronic Statistics Textbook. Tulsa, OK: StatSoft. Retrieved September, 12, 2007, from http://www.statsoft.com/textbook/stathome.html

Stoddart, T., Connel, M., Stofflet, R., \& Peck, D. (1993). Reconstructing elementary teacher candidates' understanding of mathematics and science content. Teacher and Teacher Education, 9(229), 241.

Stotsky, S. (2006). Who should be accountable for what beginning teachers need to know? Journal of Teacher Education, 57(3), 256-268.

Thompson, A. G. (1992). Thompson. A. G. (1992). teachers' beliefs and conceptions: A synthesis of the research. . In D. A. Grouws (Ed.), Handbook of research on mathematics teaching and learning (pp. 127-146). New York: Macmillan.

Tilgner, P. J. (1990). Avoiding science in the elementary school. Science Education, 74(4), 421-431.

Tobin, K., \& Tippins, D. J. (1993). Constructivism as a referent for teaching and learning. In K. Tobin (Ed.), The practice of constructivism in science education (pp. 3-21). Hillsdale, NJ: Erlbaum.

Tobin, K., Tippins, D. J., \& Gallard, A. J. (1994). Research on instructional strategies for teaching science. In D. L. Gabel (Ed.), Handbook of research on science teaching and learning (pp. 45-93). New York: MacMillan

Tosun, T. (2000). The impact of prior science course experience and achievement on the science teaching self-efficacy of preservice elementary teachers. Journal of Elementary Science Education, 12, 21-31.

Trigwell, K., Martin, E., Benjamin, J., \& Prosser, M. (2000). Scholarship of teaching: A model. Higher Education Research \& Development, 19(2), 155-168. 
Tschannen-Moran, M., Hoy, A. W., \& Hoy, W. K. (1998). Teacher efficacy and meaure. Review of Educational Research, 68, 202-248.

University of North Dakota. 2005 - 2007 graduate \& undergraduate academic catalog. United States: University of North Dakota Office of the registrar, and The UND Graduate school.

Watters, J. J., \& Ginns, I. S. (1994). Self-efficacy and science anxiety among preservice primary teachers: Origins and remedies. Research in Science Education, 24(1), 348-357.

Wigfield, A., Galper, A., Denton, K., \& Seefeldt, C. (1999). Teachers' beliefs about former head start and non-head start first-grade children's motivation, performance, and future educational prospects. Journal of Educational Psychology, 91, 98-104.

Woolfolk, A. E., \& Hoy, W. K. (1990). Prospective teachers' sense of efficacy and beliefs about control. Journal of Educational Psychology, 82(1), 81-91.

Young, B. J., \& Kellogg, T. (1993). Science attitudes and preparation of preservice elementary teachers. Science Education, 77, 279-291. 